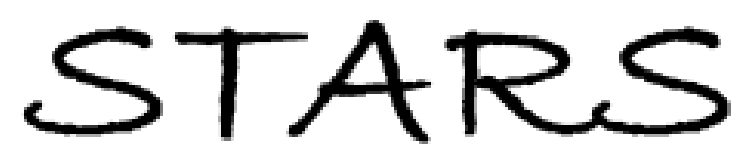

University of Central Florida

STARS

PRISM: Political \& Rights Issues \& Social Movements

$1-1-1925$

\title{
The logical influence of Hegel on Marx
}

Rebecca Cooper

Find similar works at: https://stars.library.ucf.edu/prism

University of Central Florida Libraries http://library.ucf.edu

This Book is brought to you for free and open access by STARS. It has been accepted for inclusion in PRISM: Political \& Rights Issues \& Social Movements by an authorized administrator of STARS. For more information, please contact STARS@ucf.edu.

\section{Recommended Citation}

Cooper, Rebecca, "The logical influence of Hegel on Marx" (1925). PRISM: Political \& Rights Issues \& Social Movements. 287.

https://stars.library.ucf.edu/prism/287

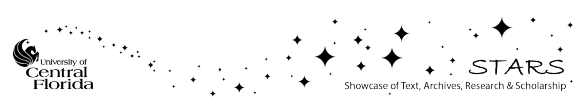


UNIVRRSITY OF WASHINGTON PUBLICATIONS

in

THE SOCLAL SCIENCES

Vol. 2, No. 2, pp. 79-182.

October, 1925

\title{
THE LOGICAL INFLUENCE OF HEGEL ON MARX
}

\author{
By \\ REBECCA COOPER
}

UNIVERSITY OF WASHINGTON PRESS

SEATTLE 


\section{University of Washington Publications}

The University of Washington Publications are offered in exchange for similar publications issued by universities, scientific societies and other institutions. These papers contain the results of research work in various departments of the University. They are issued in separate monographs numbered in several series. There is no stated interval of publication. All inquiries and all matter sent in exchange should be addressed to the University of Washington Library, Seattle, Washington. Inquiries regarding purchase of these publications should be addressed to the Editorial Secretary, University of Washington, Seattle, Washington.

\section{ANTHROPOLOGY}

Vol, 1. 1. The Whaling Equipment of the Maksh Indians, by T. T. Waterman (formerly Vol. 1 , No. 1 of the University of Washington Publications in Political and Social Science, discontinued). $\mathrm{Pp}$.

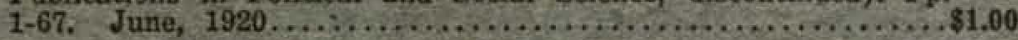

2. The Distribution of Kinship Systems in North America, by Leslie Spier. Pp. 69-88. Maps 1-9. August, 1925...............

3. An Analysis of Plains Indian Parfleche Decoration, by Lestie Spier. Pp. 89-112. August, 1925 ..........................

4. Klallam Folk Tales, hy Erna Gunther. Pp. 118-170. August;

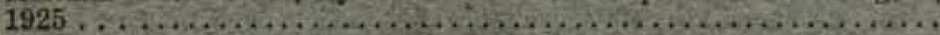

\section{FISHERIES}

Vol. 1, 1. Preserved Piekled Herring, by Clarence Louis Anderson. Pp.

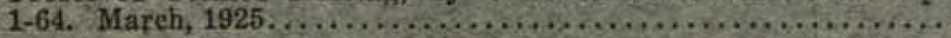

2. Fleld Characters Identifying Young Salmoniod Dishes in Fregh Waters of Washington, by Donald R. Grawlord. Pp. 12. April,

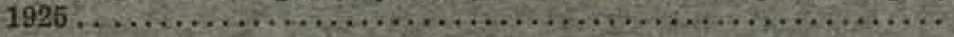

3. Synostosis in the Spinal Column of the Rainbow Trout, by Donald R. Crawford. Pp. 8. April, 1925........................

4. A Study of the Gases in Canned Foods, by Ray W. Clough, Oscar E. Shostrom, Ernest D. Clark. Pp. 80-100. September, 1925....

5. Notes on the Presence of Indol in Sea Foods and Other Food Products, by Ray W. Clough, Oscar E. Snostrom, Ernest D.

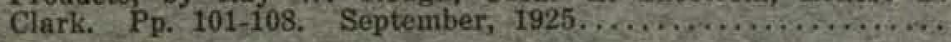

\section{GEOLOGY}

Vol. 1. 1. Tertiary faunal horizons of Western Washington, by Charles E. Weayer. Pp. 1-67. February, 1916,..................... 1,00

2. Paleontology of the Oligocene of the Chehalis Valley, by Katherine E. H. Van Winkle. Pp. 69-97. January, 1918,..........

3. Fauna from the Eocene of Washington, by Charles E. Weaver and Katherine Van Winkle Palmer. Pp. 1-56. June, 1922...

4. Foraminifera from the Bocene of Cowlitz River, Lewis County, Washington, by $\mathrm{G}$. Dallas Hanna and Marcus $\mathrm{A}$. Hanna. P . 57-64. Oetober, 1924 ................................

\section{LANGUAGE AND LITERATURE}

Vol. 1. The Poems of Henry Howard, Farl of Surrey, by Frederick Morgan Padelford. Oetobex, 1920. Unbound, \$2.00. Bound..... 3.00

2. 1. Spenser's Use of Ariosto for Allegory, by Susannah Jane McMurphy, Pp. 1-54. November, $1923 . . . . . \ldots . . . . . . .$.

2. Thomas Delker: A Study in Bconomic and Social Background. by Kate 1. Gregg. Pp. 55-112. July, 1924, .................. 


$$
\text { E. Galatiky }
$$

UNIVERSITY OF WASHINGTON PUBLICATIONS

IN

THE SOCIAL SCIENCES

Vol. 2, No. 2, pp. 79-182.

October, 1925

\title{
THE LOGICAL INFLUENCE OF HEGEL ON MARX
}

\author{
By \\ REBECCA COOPER
}

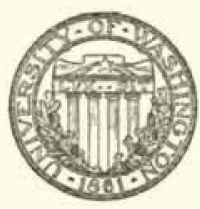




\section{FOREWORD}

Owing to the peculiar historical circumstances under which the Marxian theory was first elaborated conjointly by Marx and Engels, it is not feasible to assign certain specific parts of the system definitely to one or the other of its originators. No attempt, therefore, will be made in the following work to distinguish between the respective contributions of Marx and Engels. The theory as a whole is due to these two men, so that a general reference to either carries with it the implication of the other's influence. Thus, for example, they admittedly collaborated on the Communist Manifesto, which is an epitome of the whole Marxian system. Engels' rough draft shows that though the theory is always called "Marxian", Engels, too, had all the essential ideas worked out. And there is plenty of proof, in letters and biographies, of their subsequent close collaboration.

Regarding the relation of the Marxian theory to the doctrines of Hegel's system, the plan in general adopted is evident from the following explanation. Hegel having developed in single works systematic philosophies of history and of politics, it is convenient first to give a digest of the ideas therein which are relevant to the present treatment, and to follow this immediately by a discussion of the Marxian theory in its Hegelian reference. On the other hand, Hegel has nowhere elaborated a theory of economics. The emphasis of the economic discussion is therefore in the direction of Marx. The Marxian view is thus presented first, and this is followed by chapters tracing the connections of the Marxian theory with principles stated by Hegel.

April, 1925

Rebecca COOPER

University of Washington. 


\section{CONTENTS}

CITAPTER

PAGE

Introduction $\ldots \ldots \ldots \ldots \ldots \ldots \ldots \ldots \ldots \ldots \ldots \ldots \ldots \ldots \ldots \ldots \ldots \ldots \ldots \ldots, 85$

Part I. Historical THEORY

1. Hegel's Philosophy of History ....................... 95

Section 1 , General Theory......................... 95

Section 2, Classification of Historical Data.................. 101

II. Engles' Analysis of the Philosophical Background of Historical

Materialism ...................................... 103

III. The Abstract Theory of Historical Materialism and The Philosophy of Hegel ...................................... 107

IV. The Concrete Theory of Historical Materialism and the Philosophy of Hegel ...................................... 114

Part II. Political Theory

I. Hegel's Philosophy of Right....................... 127

II. Hegel's Philosophy of Right and Corresponding Marxian Principles. 134

PART III. ECONOMIC THEORY

I. A General Survey of Marx's Capital..................... 145

II. Marx's Theory of Value............................ 149

III. The Theory of Value and the Philosophy of Hegel............ 157

IV. The Marxian Process of Circulation and its Relation to Hegel's Logic

Section 1. Marx's Theory of the Metamorphosis of Commodities. 169

Section 2. Hegelian Concepts in the Theory of the Metamorphosis of Commodities.......................... 171

Section 3. The Transformation of Money into Capital. The

Marxian General Formula for Capital................... 174

Section 4. Hegelian Concepts in the General Formula for

Capital ......................................... 176

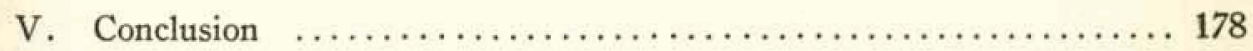




\section{INTRODUCTION}

Hegel's influence on both the content and the terminology of the works of Karl Marx and Frederick Engels has indeed been so profound that a thorough understanding of these works may be said to presuppose an understanding of this relationship. Especially the terminology of the Marxians becomes intelligible only when approached through its Hegelian origin. Nevertheless, it is very easy for students of philosophy with some knowledge of Hegel to gain ty a superficial reading of Marx an exaggerated and false impression that Hegel's influence was dominant. Leaving aside what is original in the theory, it is wise to bear in mind that there are a number of other and non-Hegelian contributing factors of very great importance. Though it is the purpose of this study to investigate in detail only the Hegelian influence, some brief mention of these others seems necessary to a more accurate estimate of the one which is our chief concern.

There are in the first place a number of historical events which affected greatly both the Marxian economics proper, and the more general theory of historical materialism. These events were all revolutionary in character, and include the following of particular importance in this connection: the Industrial Revolution, the French Revolution, the Revolutions of 1848, and the Commune of Paris.

The chief intellectual influences may be listed as follows: (1) the Utopian socialists, including the Frenchmen, Saint Simon and Fourier, and the Englishman, Robert Owen; (2) the economists of the Manchester school, Adam Smith and David Ricardo, together with their precursors and their immediate followers; (3) that modification of the philosophy of Hegel himself, represented by the Left Movement of the Young Hegelians, in which connection the name of Feuerbach is outstanding.

Of the historical influences on the development of the Marxian theory, it may be said in general that the period in which the authors lived was peculiarly auspicious for the birth of a revolutionary social philosophy. It was at the time when all the great revolutions of the early modern period were taking place, or had taken place recently enough to impress themselves strongly upon any careful social scientific study. The effects of the great Industrial Revolution were just being felt and well understood in continental Europe, and were a splendid source for Marx's researches and generalizations regarding the concentration of capital, the displacement of workers by machinery and the growth of the "industrial reserve army", the increasing (relative) misery of the proletariat, and the revolutionary spirit thereby engendered, and the entire matter of the disposal of surplus goods, involving the mad hunt for colonial markets with the inevitable result in world-wide imperialistic wars. 
The French Revolution, though not such ancient history as to have lost its vital interest, was sufficiently distant in time to admit of accurate interpretation on the basis of subsequent developments. Marx was the first to elaborate the theory (since become the accepted view of all recognized historians) that the French Revolution was a typical bourgeois revolution, the two opposing classes being the old privileged caste and the new bourgeoisie, which had been chafing under the restraints imposed on business by the worn out institutions of the monarchy. The bourgeoisie won out completely, and the workers who did their fighting for them received the very doubtful reward of becoming the "free" wage slaves the capitalist class thus established. From this event Ma:x and Engels derived much of their theory of social revolutions, as well as their estimation of political democracy of the bourgeois type, popularized by the famous slogan, "Liberty, Equality, and Fraternity". In the revolutions of 1848, the Marxians were made aware of the power and tenacity of resistance on the part of the old ruling class (exemplified in the strong stand of Metternich), and of the character of the needs and revolutionary expression of the proletariat as manifested by their participation in this highly confused, but essentially capitalistic revolutionary period. From the valiant, but abortive, proletarian revolution known as the Paris Commune, Marx and Engels obtained much of their theory of the role and function of the state as an oppressive organ belonging to the class in power, and the consequent attitude of the revolutionary proletariat toward it.

Marx was not a socialist when he left college after completing his work for the degree of doctor of philosophy. His opinions were rather those of the radical bourgeoisie. However, he became interested in the socialist doctrines to which his editorship of the Rhenische Zeitung exposed him. He therefore left Germany and went to Paris with the definite purpose, apparently, of familiarizing himself with socialist theories. He then studied the Utopian socialists with whom Engels was already familiar. The contributions of these Utopian socialists are listed by Engels as follows : ${ }^{1}$ Saint Simon had a sophisticated view of the effect of economic conditions on historical events, and was probably the first to suggest the interpretation of the French Revolution as a strictly class-war; he held also that politics is the science of production. Fourier contributed chiefly a very acute criticism of the capitalist system; he pointed out its contradictory nature, and referred especially to the conflict resulting from an attempt to solve these contradictions, the result of which is that "under civilization poverty is born of superabundance". Owen strongly hinted at the labor theory of value and the theory of surplus value when he expressed the view in common sense language that the difference between that which labor produces and that which it receives goes to the rich to pay their dividends and interest. Owen conceived the idea also of the measurement of value by the hours of work. And he came very close to an important principle of historical

${ }^{1}$ Socialism, Utopian and Scientific (Chas. H. Kerr \& Co., Chicago, 1918) 52-75. 
materialism when he maintained that communism could rest only on the foundation of machine production.

Of the English economists it is necessary to mention only $\Lambda$ dam Smith and David Ricardo, the two foremost writers of the Manchester school, in whose doctrines are embodied all the important principles of their predecessors (though the Marxians made a thorough investigation of these criginal sources). The Manchester economists are famous for having propounded the highly revolutionary doctrine that there are natural economic as well as natural physical laws. Their most important economic law is that of the exchange of equivalents, from which follow certain principles very helpful to the free development of the rising young capitalist system. For example, the idea of mutual benefit through free trade took the place of the antiquated doctrines of the Merchantilists. The advocates of the principle of laissez faire in general found support for their views in the doctrine that economic laws govern the economic side of life, and there is therefore no danger of the confusion of anarchy. Whether the theory of social laws as contained in the Marxian system was derived from the Manchester economists, or from the philosophy of Hegel, is immaterial-it is sufficient to notice that it might have come from either source, and was probably taken partly from each, although it is certain that from Hegel was gleaned the principle of social laws governing social development and change over a period of time. The great contribution, however, of the Manchester school to the Marxian system of economics was the labor theory of value. Not only was it explained by these early economists that only value equivalents can exchange for each other, but it was further argued that the basis for this equivalence, or of exchange value, is the labor required for the production of the commodities concerned. Of Marx's indebtedness to Ricardo and Adam Smith for the labor theory of value there can be no doubt. $\mathrm{He}$ acknowledged it himself, and the character of his work makes it possible to refer to him as the last great follower of the Classical school, in whom the tendencies of this movement were carried to their logical conclusion, with the result that they reached a climax and developed into something new. And it was through Marx rather than through Mill that the labor theory of value, the most important and characteristic feature of the Manchestrian economics, was preserved and developed.

Since my entire problem consists of an attempt to discover the extent and character of the influence of Hegel's philosophy on the Marxian social and economic theories, it will be interesting, and sufficient, at this point, to note some of the estimates of that influence made by the Marxians themselves, and by the more prominent authorities, both anti and pro-Marxian. It may be mentioned in passing that though the opinions of these latter are usually stated authoritatively enough, little proof, or even argument, is adduced in support of them.

The most illuminating judgment of all is contained in the preface to Capi- 
tal. Marx here explains as follows: "My dialectical method is not only different from the Hegelian, but is its direct opposite. To Hegel, the life-process of the human brain, that is, the process of thinking, which under the name of the Idea', he even transforms into an independent subject, is the demiurgos of the real world, and the real world is only the external, phenomenal form of 'the Idea'. With me, on the contrary, the ideal is nothing else than the material world reflected by the human mind, and translated into forms of thought.

"The mystifying side of Hegelian dialectic I criticised nearly thirty years ago, at a time when it was still the fashion. But just as I was working at the first volume of Das Kapital it was the good pleasure of the peevish, arrogant mediocrities who now talk large in cultured Germany, to treat Hegel in the same way as the brave Moses Mendelsohn in Lessing's time treated Spinoza, that is, as a 'dead dog'. I therefore openly avowed myself the pupil of that mighty thinker, and even here and there, in the chapter on the theory of value, coquetted with the modes of expression peculiar to him. The mystification which the dialectic suffers in Hegel's hands by no means prevents him from being the first to present its general form of working in a comprehensive and conscious manner. With him it is standing on its head. It musi be turned right side up again, if you would discover the rational kernel within the mystical shell.".2

Engels, too, has some very penetrating views to offer on the subject. In Socialism, Utopian and Scientific ${ }^{3}$ he says: "Hegel had freed history from metaphysics-he made it dialectic; but now idealism was driven from its last refuge, the philosophy of history; now a materialistic treatment of history propounded, and a method found of explaining man's 'knowing' by his 'being', instead of, as heretofore, his 'being' by his 'knowing'." "Therefore," he says in another work, "the dialectic of Hegel was turned upside down, or rather it was placed upon its feet instead of on its head, where it was standing before. And this materialistic dialectic which since that time has been our best tool and our sharpest weapon was discovered." 4

With this view of the matter all pro-Marxian scholars have inclined to agree. Thus we find Spargo $0^{5}$ merely paraphrases these and similar statements. Labriola goes more deeply into the subject, treating the relationship from the point of view of an Hegelian (of the Left) as an all-important link in the didlectic movement of social thought. ${ }^{3}$

Seligman, ${ }^{7}$ Salter, ${ }^{8}$ Bonar, ${ }^{2}$ and Beer $^{10}$ are all non-Marxians, but they have

${ }^{2}$ Marx, Capital (Chas. H. Kerr \& Co., Chicago, 1906) 1.25.

${ }^{3}$ P. 91.

4 Engels, Feuerbach (Chas. H. Kerr \& Co., Chicago, 1908) 96.

5 Karl Marx, His Life and Work (B. W. Heubsch, New York, 1910) 54-55.

- Socialism and Philosophy, 185. 22-23.

7 Economic Interpretation of History (Columbia University Press, New York, 1902)

${ }_{8}$ Karl Marx and Modern Socialism 21.

- Philosophy and Political Economy (Swan Sonnenschein \& Co., London, 1893) 338.

${ }_{10}$ Life and Teaching of Marx (National Labour Press, London) Introduction, 9-22; 126. 
expressed, or implied, full agreement with the judgment of the Marxians. Seligman and Bonar, especially, do little beyond paraphrasing and quoting from Marx and Engels, while Salter, and still more, Beer, make some attempt to estimate the contributions of Hegel, and to compare them with other intellectual and historical influences. For example, Beer makes this acute summary statement: "Marx was led to interpret these events"- that is, the French Revolution and the English Industrial Revolution-"in this way, and to make them the basis of his conception of history chiefly through the influence of Hegel, Ricardo, and the English anti-capitalist school following upon Ricardo. To the end of his life he clung to the opinion that dialectic, as Hegel formulated it, was indeed mystical, but, when materialistically conceived, contains the laws of the movement of society." ${ }^{11}$

Another more doubtful, but more interesting type of Marxian criticism consists in attributing alleged errors in this system to an Hegelian origin. Thus Simkhovitch and Böhm-Bawerk in a rather general way attribute the "fallacies" of the Marxian analysis and general method to its relationship with the philosophy of Hegel. Simkhovitch for example, makes the statement that "to Engels this dialectic method was a fetish," and attempts further to identify the revolutionary thought of the Marxians with the dialectical movement of Hegel's logic, which proceeds by means of negations and negations of the negation. ${ }^{12}$ Böhm-Bawerk, beyond a doubt the most original and capable adversary of Marxism, may well be quoted more fully, because he represents at its best this type of criticism: "Herein lies, I believe, the Alpha and Omega of all that is fallacious, contradictory, and vague in the treatment of his subject by Marx. His system is not in close touch with facts. Marx has not deduced from facts the fundamental principles of his system, either by means of a sound empiricisn, or a solid economico-psychological analysis, but he founds it on no firmer ground than a formal dialectic. This is the radical fault of the Marxian system at its birth; from it all the rest necessarily springs." ${ }^{13} \mathrm{He}$ further compares and estimates Hegel and Marx at the same time: "Marx, however, will maintain a permanent place in the history of social sciences for the same reasons and with the same mixture of positive and negative merits as his prototype, Hegel. Both of them were philosophical geniuses. Both of them, each in his own domain, had an enormous influence upon the thought and feeling of wholegenerations, one might almost say, even upon the spirit of the age. The specific theoretical work of each was a most ingeniously conceived structure, built ur by a magical power of combination of numerous stories of thought, held together by a marvelous mental grasp, but,- - house of cards."14

Three other critics, who share this attitude in a general way but apply it more particularly to one specific phase (at the present time the most vital

11 Ibid. 126 .

${ }^{12}$ Simkhovitch, Marxism Versus Socialism (H. Holt \& Co., New York, 1913) 248.

${ }^{13} \mathrm{Böhm}$-Bawerk, Karl Marx and the Close of His System (T. F. Unwin, London, 1898) 190.

14 Ibid. 221. 
phase) of the Marxian theory are Veblen, Skelton, and Bernstein. They agree in ascribing to a purely abstract, dialectical basis, the Marxian prognostication of a future state of communism. Thus, in each may be found the same idea, variously, but always cleverly, expressed. Veblen puts it this way: "To Marx, the neo-Hegelian . . . . the goal of the life-history of the race in a large way controls the course of that life-history in all its phases, including the phase of capitalism. This goal or end, which controls the process of human development, is the complete realization of life in all its fullness, and the realization is to be reached by a process analogous to the three-phase dialectic, of thesis, antithesis and synthesis, into which scheme the capitalistic system with its overflowing measure of misery and degradation, fits as the last and most dreadful phase of antithesis. Marx as a Hegelian is necessarily an optimist and the evil (antithetical element) in life is to him a logically necessary phase of the dialectic; and is a means to the consummation, as the antithesis is a means to the synthesis." ${ }^{15}$

The statement of Bernstein, the great Revisionist, to the same effect is a fine example of an erroneous argument most convincingly expressed: Marx "retained in principle the Hegelian dialectical method, of which he said that in order to be rationally employed it must be 'turned upside down', that is, put upon a materialist basis. But as a matter of fact he has in many respects contravened against this prescription. Strict materialist dialectics cannot conclude much beyond actual facts. Dialectical materialism is revolutionary in the sense that it recognizes no finality, but otherwise it is necessarily positivist in the general meaning of the term. But Marx's opposition to modern society was fundamental and revolutionary ...... And here we come to the main and fatal contradiction of his work. He wanted to proceed . . . scientifically. Nothing was to be deduced from pre-conceived ideas; . . . . . And yet the final conclusion of the work, . . . . is a pre-conceived idea; it is the announcement of a state of society logically opposed to the given one. Imperceptibly the dialectical movement of ideas is substituted for the dialectical movement of facts." ${ }^{\prime 10}$

And finally Skelton's statement may be given as an excellent sample of the sort of popular, highly rhetorical, but manifestly unproven criticism to which the Marxians have from the first been subject: "One ray of light pierces the gloom of the class-struggle doctrine. The present conflict is to be the last, the victorious proletariat will have no inferior to oppress, and will usher in a classless commonwealth, where the wicked will cease from troubling and the fighters be at rest. This eschatological side of the Marxıan theory is, in all probability, not so much a theological echo as yet another illustration of Hegelian influence, the final cessation of class struggle being a deduction from the Hegelian postulate of the final reconcilement of the dialectic conflict in the attainment of an absolute synthesis. Only the teleological optimism of the Hegelian formula can

${ }^{15}$ Veblen, The Socialist Economics of Karl Marx and his Followers, Quarterly Journal of Economics 20.594-5.

${ }^{16}$ Bernstein, "Karl Marx," Encyclopedia Britannica, Eleventh Edition. 
explain Marx's assumption that the clash of classes would lead, not to chaos and relapse to lower levels, as has happened before in the world's history, but to the triumph of the oppressed and living happy ever after in classless Eden." ${ }^{\prime 17}$

Of all the non-Marxian critics, however, Croce presents the most unusual intepretation - an intepretation which brings into light an all too neglected point, namely, the freedom with which Marx and Engels applied the dialectical principles on which it is alleged they were so dependent for their theory. Several passages from Croce in this connection are well worth quoting: “. . . . the link between the two views"- of Hegel and Marx - "seems to me to be, in the main simply psychological. Hegelianism was the early inspiration of the youthful Marx, and it is natural that every one should link up the new ideas with the old as a development, an amendment, an antithesis. As to the Hegelian dialectic of concepts, it seems to me to bear a purely external and approximate resemblance to the historical notion of economic eras and of the antithetical conditions of society." ${ }^{18}$ Farther along in his book, Croce says: "Then, too, there is the Hegelian phraseology beloved by Marx, of which the tradition is now lost, and which, even within that tradition he adapted with a freedom that at times seems not to lack an element of mockery." 10

It will be necessary to state my own conclusion here only very briefly. It agrees in general with the judgment of Marx and Engels, tempered, however, by a tendency to agree also with that of Croce that the relationship is merely psychological, rather than fundamentally logical. It seems to me that the system as it was presented by its authors is really related to Hegel in the way that they held, and therefore admits of quite a detailed comparison. However, it seems to me, too, that the main points of Marxism can, without serious alteration, be entirely divorced from the Hegelian logic, phraseology, and general method. It is necessary to bear in mind the distinction between the actual connection, with the system as originally presented, and the necessary connection, with the system as consisting of certain fundamental principles which are independent of the mode of statement employed by the Hegelian trained Marx and Engels. I am concerned in this study to discover in detail the actual connection, and I shall give only a brief suggestion of the possibility of a separation which shall leave the Marxian system intact. 113.

${ }^{17}$ Skelton, Socialism, A Critical Analysis (Houghton, Mifflin Co., New York, 1911) ${ }_{18}$ Croce, Historical Materialism and the Economics of Karl Marx (H. Latimer, London, 1914) 6-7.

10 Ibid. 49. 
PART I

HISTORICAL THEORY 


\section{HEGEL'S PHILOSOPHY OF HISTORY}

SECTION I, GENERAL THEORY

The evolution of thought is found, says Hegel, in the history of philosophy, but only in an external way. It is surveyed intimately, "in its native medium" by the system of philosophy. Now, as he goes on to say, truly existing thought must be concrete, therefore, an idea. Viewed universally, it must be the Idea, or the Absolute. ${ }^{20}$ This is the type of reasoning by which Hegel reaches the conclusion that reality is fully expressed in the system of philosophy, and it is for Hegel but a characteristic and easy step to the further result that the system of philosophy is the Hegelian system. It is not to be wendered at, then, that Hegel's general philosophy should have covered, more or less thoroughly, practically every phase of reality, not excepting the purely social phases of man's existence.

The Absolute, which is the inner, the fundamental, nature of the universe, is essentially a rational or an intellectual being, and is therefore designated by Hegel as the "Reason". It is the Reason, then, which as the basis of reality, manifests itself in the world as it appears to us. A complete, though in some respects not a detailed, account of the processes of this revelation is supposed to be contained in the Encyclopedia of the Philosophical Sciences, written by Hegel. The three parts of this work represent the three main stages of the manifestation of the Reason. The first book of the Encyclopedia is the Logic, which may be described as the immediate, abstract, pure form of this manifestation. It is, naturally, the thesis, the affirmation, or in other words, the first member of the all-pervading Hegelian triad. The second book is the Philosophy of Nature; it presents an account of nature, or the objective world, the world of the physical sciences. In the triad it is the antithesis, or the negation; for opposed to the abstract form of the Reason, as it is expressed in the system of logic, there must be a mediated, differentiated stage, in this case, the natural world. But as with all opposition, the two sides of the antagonism, the thesis and the antithesis, the affirmation and the negation, must be reconciled-ihere must be a synthesis or a negation of the negation. The third book of this series constitutes such a synthesis. It is called the Philosophy of Mind, or Spirit, and concerns itself with the realm of man and his institutions. The opposition between thought and nature is completely resolved in this sphere of the social institutions of man.

The Philosophy of Mind is in its turn divided into three sections, or categories: "mind subjective", that is, the development of the individual mind; "mind objective", or the history of man, and the nature of his social institutions; "absolute mind", or the supreme union or synthesis of the individual and the social as it is attained in the three highest spheres of man-art, religion, and

${ }^{20} \mathrm{Hegel}$, Logic (Second Edition, Clarendon Press, Oxford, 1892) Section 19. 
philosophy. Now at last the Absolute has reached its great goal, which was self-realization-attained it through the reconciliation of its self-engendered opposition between abstract-universal and concrete-particular, between individual and social, and between subject and object. This is the end of the Hegelian systematic philosophy, for the highest goal, the peculiar end of all philosophy, namely, Absolute Truth, that is, the Absolute, itself, has at last been achieved.

The Philosophy of History must be considered in some detail because of its quite evident influence on the Marxian doctrine of historical materialism. Though a separate work, the history is undoubtedly but an elaboration of one of the lesser categories of the complete system as it appears in the Encyclopedia, in other words, it is itself an integral part of the unified system. and, as such, is inseparable from it. Thus, universal history is found as a category of the state, which itself belongs to the third division, namely, social ethics, under the second of the three main categories, mind objective. Just as the Philosophy of Right is an elaboration of mind objective, so the Philosophy of History is an elaboration of the category of universal history.

Now, from the fundamental conception of Hegel's philosophy, that Reason is the sovereign of the world, "the substance of the universe; to wit, that by which and in which all reality has its being and subsistence, the infinite complex of things, the entire Essence and Truth" ${ }^{21}$ it follows with inexorable certainty that the history of the world is a rational process. History, and the entire scheme of the development of the universe are rational and consequently fundamentally perfect.

Following the account of the metaphysical basis of Hegel's philosophy of history it is necessary by way of introduction to present also a brief account of the method of historical research which Hegel professes to adopt. On this point, he makes a very significant statement, to the effect that history must be treated "historically," that is, "empirically." Laws are not to be concocted first, and then superimposed upon the facts of history; rather, history must be carefully studied and from it in this way must be derived the general laws which govern its movement. There must, of course, be a careful selection of important facts, but this is really what is meant by tracing out the general tendencies and discovering the laws of historical progress. ${ }^{22}$ It is apparent that Hegel does not deliberately do what so many of his critics accuse him of doing. It was not part of his theoretical system to fit into an apriori logical scheme, with whatever necessary distortion, the facts of human progress, even though in actual practice, this is exactly what he does. It must be recognized that Marx was an extraordinarily close and able student of Hegel, and that consequently he was cognizant of all phases of that philosopher's work. In this case, it seems to me, he quite clearly adopted Hegel's avowed theory of historical method, while rejecting critically his application. Hegel's bare intention is as important for purposes of this comparison as any other feature. It is necessary,

${ }^{21}$ Hegel, Philosophy of History (Colonial Press, New York, 1899) 52, 57.

22 Ibid. 54. 
too, to distinguish carefully between consequences which follow logically from the main Hegelian tenets, and claims made by Hegel. Thus, as Mc'Taggart and Royce have both explicitly stated, and even Hegel himself hinted, it should be possible, theoretically, to deduce absolutely every fact of existence, whether in:portant or trivial, from the essential principles of the logic, which are indubitable. However, inconsistent though it may be, this bare logical consequence is disregarded, and the ideal of the empirical method, as explained above, is stated, though not always followed.

Any account of Hegel's method of historical research would be incomplete without mention of a certain point of view, and for that time it was a very radical one, namely, that "in the history of the world, the individuals we have to do with are peoples, totalities that are states." ${ }^{23}$ In the Marxian scheme, this principle is fundamental.

Leading up to the main concepts of the philosophy of history, Hegel makes it quite clear that, though the world includes both nature and spirit, and nature does exert some influence on world history, still, it is primarily as the most concrete expression of spirit alone that history will be viewed. On one or two occasions only does Hegel make exceptions to this rule; they prove, however, to be very radical departures from the main trend of the system, and I shall refer to them later.

Since it is as the manifestation of Spirit that world history is to be studied, and interpreted, the first step in the investigation must be an analysis of the nature of Spirit itself. Hegel explains that its nature is the direct opposite of that of matter; therefore, just as the essence of matter is gravity, so the essence of Spirit is Freedom. Thus, while matter has its essence out of itself, Spirit is self-contained existence, and this is what is meant by Freedom. For to be free, one's existence must depend on one's self. Now, the meaning of self- contained existence is further explained as self-consciousness, consciousness of one's own being. In the case of Spirit, this means becoming actually that which it was potentially, or, "the History of the World is none other than the progress of the consciousness of Freedom." ${ }^{24}$ The meaning of these rather cryptic phrases will become quite clear, I think, in the course of the further elaboration of the doctrine.

Though Freedom is the basis of world history, it cannot itself make that history. This is because the principle, the destiny of Freedom is but "an undeveloped Idea"; it is only general, or abstract, and requires, therefore, the opposition of a second element in order to produce actuality or realization. "The means it uses," Hegel says, "are external and phenomenal presenting themselves in history to sensuous vision." ${ }^{25}$ Specifically this second element is composed of the needs, the passions, the interests of man. Such means must be employed, it is explained, because the making of history requires the activity of people, and people act only for some object in which they are interested.

23 Ibid. 58.

24 Ibid, 53-54.

25 Ibid. 65. 
The concrete unity of these two factors (there must be a unification o: resolution of all such antagonistic elements) is Liberty under conditions of the morality of the state. ${ }^{26}$ The state is pure, powerful and well-established when the interests of the individual coincide with it exactly. At the beginning of history, such an idea exists only implicitly. It becomes more and more explicit or conscious during the process of historical development. Each stage of its progress toward its goal is accomplished by the reconciliation of these fundamental polar opposites: formal Freedom, on one hand, as the general, implicit, universal Idea of Spirit (the an-sich), and, on the other hand, the differentiation, limitation, particular, explicit, or realizing activity of the individual (the furr-sich). The objective reality, the liberty-insuring state, is the synthesis brought about by mediation of this human activity, which, consequently, must be considered the middle term, or the dynamic element in historical progress. In a note Hegel explains that by the aims of individuals he does not mean the mere desire or caprice of these individuals, but rather such general considerations of duty, justice, and the like, as are established by the code of morals and state regulations. ${ }^{27}$

Of the state, which is the grand result of all historical movement, Hegel says: "The end to be attained is the union of the subjective with the rational will, it is the moral whole the state, which is that form of reality in which the individual has, and enjoys, his freedom, but on condition of his recognizing, believing in, and willing that which is common to the whole." And again, "The state is the idea of the Spirit in the external manifestation of human will and freedom." ${ }^{28}$

Certain of the more fundamental aspects of this supreme human institution the end and aim of all historical development, should be described before the movement which produces it is analyzed more fully. In the first place, a general and important fact is proclaimed, namely, that all historical changes are inseparably bound up with changes in political forms; which means simply that by an historical change is meant an alteration in the social or political structure of any society. And from this it becomes apparent that constitutions are peculiar to certain peoples at certain times; consequently it is impossible and absurd to arbitrarily apply a particular constitution to a people to which it did not appear naturally, in the course of history.

Corresponding to these objective forms of the existence of Freedom in the state there is the subjective realization in art, law, morals, religion, science and philosophy. Expressed in the three highest branches of human learning and understanding, ranging from the comparatively ineffective to the most complete realization of fundamental truths the following great triad is formed: first, in art are represented sensuously the forms of the divine intuition; then, in religion, awareness is attained of infinite feeling and conception, and lastly, in

26 Ibid, 69.

${ }^{27} \mathrm{Ibid}$. 25, note.

${ }^{28} \mathrm{Ibid}$. 96. 
philosophy, in the highest position of all, the knowing of truth, is thought experienced.

Having given, as Hegel expresses it, "the Design of the World," the next step is an account of the "Progress of the World's History." In general, the principle of all development involves an inner capacity striving to realize itself. ${ }^{30}$ In the case of organized natural objects of which it is also a property, this expansion is independent of external causes-due rather to an internal principle, a simple essence; the very opposite, however, is true of the growth and development of Spirit-no longer is it direct and unhindered, on the contrary, it is accomplished only through striving and opposition. "The realization of its idea is mediated by consciousness and will . . . Thus Spirit is at war with itself; it has to overcome itself, as its most formidable obstacle . . . What Spirit really strives for is the realization of its ideal being, but in doing so it hides that goal from its own vision and is proud and well satisfied in this alienation from it." ${ }_{31}$

This tremendous struggle of universal history, for the ultimate goal, which is absolute, or concrete Freedom, is accomplished through three stages: ". . the first step in the process presents the immersion of Spirit in Nature"; the second shows it as advancing to the consciousness of Freedom-however, this step is partial and imperfect; the third step is the escape from this imperfect state of Freedom to its pure, completely-realized form.

The actual process of this development constitutes the dialectic of progress; it is essentially an advance from the less perfect to the more perfect, "but the former must not be understood as only the imperfect, but as something which involves the very opposite of itself, the so-called perfect, as a germ or an impulse." ${ }^{32}$ It is this opposition between the perfect and the imperfect (the imperfect necessitates the perfect as its opposite) that results in the initiation of the entire process known as human history. This process begins only with the appearance of states, for it is here that for the first time some degree of consciousness of Freedom arises; ". . . . the periods that were passed by nations before history was written among them ... . are ... . destitute of objective history because they present no subjective history, 'no annals." ${ }^{33}$

The specific medium of change from one form of society to another, from one historical epoch to the next, is the body of ideals espoused by the enlightened and far-seeing portion of any community or nation. The old social system is foredoomed to dissolution as a transitory stage in the self-development of the World Spirit. Spirit must be in constant flux; it must continually erect against itself an antagonist which it as consistently overcomes. But in so doing it reaches a new and higher level, which rests, not on the ruins of the past, but on the past which has been elevated and re-embodied in his own im-

30 Ibid. 105.

31 Ibid. 106.

32 l.bid. 108.

ss Ibid. 113 . 
proved shape. In terms of its metaphysical basis, Hegel summarizes his position in perfectly clear and concise language, as follows: "But for Spirit, the highest attainment is self-knowledge, and advance, not only to the intuition but to the thought- the clear conception of itself. This it must, and is also destined to accomplish, but the accomplishment is at the same time its dissolition, and the rise of another Spirit, another world historical people, another epoch of Universal History." ${ }^{34}$

"The very essence of Spirit is activity; it realizes its potentiality-makes itself its own deed, its own work - and thus it becomes an object to itself; contemplates itself as an objective existence. Thus is it with the spirit of a people; it is a spirit having strictly defined characteristics which erects itself into an objective world, that exists and persists in a particular religious form of worship, customs, constitutions, and political laws - in the whole complex of its institutions - in the events and transactions that make up its history." 35

The entire procedure may be summed up in a few words: The spirit of a people is the concrete realization of Universal Spirit; it is, however, but an imperfect form. In opposition to this its imperfect expression, Universal Spirit, posits the more perfect in the form of the thoughts and ideals of the people-at least, of the more advanced portion of them. The imperfect and the more perfect confront each other in opposition, the society which has this contradiction between the real and the ideal is superseded by a new society, a new historical era. This new national spirit embodies within itself all of past history, but is subject to the same disintegrating process.

Though great men are significant in history it is not they who initiate and accomplish these changes. They do not bring about anything that would nct have come to pass without them. Their greatness consists in the fact that they are aware of the aim of Spirit before ordinary people are. Their function is merely to accelerate the progress of history.

The section in Hegel's Philosophy of History on the "Geographical Basis of History" is filled for the most part with facts which have no bearing on this discussion. But it contains also certain incidental passages so significant that they cannot be overlooked. In some degree, they amount to contradictions of the main theory, just stated. At the beginning of the treatise Hegel speaks of nature as the extrinsic, yet necessary, basis of the spirit of the people. It seems then to constitute the first obstacle to be overcome, and from this point of view, to be the first standpoint in the development of Freedom. This affords an explanation of the fact that history must find its beginnings in the temperate zone. Then, as an application of this general principle, appears an amazing passage, clearly opposed in spirit to the trend of Hegelianism, but closely parallel to fundamental Marxian tenets: "As to the political conditions of North America, the general object of the existence of this state, is not yet fixed and determined, and the necessity for a firm combination does not yet

s4 Ibid. 125.

35 Ibid. 127. 
exist, for a real state and a real government arise only after a distinction of classes has arisen when wealth and poverty become extreme and when such a condition of things presents itself that a large portion of the people can no longer satisfy its necessities in the way in which it has been accustomed so to do. But America is hitherto exempt from this pressure, for it has the outlet of colonization, constantly and widely open, and multitudes are continually streaming into the plains of the Mississippi. By this means the chief source of discontent is removed, and the continuation of the existing civil conditions is guaranteed." ${ }^{36}$ Another statement, which Hegel makes in the same section, sounds remarkably like an economic interpretation: "Had the woods of Germany been in existence, the French revolution would not have occurred."

\section{SECTION II}

\section{CLASSIFICATION OF HISTORICDATA}

Both Hegel and Marx carefully divide the course of history into main epochs from the beginning to modern times. No feature of the two systents brings out more clearly the vast gulf between them, the fundamentally different point of view; though, on the other hand, no feature shows better the striking resemblance, the close logical relationship.

Hegel begins his division with the broad generalization that "History moves from East to West." The basic principle of its movement is succinctly stated as follows: "The East knew and to the present day knows only that One is Free; the Greek and Roman world, that Some are Free; the German world knows that $A l l$ are Free. The first political form therefore which we observe in history is Despotism, the second, Democracy and Aristocracy, and the third, Monarchy."

It is on this basis, then, of the degree and quality of Freedom attained, that history is divided into three stages. The first stage is that of Asiatic despotism-the stage at which "One is Free." This division is fir st because Frecdom appears in an elementary, abstract, and general form. It is objective, not subjective in the wide sense necessary to the concrete realization of Spirit. Whatever subjectivity there is, is concentrated in the "One," in the individual ruler. The inferior form of subjectivity appearing in other individuals cannot function as the antithesis of the implicit, immediate form of objective Freedom, to be resolved in the higher synthesis. It is not true Freedom, but a low order of caprice, which results in the unrestrained outrages of hordes. Therefore, this period may be justly designated as "unhistorical history," for it precedes, rather than forms a part of, the development and progress of concrete Freedom. Nor is this judgment confuted by the fact that changes do occur among these Oriental states, for the destruction of the old state involves the substitution of a new one, which in every respect is but a stupid repetition of the old.

se Ibid. 141. 
The transition from this stage to the next is explained on the general principle of the necessity for Spirit to evolve and change. More specifically, the explanation is to be found in the fact that sufficient subjectivity existed among the unhistorical states to permit of their destruction by each other, and eventually of their being completely subdued by a power higher in the scale of historical development, that is, by the Greeks. Thus, the transition began, when Egypt became a province of Persia, and Persia in its turn fell before the power of the Greeks because, like all other Asiatic states, it lacked the spirit of true unity.

The next stage, ushered in by the Greeks, includes first of all the Greeks themselves, and then in the same main era, but on a somewhat higher level, the Romans. Subjective freedom is a feature of the Greeks, expressing itself in the wonderful art of that people. However, the unity between the individual and objective Freedom at this stage is only immediate, in other words, essentially unconscious. Because of this defect, the Greek world gave way to the Roman. The transition came about practically because of the divided state of the Greeks. The country was composed of supposedly independent states, which in reality were not independent at all. They had little power, and no security. They were extremely individualistic, made war on each other, and were eventually all destroyed.

The Roman world, which overcame the Greek, was an improvement in that riotous individuality was replaced by a pronounced unity. There was a complete absorption by the state of all other individuals, who willingly gave over to it all the power. The reign of abstract universality became inaugurated.

The dialectical triad requires that this double period shouid be superseded by a newer and higher epoch, in which the second, the Greek and Roman characteristics, are merged with those of the first, the Oriental, form of society. This union, the fusion of the East and the West, was accomplished by the development of Christianity. Religion had come to take the place of art as the medium of Man's communion with and knowledge of Reality, but religion, too, passed through a period of growth and development, chefly the elimination of such defects as formalism, image-worship all sorts of bloody dispute;, and most important of all, the clash between Church and State, which appeared in both the Eastern and Western Roman empires.

The supreme result of the intervention of Christianity was the German Christian world, destined to stand as the realization of Spirit in complete uni y with itself, its character fully developed as concrete Spirit. The early opposition between the first crude barbarous German state and Spirit as manifested in the Church is overcome by the secular becoming intellectual and realizing the rational unity of Church and State. The basis of the German nation is philosophy and it is through philosophy that Freedom has at last succeeder in the realization of its final goal, complete self-consciousness, which for it means true existence. 


\title{
ENGLES' ANALYSIS OF THE PHILOSOPHICAL BACKGROUND
}

\author{
OF HISTORICAL MATERIALISM
}

Engels has given a very acute and fairly comprehensive account of the evolution of the dialectic as this term is used by Hegel and the Marxians. He begins with an appreciative reference to Heraclitus, whom he considers the founder of the true conception, and all because Heraclitus viewed reality as in a constant state of "flux," and drew the conclusion that being and not-being are not mutually exclusive, but that everything is both being and not-being, everything both is and is not, and in fact, that essential to reality are the opposites of which it is composed. All of this Engels considers true as far as it goes, but it is essential, he holds, to know not only the broad general truth, but also the detailed facts of the actual development. These necessary facts, he asserts, are supplied to the philosopher only by the efforts of the men of sćience; therefore, they come much later than these bare outlines of the dialectic.

Meanwhile, the dialectic as a mode of reasoning was discovered and used, he points out, by the greatest of the ancient Greek philosophers, Plato and Aristotle; and in modern times it has been used successfully by such philosophers as Descartes and Spinoza, and among other French intellectuals, sy Diderot and Rousseau. The necessary scientific work, the observation and classification of facts was begun by the Greeks of Alexandria, carried further in the Middle Ages by the Arabs and finally, substantially advanced by the stupendous discoveries made by scientists in Engels' own day. Three epochmaking modern discoveries are listed by him as follows: (a) the cell, (b) the metamorphosis of energy, and (c) the Darwinian theory of evolution.

But, unfortunately for the advancement of true knowledge, scientific investigations of this sort produce a "metaphysical" habit of mind, a tendency to view things artificially, separated, isolated from other things, or at what Hegel calls "the level of the understanding." Even such astute scientific philosophers as Bacon and Locke made the mistake of employing this erroneous method. Their way of looking at things was according to rigid, fixed categories; everything must either be or not be; it must be either yes or no, positive or negative, form or content, cause or effect-nothing can be both. All their thoughts about reality were in terms of these absolutely irreconcilable antitheses. This way of regarding things also makes an unmistakably strong appeal to common sense. Nevertheless, a closer examination will show that such an attitude is not only inadequate, but results in a serious falsification of the facts.

According to the true, or dialectical view, all things merge gradually into each other and are in a continuous process of change; in other words, they both are and are not. For example, a body both is, and is not dead-dying is 
a gradual process. It follows, therefore, that the opposites lisied above belong to an antithesis, each pole of which is as inseparably connected with the other as it is separate from it.

And to the dialectical philosophers must be given the creait of first viewing things truly "in their essential connection, concatenation, notion, origin and ending." In Germany, this realization began with Kant, whese nebular hypothesis, which was verified later by La Place, did much to further the evolutionary interpretation of nature. The tendency, so established, reached its culmination in Hegel.

Hegel, however, made a most valuable contribution, when for the first time, he propounded an evolutionary view of history. Though he attempted a great thing and traveled far in the direction of accomplishment, he was ton much hampered by certain unavoidable limitations to make a really successful philosophy of history possible for him.

Engels then expounds what he considers Hegel's three de-isive limitations: (a) Though Hegel probably knew more than any other one man of his time, he couldn't know everything-he was confined within the limits of his own knowledge. (b) $\mathrm{He}$ was confined within the limits attained by the science of his own particular age; to quote Engels from Landmarks, "It was self-evident that the old philosophies of Nature-in spite of all their actual value and fruitful suggestiveness - could be of no value to us. There was an error in the Hegelian form, as shown in this book, in that it recognized no progression of nature in time, no 'one after another' (nacheinander), but merely 'one beside another' (nebeneinander). This was due on the one hand to the Hegelian system itself, which ascribed to the Spirit (Geist) alone a progressive historical development, but on the other hand, the general attitude of the sciences was responsible." (c) Hegel was an idealist. He taught that Reason is the soul of the existing world. It manifests itself according to necessary laws of its being through the various stages and levels of the world as we know it, attaining at the end the Absolute Idea. ${ }^{37}$ We give Engels' own exposition, "According to Hegel, the dialectic development apparent in nature and history, that is a causative, connected progression from the lower to the higher, in spite of all zigzag movements and momentary setbacks, is only the stereotype of the selfprogression of the Idea from eternity, whither one does not know, but independent at all events of the thought of any human brain. This topsy-turvy ideology had to be put aside. We conceived of ideas as materialistic, as pictures of real things, instead of real things as pictures of this or that stage of the Absolute Idea. Thereupon, the dialectic became reduced to knowledge of the universal laws of motion-as well of the outer world as of the thought of man-two sets of laws which are identical as far as matter is concerned but which differ as regards expression, in so far as, the mind of man can employ them consciously, while, in nature, and up to now, in human history, for

${ }^{37}$ Engels, Feuerbach (Chas. H. Kerr \& Co., Chicago, 1908) 94. 
the most part they accomplish themselves unconsciously in the form of external necessity, through an endless succession of apparent accidents." ${ }^{38}$

Engels then asserts that Hegel is guilty of a very grave inconsistency. Engels claims that, since the dialectical process is identified with reality as a whole, it is absurd for any one to claim to have attained the Absolute Truth, as Hegel does-for how can any individual, himself a member of this evolutionary process, conceivably know it in its entirety, especially when, as is probably the case, it has no end? Yet, there is no more important concept in Hegel's system as it stands than that of the Absolute Idea, the completc Truth; and certainly no conception could be more flagrantly opposed to the general trend of the dialectical movement.

Engels' criticism of Hegel's philosophy may well be concluded with this sweeping judgment: "Correctly and ingenuously as many individual groups of facts were grasped by Hegel, yet . . . . there is much tha: is botched, artificial, labored, in a word, wrong in point of detail."

The character of the Hegelian system made it easy and inevitable that there should appear many and varied interpretations of it, ranging from the extremely conservative to the extremely radical. Hegel himself must be classed with the conservatives.

The group representing the radical wing of Hegel's followers has already been referred to, namely, the Young Hezelians. The organ of this faction was the Rheinische Zeitung. The leaders were concerned chiefly with anti-religious ideas. Many of them wrote treatises opposing the ordinary Christian doctrines, for example: Leben Jesu, by Strauss; Christianity, by Bruno Bauer, and Wesen des Christenthums, by Feuerbach.

But of the entire group, Feuerbach was the first frankly to reject the idealism of Hegel in favor of the materialistic view that "Nature exists independently of all your philosophy." ${ }^{3}$ "The material, sensible world, the worid of ordinary experience is the only reality. "Matter is not a product of mind, but mind itself is only the highest product of matter." In other words, as Engels points out, this is nothing but materialism. It is, however, a materialism which must not be confused with the special form of materialism which flourished in the Eighteenth Century and later, represented by such men as Büchner, Vogt, and Moleschott. These men held a rigid mechanical view, very different from the doctrine propounded by Feuerbach, and which later was to become an integral part of the Marxian system. The limitations of that earlier position may be accounted for by the phenomenal growth of the mechanical sciences during that period, a circumstance which would naturally lend support to a crude mechanical materialism.. ${ }^{40}$ Unfortunately, too, evolutionary science had not yet come into existence to be a counteracting influence to th:s 
tendency to a purely mechanistic view of things. Although Kant had helped somewhat to remedy this philosophical error, it remained for Hegel to effectually put such an attitude into the discard.

However, the new materialists, on rejecting the crude, atomistic doctrine of their predecessors, did not adopt the "positivistic" attitude of Kant and others. On the contrary, all such philosophies, systems which speak of a world beyond the world of our experience, about things-in-themselves-were equally opposed to the new conception.

It was this type of materialism, then, a non-mechanistic, non-static materialism, that Feuerbach combined with the dialectic of Hegel, divested, naturally, of all idealism, to produce as a result what Engels called a "dialectical materialism," and which he and Marx adopted as the philosophical basis of their social scheme. But, while Feuerbach who had led them to this position receded, saying, "Backwards I am in accord with the matter, but not forwards," Marx and Engels continued firmly in the new direction. ${ }^{41}$

This account of the development of the dialectic is by no means complete, nor is it entirely accurate. It is important to my comparison in that it throws considerable light on the Marxian conception of the meaning of the dialectic: It will be observed that Engels selects from the history of philosophy those doctrines tending to assert an evolutionary, as opposed to a static view of things, and to emphasize the material rather than the spiritual, or idealistic. These two elements, the evolutionary and the material, together form the ground work of the Marxian theory of historical materialism. These particular interests are indicated as clearly by Engels' omissions as by his selections. While any ordinary philosophical account of the dialectic, as that term has come to be applied to the Hegelian type of logic, would include some mention of the scholastic method of presenting in parallel form opposite sides of any question, and more especially of Hegel's immediate forerunners, Fichte and Schelling, Engels' account leaves them unmentioned. It is true that he does credit Kant with having made a significant contribution to the dialectic, but he points, curiously, to Kant's "nebular hypothesis" as being contributory in this connection because of its evolutionary implications. The doctrine of the antinomies which is usually considered in the direct line of development of the Hegelian dialectic through the philosophies of Fichte and Schelling is simply left out of Engels' analysis. 


\section{III}

\section{THE ABSTRACT THEORY OF HISTORICAL MATERIALISM}

AND

THE PHILOSOPHY OF HEGEL

The Marxian philosophy of history is based on a metaphysics which is the reverse of that underlying Hegel's historical doctrine. In fact, the point of departure of the Marxian from the Hegelian system is this reversal of the Hegelian metaphysics. Hegel is an idealist; Marx is a materialist, and the social philosophy of each is intimately bound up with and dependent upon its own peculiar metaphysical basis.

However, the materialism of the Marxians, as Engels so painstakingly explains, is not a crude mechanical view. It has a specific meaning which is very different, and may be broadly expressed in Engels' words, as follows: ". . . now a materialistic treatment of history was propounded, and a method found of explaining man's knowing by his being, not his being by his knowing." Probably in the strict modern sense of the word, this doctrine should not be called materialism; for, though not incompatible with a materialistic view of the fundamental reality, it is entirely compatible also with practically all other melaphysical positions-though not, of course, with the Hegelian. Metaphysically, two important assertions, or rather, a denial and an assertion are made: firstly there is an emphatic rejection of the doctrine that Reason, as opposed to the phenomenal world, is the true reality, and instead, a somewhat positivistic position is held, since the existence of all such mysterious entities as the Kantian ding an sich is explicitly denied (though there is nothing to indicate that atoms, and other non-phenomenal entities of science are to be included in this class of rejected things); secondly, the assertion is made that thoughts are reflections of actual events of the real world, and that this is their only origin-therefore, ideas or thoughts do not engender historical progress (though they may accelerate it); on the contrary, the necessity for movement inherent in things accounts for all development, and the course of this development naturally appears reflected in the thoughts of men.

In this argument the Marxians seem to have been objecting especially to Hegel's doctrine that since Reality is Reason and Reason expresses itself in its purest form in men's minds, as the logic, then the fundamental nature of the world must be fully revealed by this long and complicated series of men's ideas. For to the Marxians, this gives mere ideas a priority and general superiority to world events which manifestly they do not have. And for them this question, which on the surface seems to be a mere metaphysical quibble, looms very large, not only in social theory, but in a practical way as well. For it is necessary that men realize the relation of their ideas to reality in order that they may fully appreciate the extent of their powers while not over-estimating 
them, and thereby becoming completely and hopelessly impotent. Men's ideas, according to the Marxians, correspond to the environment in which they live and the characteristics of this environment are determined by its basic, that is, its economic, structure. Decadent social systems produce within themselves the germs of a new society, and these in turn produce the advanced ideas of the people. These ideals naturally affect the behavior of the people who have them, often to the extent of producing a complete change in the social order.

After establishing in this manner the ability of human beings to describe and analyze the world, the Marxians then proceed to give their account of it. The most important discovery ever made about reality is that of its dialectical or evolutionary nature. This characteristic belongs not only to natural, but to human history as well. The nature of this dialectical movement must be worked out in great detail, and for this purpose it is necessary to go to the facts of history, and from them, by the methods of scientific proccdure derive in full the laws of its development. All natural and historical laws must be arrived at by this means; above all things, they must not, if they are to have validity, be conjured up in the human imagination, or intellect, and in a completed, a priori form superimposed upon the facts, which, in all probability, would require twisting and altering to make them fit in. Engels brings this out very well in answer to an objection by Herr Duehring: "Although Marx therefore shows the occurrence of this event as negation of the negation, he has no intention of proving by this means that it is a historical necessity. On the contrary, after he has shown that the actual fact has partially to declare itself, he shows it also as a fact which fulfills itself in accordance with a certain dialectic law. That is all. It is therefore again merely supposition on Herr Duehring's part ${ }^{43}$ to assert that the negation of the negation must act as a midwife by whose means the future is brought out of the womb of the present, or that Marx wants to convince anyone of the necessity of social ownership of land and capital upon the theory of the negation of the negation."

From a similar statement in the Philosophy of History ${ }^{44}$ it would seem at first sight that on this point at least Marx and Hegel are in complete agreement. For the Marxians, however, this is a general principle of all investigation; while for Hegel it seems to have been adopted inconsistently in the case of history because of the obvious impossibility of accomplishing that which follows logically from the fundamental principles of the system, namely, the deduction from these principles of every thing in this completely "rational" world.

Needless to say, the Marxians disagree too, with the doctrine that the dialectical form of development must be attributed to the Reason as the law of its growth. There can be, for the Marxians, no "pure logic" in the Hegelian sense of a system of a priori categories representing abstractedly the exact and necessary forms, according to which every event in the world must occur.

43 Also Skelton, Bernstein and Veblen. See above, 89-91.

${ }^{44}$ P. 54. 
That for Hegel and the Marxians the term "dialectic" had the same meaning may be shown by simply selecting passages from their works in explanation of this concept. The similarity is so close, that, except for the greater simplicity of the Marxian phraseology, and a characteristic difference in the choice of examples, the statements might be interchanged. Thus, the following passages may be given as typical of Hegel's analysis of the meaning of the dialectic as such: "But by Dialectic is meant an indwelling tendency outwards and beyond; by which the one-sidedness and limitation of the formulae of understanding is seen in its true light, and shown to be the negation of these formulae. Things are finite, just because they involve their own dissolution. Thus understood, Dialectic is discovered to be the life and soul of scientific progress, the dynamic which alone gives an immanent connection and necessity to the subject-matter of science;

"(1) It is of the highest importance to apprehend and understand rightly the nature of Dialectic. Wherever there is movement, wherever there is life, wherever anything is carried into effect in the actual world, there Dialectic is at work. It is also the soul of all knowledge which is truly scientific. In the popular way of looking at things, the refusal to abide by any one abstract form of the understanding is reckoned mere equity . . . . . when we look more closely, we find that the limitations of the finite do not merely come fronwithout; that its own nature is the cause of itts abrogation, and that by its own means it passes into its counterpart . . . . . but the true view of the matter is, that life, as life, involves the germ of death, and that the finite, being at war within itself causes its own dissolution." He further states, "Positive and negative are supposed to express an absolute difference. The two, however, are at bottom the same; the name of either might be transferred to the other. Thus, for example, debts and assets are not two particular and selfsubsisting species of property. What is negative to the debtor, is positive to the creditor. A way to the east is also a way to the west. Positive and negative are therefore intrinsically conditioned by one another, and have a being only when they are connectively referred to each other. The north pole of the magnet cannot be without the south pole, and vice versa. If we cut a magnet in two, we do not have a north pole in one place, and a south pole in another . . . . " ${ }^{45}$ and so forth for many more paragraphs.

And in Engels' works appear the following surprisingly simila1 passages: "As long as we regard things as static and without life, each by itself, separately, we do not run against any contradictions in them. We find certain qualities sometimes common, sometimes distinctive, occasionally contradictory, but in this last case they belong to different objects and are hence not selfcontradictory. While we follow this method we pursue the ordinary metrphysical $^{46}$ method of thought. But it is quite different when we consider

45 Hegel, Logic (Clarendon Press, Oxford, 1892) 125-127.

46 It is interesting and significant to note the similarity of Engels' meaning of the "metaphysical" attitude to Hegel's "level of the understanding." See above, 103. 
things in their movement, in their change, their life and their mutually reciprocal relations. Then we come at once upon contradictions. Motion is itself a contradiction since simple mechanical movement from place to place can only accomplish itself by a body being at one and the same moment in one place and simultaneously in another place by being in one and the same place and yet not there. And motion is just the continuous establishing and dissolving of the contradiction." 47

"Further, we find upon closer investigation that the two poles of an antithesis, positive and negative, for instance, are as inseparable as they are opposed, and that despite all their opposition, they mutually interpenetrate.":s

"Nature is the proof of dialectics, and it must be said for modern science that it has furnished this proof with very rich materials increasing daily, and thus has shown that, in the last resort, Nature works dialectically and not metaphysically; that she does not move in the eternal oneness of a perpetually recurring circle, but goes through a real historical evolution . . . . ${ }^{\prime 40}$

Both schools of thought agree to the application to the progress of history of these essential principles of the dialectic. They both maintain, for example, that history presents itself, not as a series of separate events which follow each other in a contingent, unregulated fashion, subject only to accidental, chance causes, but rather as a movement, a development, a series, the members of which (in this case, stages of history) merge into each other, pass from one to the next in accordance with the underlying and necessaty forces which govern reality.

According to both Hegel and Marx, the dialectic in history operates fundamentally in this fashion: any given state of society at its height and in its purity must logically be considered as the thesis or affirmation, that is, as the first member of the inevitable triad; but within the confines of this system there is engendered by it its own opposite, the "germ" of a new society by which it will be presently and necessarily ${ }^{50}$ replaced-this "germ" is then the second stage, the antithesis, or the negation. The contradiction between these two opposite elements must in some way be overcome. This is accomplished by a sort of resolution in which neither side succeeds in establishing itself as such, nor is either in any sense annihilated. Both the old society and the disrupting element, representing the new, are retained, and in a fused and elevated form, together they make up the new stage of history. This new historical era must therefore be regarded as the logical synthesis, the negation of the negation - in which, as Hegel puts it, the thesis and the antithesis are "aufgehoben."

The agreement between the Hegelian philosophy of history, and the theory 151.

47 Engels, Landmarks of Scientific Socialism (Chas. H. Kerr \& Co., Chicago, 1907)

${ }^{48}$ Engels, Socialism, Utopian and Scientific 82.

40 Ibid. 83.

${ }^{50}$ For the Marxians, this is a sort of empirical necessity, that is, a necessity discovered through observation of the facts; while for Hegel, of course, it is a logical necessity, a necessity of the reason. 
of historical materialism is by no means so complete with regard to the specific things which in real history fill in the steps of the bare logical statement of the nature of development. Thus, in place of the Hegelian Freedom, the essence of Spirit, the Marxians regard economics, the means of production and exchange, as the force fundamentally responsible for the general character of all historical epochs, and for the transition of one to the next.

The further details of the two systems differ as greatly in content, and are yet as parallel in form and position as are the two fundamental bases, freedom and economics. According to the Marxians, in all societies, and at all periods, the outward and complicated customs and institulions which supply color and character to a people derive their essential nature from the economic structure, of which they are but the faithful reflections. The mose immediate reflection of the means of production and exchange appears in the form of distribution and the appropriate economic classes. Around these is built the entire political, religious, and social organization. And just so long as the character of these institutions remains appropriate to the prevailing economic system, they facilitate and strengthen it. However, economics structures are dialectic, or evolutionary, that is, they must change continually, develop, grow, and pass eventually into new and fitter forms. Unfortunately, though, while the machinery of production is developing constantly according to the laws peculiar to it, the forms of production, that is, the subsidiary institutions (which are the forms of distribution and the corresponding economic classes) fail to keep up with these changes, become then inappropriate, retard and hinder, and in general come into conflict with the new order of economics. This conflict of the old and the new takes the form of an antagonism between the two classes of society which represent, respectively, the old form struggling to maintain itself, and the new form which is attempting to supersede it. Historical changes, then, are brought about by class struggles which terminate regularly in the oppressed class, which is destined in the eccnomic order of things to institute the new social system, overthrowing by means of revolution the old ruling class, which has been defending obsolete relations of production. The result of such revolutions is a new arrangement of society in which the old oppressors have little place, and the former master class consequently goes out of existence, or remains as a vestige only. The warring classes, of course, are motivated each by its own economic interests; but this does not prevent either of them from invoking the aid of attractive ideals as a spur to more zealous activity on the part of its supporters. It is, perfectly natural that this should be done as proved by the fact that in the past it has been done on every such occasion.

Then, last of all, according to the Marxians, the new suciety is truly a synthesis of the antagonistic elements; for nothing can be really and completely destroyed; to all things there exist their opposites, and between them there is a struggle, yet in no instance is anything wiped out of existence by its opponent-instead, there appears a new element which contains in a modi- 
fied and fused, but still existing form both sides of the antagonism. Thus embodied in the new economic system there appear on a higher level all the useful features of the old method of production. The old features in this sort of combination with the new features which the old have generated, and raised up against themselves, constitute the concrete material of any social system.

This general and rather abstract scheme of historical materialism seems at first sight to be quite different from Hegel's philosophy of history, yet there is really a surprisingly close parallel between them. In pointing out this correspondence between the important features of the Marxian doctrine with those of the Hegelian, it is not intended that there should be implied a deliberate attempt by Marx and Engels to follow the order and method of Hegel's interpretation, merely substituting for his working forces the quite different forces of their own conception. It is much more probable that the two socialist philosophers were so steeped in the general method of Hegelian dialectic that they applied it as naturally and freely to their social philosophy as did the original author himself.

As stated before, the Hegelian conception of Spirit corresponds with the Marxian notion of the economic forces of society since each is held to be basic to all historical progress. In each system there appear slso corresponding conceptions of a complete society, a society as a whole, or a "concrete society." According to Hegel, the general color of such a society depends upon its historical level, that is, the stage so far attained by Freedom, of which it is the concrete expression, in its progress toward complete realization. In marked contrast is the Marxian view that any society taken as a whele, with its religious, political, aesthetic, and intellectual institutions and opinions, owes its pattern and tone to the stage in the development of the "tool," or, in other words, the degree of complication and effectiveness attained by the means through which economic goods are produced.

There is also a peculiar resemblance between the two very diffcrent instruments for affecting historical progress. For both Hegel and the Marxians the "germ" of the new society is generated within the "sheil" of the old, or to use an expression employed first by Hegel and later by both Marx and Engels, the "germ" of the new society appears "in the womb of the old." For Hegel, the "germ" consists of the ideals held and striven for by the more advanced and enlightened portion of the group who somehow gain a realization of a more developed Freedom. The "germ" in the Marxian system is more complicated. New and more efficient methods of production come to take the place of antiquated tools and organization; new methods of production involve an altered form of distribution, to which corresponds, of course, a new line-up of economic classes; the new methods with their classes and class ideologies are the "germ" of the new society. In both systems, ideals play a prominent part (more so in Hegel's than in Marx's) but, whereas, for Hegel, these ideals appear from the rational necessity that Freedom should become completely self-conscious through a gradual series of connected stages, 
passing from one to another by means of self-posited oppositions-in this case ideals of greater or less freedom-for the Marxians these "ideals" are induced with significant directness, and represent more or less frankly the economic interests of the classes concerned, and the function they serve, as explaincd above, is that of a weapon employed by them in their struggle against each other for economic supremacy. And finally, it is necessary only to mention that the result of the conflict, for both, is a "higher synthesis" in which the antagonists, the thesis and the antithesis, have been aufgehoben.

It is interesting and important to note that both thinkers state explicitly that groups, peoples, classes, as they are variously designated, constitute the units of historical study, and that consequently, no claim of application to individuals is made for the general principles arrived at. In fact, it is necessary only to glance at the attempts of the two philosophers to apply their generalizations to become convinced that neither in theory nor in practice was such an absurdity maintained.

Another point of some importance is the fact that Marx incorporated almost without modification Hegel's conclusions as to the role of the "great man" in history. For Hegel the "great man" is simply unusually wide-awake, intelligent, or capable, and as already explained, discovers before other people the next step in the development of Freedom, strides forward, leads the movement toward it, and, of course, sooner or later, succeeds; since the change he desires is destined to come anyway, all he can possibly accomplish is a certain amount of acceleration. This view agrees essentially with that of Marx, who also holds that the great personage is made by favorable circumstances-that he is sufficiently clever and fortunate to be the leader of one or other of the warring classes, which exist independently of him. If the group of which he is the head is victorious he becomes a hero of history, and if it fails he may still be remembered. 
IV.

\section{THE CONCRETE THEORY OF HISTORICAL MATERLALISM}

AND

THE PHILOSOPHY OF HEGEL

It is necessary now to give in comparison with Hegel, the more concrete Marxian theory, that is, the theory as it is applied by Marx and Engels to the main divisions of history. While in Hegel probably the bare theoretical statement of the philosophy of history is more significant than his application of it, in the writings of the Marxians the practical application is undoubtedly of far more value, because much clearer and more precise than any of their scanty general statements.

After having decided that the material factor is dominant in history, Marx next concludes that the predominant element in the material basis is economic. In this he departs from such other materialistic philosophers of history as Buckle and Montesquieu on these grounds: history is fundamentally a changing process; therefore, a theory of history must above all things involve an explanation of the fact and the manner of this change; since it is obvious that what is in itself static cannot produce what is escentially a movement, an explanation of history exclusively in terms of physical environment must be rejected, and the more adequate interpretation accepted, that tools of production expand and develop through an inner necessity ${ }^{51}$ of their nature, and that each important alteration in the tools, or means of production, is accompanied by a corresponding change in the entire social organization.

Upon this economic basis, the Marxians divided history into three general stages, as follows: (1) pre-civilization, or the era of primitive communism, (2) civilization, ${ }^{52}$ or the reign of private property, (3) the stage of future communism. In this three-fold division there is more of a suggestion of the Hegelian triad than its mere figure three, for the future state of communism will be a combination in a very real sense of the two preceding stages. Its communistic features will be very similar to those of primitive communism, but they are to rest on a foundation very different from that of its primitive predecessor. Instead of the pre-civilized methods of gaining a living by hunting and fishing, the communism of the future will know all the advantages (without the flagrant disadvantages) of a highly matured machine industry, the product of the long years of development during the period of civilization.

The second member of the Marxian general historical triad corresponds to Hegel's complete period of history. Hegel refuses to grant pre-state

${ }^{51}$ This does not mean a mysterious inner force, but just the natural evolution and improvement of tools.

${ }^{52}$ This use of the word "civilization" is from L. Morgan, but his use of the term "ancient society" as a synonym for "pre-civilization" is not followed. 
peoples a place in history proper; the Marxians begin their era of civilization with the introduction of private property, the maintenance of which requires the organization of the state. Thus the entire subject of Hegel's philosophy of history coincides in time with only a portion of the range of human development included in the Marxian survey.

One further curious difference in this connection must be noted: for the Marxians a future and most desirable stage forms an integral part of their scheme; while Hegel seems to have considered the German world sufficiently exalted to represent the complete realization of Spirit. Theugh he did suggest, inconsistently ${ }^{53}$, that America may be viewed as the state of the future-what this future is, or how Hegel reconciles this with previous and less incidental statements, it is difficult to see.

The middle period of the Marxians, the period of civilization, of private property and of the state, evolved out of the earlier stage because of certain economic changes, chiefly, the invention of the plow, which brought about a division of labor, making slavery profitable and thereby calling i: into existence. With the establishment of private property, there appeared the state to function as its protector. This view is in contrast to the Hegelian concept in which the state marks the first beginning of the consciousness of Freedori, since the state and written laws go together, and Hegel does not recognize the possibility of the consciousness of Freedom until it has been expressed in some written record, such as a code of laws.

The three divisions within the period of civilization represent for the Marxians three different forms of society based on as many forms of private property. In each stage there are two main classes, the exploiters and the exploited, the owners of the means of production and the workers who operate them. ${ }^{54}$

The Marxians have adopted the following names for these divisions of civilization: the first stage, known as Ancient Society, was based on slave labor; the second was called Feudal Society because resting on a foundation of serf labor; while the third, or present system of Capitalist Society is characterized by a peculiar form of bondage known as wage slavery.

Even more important than the explanation of any particular stage in history is the discovery of the causes of the downfall of one scrt of society and its replacement by the next. In the Hegelian system this explanation is given almost wholly in terms of such non-material and glorified forces as the "degree of the consciousness of Freedom," and the realization by the most complete representative of Spirit that not only One, but Many, or still better, All are Free. The Marxians, on the other hand, justify the title of their theory

${ }^{53}$ Hegel, Philosophy of History (Colonial Press, New York, 1899) 142.

os "The essential difference between the various economic forms of society, between, for instance, a society based on slave labor, and one based on wage labor, lies only in the mode in which the surplus labor is in each case extracted from the actual producer, the laborer."-Marx, Capital (Chas. H. Kerr \& Co., Chicago, 1919) 241. 
by attributing all historical changes to the operation of purely "material," that is, economic causes.

Thus it was held by the Marxians that Ancient Society fell because it was so weakened by the clash of classes, and because the slaves would no longer fight in the interests of their masters, that victory for the barbarians proved an easy matter. It was "the common ruin of the contending classes." The serf took the place of the slave, because he was found more profitable to operate the very large holdings of land that had grown up, chiefly as a result of military victories on the continental territories now involved in the historical process. The serfs did not require supervision as slaves did. Thus feudalism began with only two main classes, the landlords and the serfs who worked for them.

This condition changed, however, with the appearance of certain inventions, especially the compass, ships, and some of the arts, for these new tools brought into existence a new class of merchants and artisans suitable to their use, thus paving the way for the transition to a new social system.

This transition period from feudalism to capitalism was the period of the guilds, of petty, or handicraft industry, and of the free cities. The invention of powder and printing strengthened the merchant class and the new bourgeoisie at the expense of the landlords. Rivalries between the greater and the lesser nobility were intensified. All classes came in conflict; the monarch and the guilds, the monarch and the nobility, the nobility and the guilds, the guilds merchant and the guilds artisan, and the new capitalists and all the rest. Frequently these struggles took the form of religious wars-and in this category must be placed the Thirty Years War, the Huguenot wars in France, and the insurrection of the Puritans in England.

The economic transition from the one-man, hand production of the disappearing feudal system to full-fledged capitalism was gradual and complicated. Its analysis occupies a very significant part of the economics of Marx (covering a large and important section of the first volume of Capital), and it may, therefore, be viewed as sort of a connecting link between the philosophy of history and the economics proper. It is particularly significant in comparison with Hegel because it involves the use of the Hegelian categories of quantity and quality in a peculiarly Marxian manner.

Capitalism has been from its very beginning a process of the concentration of capital. The method of production from which it developed was that of the individual ownership and use of the tools, and, consequently, of the individual appropriation of the product. This comparatively equitable arrangement because of the use of fortunes amassed chiefly by merchants, gave way to the inequality which is necessary to capitalism. These fortunes were spent in the erection of factories which were, to begin with, but enlargements of the old guild workshop; in other words, they were the result of merely quantitative changes. But this grouping of many workers under one factory roof re- 
sulted in the production of certain qualitative changes which made the transition to capitalism definite and complete. ${ }^{55}$ These qualitative changes were (1) the division of labor, (2) the use by different men of the same tools, (3) work under supervision. The significant thing is that the important qualitative change from individual to social production had been accomplished.

The categories, of quantity and quality, occur in the first main division of the Hegelian Logic. (They will be more fully discussed in connection with the theory of value.) They form the thesis and the antithesis, respectively, of the triad, the synthesis of which is measure or Mass. Under the category of measure a peculiar relationship between quantity and quality is brought out of which Marx and Engels, and especially later Marxians (these last sometimes uncritically) have made a great deal. Marxians speak of "quantitative changes becoming qualitative changes," after the degree of quantitative change has reached a certain point. This relationship is expressed by Hegel, discussing measure, as follows: "The identity between quantity and quality, which is found in Measure, is at first only implicit, and not yet explicitly realized. In other words, these two categories, which unite in Measure, claim a certain independence and applicability of their own. On the one hand, the quantitative features of the definite Being may be altered, without affecting its quality. On the other hand, this increase and diminution, immaterial though it be, has its limit, by exceeding which the quality suffers change." ${ }^{\prime s}$ Then follows a long list of illustrations. In the Marxian system, this connection occurs not only in the case cited above, of the transition from the medieval workshop to the capitalist factory, but in a number of other instances as well. Engels, for example, in answer to a Duehring criticism brings out its application in connection with a somewhat different aspect of the transition, though it applies afterward as well: "One may remark the elevated and dignified fashion in which Duehring makes Marx say the exact opposite of what he did say. Marx says "The fact that a given amount of value can only transform itself into capital as soon as it has attained a definite minimum, varying with the circumstances, in each individual case-this fact is proof of the correctness of the law of Hegel.' Herr Duehring makes him say 'Because, according to the law of Hegel, quantity is transformed into quality therefore a sum of money when it has reached a certain amount becomes capital!' He says just the opposite." ${ }^{\text {st }}$

ss "Capitalist production only then really begins, as we have already seen, when each individual capitalist employs simultaneously a comparatively large number of labourers; when consequently the labour-process is carried on on an extensive scale and yields, relatively, large quantities of products. A greater number of labourers working together, at the same time, in one place..... in order to produce the same sort of commodity under the mastership of one capitalist, constitutes, both historically and logically, the starting point of capitalist production. ... The workshop of the mediaeval master handicraftsman is simply enlarged. At first, therefore, the difference is purely qauntitative."Ibid. 353 .

so Hegel, Logic (Clarendon Press, Oxford, 1892) Section 108. 155.

${ }^{87}$ Engels, Landmarks of Scientific Socialism (Chas. H. Kerr \& Co., Chicago, 1907) 
This change from individual to social production brought about many far-reaching results. Its most immediate effect was to so cheapen goods produced by the more advanced methods that the older, individual producers found it impossible to compete and dropped out. But the method of ownership did not change. Just as under the handicraft system the owner of the tool became the owner of the product, so under the new scheme the owner of the factory and the machine made the same claim. Production had become social, but appropriation remained individual. Historically, this economic change meant the beginning of capitalism as a social system, for this fundamental contradiction is the basis of that system.

The essential economic features of capitalism constitute the main subject of the three volumes of Capital. It is necessary at this point only to enumerate them as a transition to the matter of the causes and process of the capitalist collapse. In the first place, the economics of capitalism must deal with the wealth of capitalism. This wealth consists of a certain class of material objects which are the products of human labor produced for exchange and not for use. Such objects are called by Marx, commodities. These commodities are produced by the class of workers called the prolctariat; they are owned by the capitalist class by right of their ownership of the means of production. Capitalist society is composed essentially of these two classes, the capitalists who own all the wealth and hire the workers to produce more, and the workers who own nothing, but are dependent on the wages they receive from their employers, and who though theoretically free, are bound as securely to their jobs as any slave to his master, or serf to the sciil. Surplus value, the difference between the value produced and the value received by the workers, is the only source of gain to the capitalists, and their sole reason for employing labor. The surplus goods on which capitalism is based, must in order to yield profits, be disposed of in foreign markets. The old markets are soon flooded, and new ones are sought after. Thus capitalism is characterized by a continual and ever more desperate search for more markets. The later stages of capitalism find the organization of production very highly standardized, and on a vast scale. This social system is preserved and protected by the state, which may accurately be viewed as the special organ of the upperclasses to prevent any infringement of their property rights by the lower classes.

The capitalist system, composed of these various institutions, is fraught with many contradictions, of greater or less significance, which make its eventual collapse an historical necessity. As Marx succinctly puts it: "the capitalist system is so full of inherent contradictions that its own development, if the laws of its existence are permitted to freely work themselves out, will cause it to collapse."

The most complete account of the factors and process of this collapse may be found in Engels' book, Socialism, Utopian and Scientific. The fundamental contradiction which is also the essence of capitalism has already been 
given. It is this basic antagonism (that is, between social production and individual ownership) which manifests itself through all the numerous other contradictions of the system. Thus "the contradiction between socialized production and capitalistic appropriation manifested itself as the antagonism of proletariat and bourgeoisie."

In capitalist production there are certain economic laws which operate in spite of, and even through, its characteristic anarchy or lack of organization. This confusion in production at large is in direct opposition to the compact organization within each workshop, but the law of competition underlies and operates through it. Its historical importance rests on the fact that the concentration of wealth is its direct consequence. For it is the very essence of competition to bring into use larger and more expensive machinery, with greater capacity for production. Such changes, which involve the expenditure of more and more capital, naturally bring in their wake the elimination of the unfortunate, lesser capitalists who are not wealthy enough to make the increase. These ruined members of the middle-class drop into the ranks of the unpropertied proletariat, helping to increase their numbers and make a more powerful opponent of the few successful industrial magnates who survive.

Meanwhile, due to the unemployment brought about by the installation of improved, labor-saving machinery, the distress of the proletariat is increasing. The misery thus endured (misery of inequality, even when material comforts increase, and relative misery due to sudden changes in the standard of living) brings about a revolutionary feeling, and the position of the capitalist becomes notably insecure.

These two features of the collapse of capitalism, namely, the replacement of old by new and more productive machinery, and the ever widening breach between the two economic classes, are given the characteristic Hegelian twist by both Marx and Engels in many interesting passages. For example, Marx says, referring to the enlargement of industry through competition: "The accumulation of capital though originally appearing as its quantitative extension only, is affected, as we have seen, under a progressive qualitative change in its composition, under a constant increase of its constant at the expense of its variable constituent.".5s Then, regarding the greater misery and discontent of the laboring class, Marx has this to say: "The law that always equilibrates the relative surplus population, or industrial reserve army, to the extent and energy of accumulation, this law rivets the laborer to capital more firmly than the wedges of Vulcan did Prometheus to the rock. It establishes an accumulation of misery, corresponding to the accumulation of capital. Accumulation of capital, at one pole, is, therefore, at the same time, accumulation of misery, agony of toil, slavery, ignorance, brutality, mental degradation at the opposite pole, that is, on the side of the class that produces its own product in the form of capital." ${ }^{\prime \prime}$ This passage illustrates the appli-

58 Engels, Socialism, Utopian and Scientific (Chas. H. Kerr \& Co., Chicago, 1918) 105. ${ }^{50}$ Marx, Capital, 1.689.

60 Ibid. 709. 
cation so frequently made by Marx of the Hegelian maxim of polar opposites. For Marx the capitalists and the workers are always "polar opposites," "antagonistic forces," absolutely necessary to each other, as such, yet the most deadly enemies, between whom, in the end, there can be no compromise.

The contradictions already mentioned bring about another, more directly indicative of the eventual collapse of the capitalist system, namely, the disorder known as the periodical crisis. The chief cause of these crises is the inability of the capitalists, resulting from the paucity of markets, to dispose of their surplus goods. "The enormous expansive force of modern industry," says Engels, "compared with which that of gases is mere child's play, appears to us now as a necessity for expansion, both qualitative and quantitative, that laughs at all resistance." But, "the extension of the markets cannot keep pace with the extension of production. The collision becomes inevitable, and as this cannot produce any real solution so long as it does not break in pieces the capitalist mode of production, the collisions become periodic. Capitalist production has begotten another 'vicious circle'." However, "in these crises, the contradiction between socialized production and capitalist appropriation ends in a violent explosion. The circulation of commodities is, for the time being, stopped. Money, the means of circulation, becomes a hindrance to circulation. All the laws of production and circulation of commodities are turned upside down. The economic collision has reached its apogee. The mode of production is in rebellion against the mode of exchange."

Whenever there are contradictions, something must occur to overcome them. In the case of history, each successive era is replaced by the next, which is but the resolution of the contradictions by which it was destroyed. Thus, in the present instance, it is manifest from the fact that capitalism is a bundle of contradictions that, "logically," it must go out of existence. The Marxians, however, do not rely on this abstract proof, but attempt to demonstrate from the nature of these economic and social contradictions that the continued existence of capitalism is an economic, a physical impossibility.

Having shown that such a system cannot continue long in existence, racked as it is by periodic crises which become increasingly severe and devastating and indicate a state of economic disintegration with its consequent weakening of ruling class power, and injured by an ever widening breach between the social classes, with the bolder discontent over their inferior position displayed by the lower class, the Marxians then proceed to the practical solution of the problem. In a word, this solution lies in the overthrow of the capitalist system through whatever means may be necessary, by those to whom it is a disadvantage, namely, the proletariat. Engels summarizes effectively as fullows: "This solution can only consist in the practical recognition of the social nature of the modern forces of production, appropriation, and exchange with the socialized character of the means of production. And this can only come about by society openly and directly taking possession of the productive forces

${ }^{62}$ Ibid. 116-7. 
which have outgrown all control except that of society as a whole. The social character of the means of production and of the products today reacts against the producers, periodically disrupts all production and exchange, acts only like a law of nature working blindly, forcibly, destructively. But with the taking over by society of the productive forces, the social character of the means of production and of the products will be utilized by the producers with a perfect understanding of its nature, and instead of being a source of disturbance and periodical collapse, will become the most powerful lever of production itself." Thus, the one all important end to be attained is the resolution of the fundamental contradiction between social production and individual appropriation by instituting an organization of social ownership to correspond with the method of production. The method by which this is to be accomplished is necessarily that of revolution.

True to their Hegelian affiliation, the Marxians tend to refer not only the forces and factors in history, as shown in the outline of pure theory, but also the various historical epochs, to their proper positions in the logical triad. It is curious but not necessarily inconsistent that in these two aspects of the doctrine, the same period should occupy different positions in the triad. Thus from the point of view of the forces which brought about the transition, the capitalist system seems to be the synthesis of a triad the other two members of which are: thesis, the individual production and ownership of the handicraft period, and antithesis, the introduction of cooperation which meant the domination of social rather than individual production. Capitalism as the consummation of this cooperative tendency may be regarded as combining and reconciling these opposing tendencies. In fact, the system rests entirely-though unstably-on the abeyance for the time being of the antagonism between the sucial method of production and the limited, individual character of appropriation. ${ }^{64}$ On the other hand, in Engels' Landmarks of Scientific Socialism there is a very clear statement to the effect that, though it is unnecessary for proof of a future communism to rely on pure abstract, logical deduction, it is worth observing that the conclusions arrived at by them on concrete material grounds conform with the pure outline of the dialectic. However, this should not te surprising, for, from what source was the logic derived, but from the studied events of the material world? Consequently, it is perfectly well founded and somewhat clarify to regard capitalism as a negation of feudalism, and future communism as the negation of the negation of capitalism, this classification to be based on the same old qualities of social and individual production and ownership. The introduction with capitalism of socialized production was a negation of the individual ownership of feudal days. Future society based on the socialization of ownership as well as production, will be a negation of

63 Ibid. 124.

at It may be remarked that though the basis for this analysis is clcarly present in the Marxian exposition, it is not stressed, or even explicitly stated, by the authors. 
the impossible combination which forms the essence of capitalisnı. It may, therefore, be regarded, logically, as the negation of the negation. ${ }^{65}$

There are several ways, it seems to me, of regarding the apparent divergence of this latest triad from the conventional dialectical form. It is easy to see that it does not fit in, at least not readily, with the abstract group the last member of which is a synthesis, or combination of the first and second, which are diametrically opposed, but parallel, and on an equal plane. The individual ownership of feudalism opposed by the individual ownership and social production of capitalism, and synthesized by the social production and ownership of communism offers no such symmetrical scheme. This fact requires interpretation.

The obvious, and probably the true explanation is that Marx and Engels make free and easy use of Hegel's principles and terms, making no attempt to follow the Hegelian system in detail. There is plenty of eviderce for this view, especially in Capital. To such expressions as "opposition," "negation," and "reconciliation," which occur with some frequency, the Marxians do not, in practice at least, attach an obscure metaphysical meaning. Their use of these terms is certainly a little peculiar, but the meaning they intend to convey is perfectly acceptable, logically, to common sense. Engels attempts at sone length to prove this point to the critic Herr Duehring: "But what is this dreadful negation of the negation which makes life so bitter to He:r Duehring . . ? It is a very simple process, and one, moreover, which fulfills itself every day, which any child can understand when it is deprived of mystery, under which the old idealistic philosophy found a refuge, . . . . . Let us take a grain of barley . . . . . let such a grain of barley fall on suitable soil under normal conditions; a complete individual change at once takes place in it; under the influence of heat and moisture, it germinates. The grain, as such disappears, is negated, in its place arises the plant, the negation of the grain . . . But let us take a cultivated ornamental plant . . . . . Let us consider the seed and the plants developed from it by the skill of the gardener, and we have in testimony of this negation of the negation, no longer the same seeds but qualitatively improved seed which produces more beautiful flowers. . . . . . and every new negation of the negation, increases the tendency to perfection." ${ }^{\prime \prime}$ This habit of very free adaptation of Hegelian concepts is quite sufficient to explain all discrepancies between Marxian and Hegelian triads.

However, another possible, though much less probable explanation of this particular case must be investigated. A feature of the Hegelian dialectic which is overlooked by almost everyone, though referred to by Hegel himself in the introduction to the smaller Logic, and alluded to by McTaggart in his Studies in the Hegelian Dialectic, is the fact that in the Logic itself there are three different types of triadic structure, a different one for each of the three

\footnotetext{
65 See Engels' Landmarks of Scientific Socialism, Section on the "Negation of the Negation," Chapter 7.

6e Ibid. 166-7.
} 
main divisions-though the variation is continuous, rather than appearing abruptly at each point of division. In the first type of the triad peculiar to the first division, the thesis is absolutely, or diametrically opposed by the antithesis, and the synthesis, therefore, is truly a synthesis of the two of them, since neither is more important than the other, and both have been elevated to the higher plane in which they occupy parallel positions. The second division is chiefly characterized by triads of another sort. In this division, the antithesis is not absolutely opposed to the thesis, for it appears as a development from it, and contains within itself, therefore, some portion of its logical partner. The synthesis is consequently the union and elevation of these two quite uneven elements. The third type but carries this process to its logical conclusion. In this case, the thesis develops into the antithesis, not partially, as in the previous case, but entirely, making it impossible for the antithesis to really negate the thesis, which it already embodies. Consequently, the synthesis is not a combination of the other two members of the triad, but a direct outgrowth of the antithesis alone.

Of these three possible types of the dialectical triad, the Marxian plan of historical epochs seems to conform most closely with the second. The similarity, of course, is not perfect, but in view of the fact that the Marxians used dialectical terms in this connection, the type of triadic relation employed by them is of some interest. Capitalism, a system of individual production combined with social ownership has replaced, or negated, feudalism, a society characterized by both individual production and individual ownership. It seems manifest that the antithesis in this case is not merely the opposite of the thesis. It is rather a development, containing in a partial, incomplete way, its predecessor. That is, the individual ownership of feudalism has been taken up into capitalism, while the other aspect of feudalism, namely, individual production, has been dropped. In the same manner, the future stage of communism, as the synthesis of the two preceding systems, will be a development from the antithesis, for the social production of capitalism will be combined with the social ownership of the new society. 
PART II

POLITICAL THEORY 


\section{HEGEL'S PHILOSOPHY OF RIGHT 67}

According to Hegel, the realms of law, morality, and the state constitute various stages or moments in the complete realization of Freedom. In fact, the complete realization of Freedom can be reached only in the state, because the state, as the culmination of social ethics, is the union of objective and subjective Freedom. Since, in this sphere of reality, objective and subjective refer to the two opposing and abstract stages in the development of right, namely, abstract right and morality, the state may be viewed as their real synthesis.

The discussion of the first phase or member in the triad of right, abstract right, includes analysis of the role and significance of property. A man must, first of all, according to Hegel, be a person among other persons-in other words, he must have certain rights, maintained, of course, by law. However, it is essential also, that every person become aware of himself as a personality by reflection in external reality. This state is attained through the power to command, the right to use, and to dispose of property. "But, when $\mathrm{I}$ as a free will am in possession of something, I get a tangible existence, and in this way first become an actual will. This is the true and legal nature of property, and constitutes its distinctive character." ${ }^{\text {es }}$

Hegel's attitude toward the collective as opposed to the private ownership of property follows naturally from his philosophical interpretation of the nature of property. However, he makes sufficiently explicit statement of his belief in private and his opposition to equality in the ownership of property. "The elements of nature cannot become private property.-In the agrarian laws of Rome may be found a conflict between collective and private ownership of the land. Private ownership is the more reasonable, and, even at the expense of other rights, must win the victory.-Property bound up with the family trust contains an element which is opposed to the right of personality and private ownership. . . . . The idea of Plato's Republic does a wrong to the person, in regarding him as unable to hold property." "Explaining that the above does not imply equality of ownership, Hegel says: "Since wealth depends upon application, equality in the distribution of goods would, if introduced, soon be disturbed again. What does not permit of being carried out ought not to be attempted. Men are equal, it is true, but only as persons, that is, only wich reference to the source of possession. Accordingly, every one must have property. This is the only kind of equality which it is possible to consider. Be-

67 This does not purport to be a complete exposition of Hegel's Philosophy of Right. It is but a selective account, including only those features of the theory to which there are corresponding Marxian doctrines.

68 Hegel, The Philosophy of Right (G. Bell \& Sons, London, 1896) Section 45.

60 Ibid. Section 46, note. 
yond this is found the region of particular persons, and the question for the first time comes up, how much do I possess? Here the assertion that the property of every man ought in justice to be equal to that of every other is false since justice demands merely that every one should have property. Indeed amongst persons variously endowed, inequality must occur, and equality would be wrong." 70

Hegel's attitude towards slavery as a form of property is interesting. Slavery itself stands condemned; nor can it be justified on the grounds of the separation of soul and body. "If we hold fast to the side that man is absolutely free, we condemn slavery." ${ }^{1}$ Nevertheless, Hegel holds, it depends in the last analysis on the slave himself. Slavery is a condition of the world where a wrong is still a right (to be remedied, apparently by some sort of rebellious action on the part of the slave). That which the Marxians call "wage slavery" is not included within the above condemnation of slavery as such Hegel makes of it a neat exception: "The use of single products of my particular physical endowments or mental capacities I may hand over to others for a limited time, since, when a time limit is recognized, these products may be said to have an external relation to my genuine and total being. If I were to dispose of my whole time made concrete in work, and all of my activity, I would be giving up the essence of my productions. My whole activity and reality, in short, my personality, would be the property of another."'t2

Hegel's interpretation of valious legal matters, such as contracts, crime, fraud, and the like, are interesting when compared with Marx's. Contracts, according to Hegel, express the first beginning of a common will, but are still altogether arbitrary. They permit of disagreements such that one or both parties may be either: (1) wrong, in which case, compensation is in order, or (2) fraudulent, whereupon the only compensation is punishment, or, again, (3) criminal, and then some form of legal punishment must be invoked because of the following high-flown nature with which crime is endowed, "In crime, which is wrong in its proper sense, neither right in general nor personal right is tespected. Both the objective and the subjective aspects of right are set at defiance by crime." ${ }^{\prime 3}$ Thus, Hegel maintains that violence done to my property, is injury also to my will.

This attention to the legal aspect of punishment is not accidental. The purpose of punishment is the restoration of harmony, the cancelling by retribution of the wrong which has been committed. This sort of adjustment can be brought about only by the law, since the revenge of a private person is but another wrong, requiring further adjustment. Punishment, in fact, is but the necessary complement of crime or wrong-doing, its other side, which is required to bring home to the criminal the fact of his having committed an offense

70 Ibid. Section 49 , addition.

${ }^{71} \mathrm{Ibid}$. Section 57 , addition.

${ }^{72} \mathrm{Ibid}$.

7s Ibid. Section 90, addition. 
against himself as well as against the aggrieved party. This sort of realization brought about by the law as will, constitutes a transition to the next phase, or morality. "Retribution is the inner connection and identity of two things which in outward appearance and external reality are different. Requittal seems to be something foreign, and not of right to belong to the criminal. But punishment is only the manifestation of crime, the other half which is necessarily presupposed in the first. Retribution looks like something immoral, like revenge, and may therefore seem to be something personal. But it is the conception not the personal element, which carries out retribution." ${ }^{\prime 4}$

"Morality is itself but an isolated stage, as abstract as the first stage, of abstract right, but a necessary complement to it. Together, they constitute the two opposing terms of the triad of which the ethical sphere is the synthesis. Morality differs from right in the degree of subjectivity of the individual. To the purely objective rules of conduct, and especially of probibition, must be added, for the more complete realization of Freedom, subjective conviction, or conscience. In the sphere of Morality, which may also be termed the sphere of Subjective Right, or of the 'Right of the Subjective Will,' the Person becomes a Subject. His personality, his will, no longer exists merely for others, in a pure 'state of nature,' or in the form of an aggregate of purely objective acts and relations; it exists for the person himself, in the inward forum of consciousness, of reflective thought, of conscience. In this more favorable soil is now planted his freedom, which thus first demonstrates itself to be more fundamentally a thing of the mind, or of the inward spirit, than of external possessions and real relations." 75

Only in the third, and last stage, that of ethical observance, the region of established ethical principles, is the will identical with the conception of it and has only this conception for its content. For the will must be aware cf and intend the universality of its acts. "In brief," as Morris accurately puts it, "the ideal content of the conception of Freedom is unfolded and actualized in a present, actual world of organized human and spiritual relations, in which freedom is objectively demonstrated to be, not the attribute of 'merely conscious' individuals (brutes are such individuals), but of beings, such as men, who are capable of finding in a consciousness of the universal the true substance of their own proper self-consciousness and the true motive of their own, that is, of all genuinely human-activity."

"The ethical system," says Hegel, "is the idea of Freedom. . . . . The ethical is thus the conception of Freedom developed into a present world, and also into the nature of self-consciousness." "It Freedom at this stage is thus not abstract, but true Freedom in the concrete-Freedom which is not opposed to, but united with necessity. As such a union of Freedom and necessity, the

${ }^{74} \mathrm{Ibid}$. Section 101, addition.

7 Morris (G. S.) Hegel's Philosophy of the State and of History (S. C. Griggs \& Co., 1887) 30 .

76 Ibid. 43

${ }^{n}$ Hegel, Philosophy of Right, Section 142. 
ethical system, fully developed in the state, has at last attained rationality. "The ethical material is rational, because it is the system of these phases of the idea. Thus Freedom, the Absolute Will, the objective, and the circle of necessity, are all one principle, whose elements are the ethical forces. They rule the lives of individuals, and in individuals as their models have their shape, manifestation, and actuality."7s

The unity of this stage is expressed in three levels, (1) the family, (2) the civic community, (3) the state. "The family," said Hegel, "is the direct substantive reality of the Spirit. The unity of the family is one of feeling, the feeling of love. . . . Love is in general the consciousness of the unity of myself with another." It is necessary also that there be a property basis: "It is not enough that the family has property, but, as a universal and lasting person, it needs a permanent and sure possession, or means." "\%9

The family, which is the first and universal member of the triad, is negated by the civic community, which is the opposing difference. "The civic community is the realm of difference, intermediate between the family and the state, although its construction followed in point of time the construction of the state. It, as the difference, must presuppose the state." 80 The reason for the priority of the civic community is the necessity that man as a citizen must first of all supply his own wants, thus developing the science of political economy. ${ }^{81}$ However, it is apparent to the social philosopher that in the process of satisfying these elementary wants of man, there must be a division of labor, on the basis of which society is divided into classes. Next to the family division, there is a division on an economic basis. Thus, in civil society, there is the the class of landowners and the ciass of artisans. With the development of industry and the industrial class, the form of the products of nature has been altered. In the production of industrial goods, the cooperation of three different industrial groups is necessary. For the satisfaction of individual wants there is the manual laborer, or the artisan as such - the man who, by the effort of his own hands satisfies directly the needs of some definite person. In manufacture, on the other hand, the particular needs of many people are satisfied through the more abstract collection of goods produced because of universal demand. Lastly, there is the necessary sphere of exchange or commerce through money, which is the general medium, representing the abstract value of all the merchandise.

Then, there is the universal class the duty of which is the protection of the universal interests of society. This class must therefore be relieved of the necessity of providing for itself ${ }^{82}$ - its support rests rightly on the rest of so-

78 Ibid. Section 145.

$70 \mathrm{Ibid}$. Sections 158 , addition; 170.

so $\mathrm{Ibid}$. Section 182 , addition.

${ }^{81}$ In this connection, Hegel refers to the political economists, Smith, Lay, and Ricardo, indicating a knowledge of them which might possibly have had some bearing on his theory of value.-Ibid. Section 189 , note.

82 Ibid. Section 205. 
ciety which receives benefit from it. The office of judge, for example, comes under this class of public servants. Though there are laws to regulate conduct, they cannot be sufficiently detailed for the equitable settlement of all cases; in so far as they fall short of complete rectitude, there are the freer decisions of the courts as a remedy. The police, too, must give universal service and protection, especially to property. Not only the owners of corporations are to be protected, but the corporations themselves are to be subject to police regulation in the interest of the consumer. Not laissez faire, then, but the regulation of industry is favored by Hegel. In connection with corporations, which were apparently regarded by Hegel as inevitable, the question of poverty among the masses of the people which comes as a result of the amassing of great wealth, is dealt with. Neither poor-houses nor publicly provided employment can relieve the distress of the poor; colonization is the only adequate remedy.

The state, which is logically the supreme social institution, is both rational and necessary, and there is no option about belonging to it. Even though the purely subjective will of the individual fails to acknowledge the state's supremacy, the rational, or true will must recognize the cogency of the law which is its own law. The laws of the state are binding because they are self-imposed by the rational will. Thus the union of Freedom and necessity is brought about. In this manner, Hegel gives his view of the essence of the state: "Rationality, viewed abstractedly, consists in the thorough study of universality and individuality. Taken concretely, and from the standpoint of the content, it is the unity of the objective freedom with subjective freedom of the general substantive will seeking particular ends. From the standpoint of the form it consists in action determined by thought-out or universal laws and principles. This idea is the absolutely eternal and necessary being of spirit. The idea of the state is not concerned with the historical origin of either the state in general or of any particular state with its special rights and characters." ${ }^{13}$

With regard to the "internal constitution," Hegel says "The constitution is rational in so far as the active working divisions of the state are in accord with the nature of the conception. This occurs when every one of its functions is in itself the totality, in the sense that it effectually contains the other elements. These elements, too, though expressing the distinctions of the conception, remain strictly within its ideality, and constitute one individual whole. . . . The principle of the separation of functions contains the essential element of difference, that is to say, of real rationality. . . . . The functions of the state, the executive and the legislative, as they are called, may be made independent of each other. The state is, then, forthwith overthrown. ." 84

Following the above metaphysical interpretation of the so-called "separation of powers," Hegel then gives his own account of the manner in which the state should be divided: "The political state is divided into three substantive branches:

"(a) The power to fix and establish the universal. This is legislation.

${ }^{83} \mathrm{Ibid}$. Section 258 , note.

84 Ibid. Sections 272,272 , note. 
"(b) The power, which brings particular spheres and individual cases under the universal. This is the function of government.

"(c) The function of the prince, as the subjectivity with which rests the final decision. In this function the other two are brought into an individual unity. It is at one and the same time the culmination and the beginning of the whole. This is constitutional monarchy."

Having in this manner introduced the constitutional monarchy, Hegel proceeds to imbue it with the usual complicated abstractions. In a note to the same section, he says: "The perfecting of the state into a constitutional monarchy is the work of the modern world, in which the substantive idea has attained the infinite form. This is the descent of the spirit of the world into itself, the free perfection by virtue of which the idea sets loose from itself its own elements, and nothing but its own elements, and makes them totalities; at the same time it holds them within the unity of the conception, in which is found their real rationality . . . . .

"But these various forms of the state, which belong in this way to different wholes, are in constitutional monarchy lowered to their proper place as elements. In monarchy we have a single person, in its executive several, in legislation the multitude." 85

At the head of the constitutional monarchy, there is, of course, the monarch, or the prince. "The function of the prince," said Hegel, "contains within itself the three elements of the totality (1) the universality of the constitution and the laws; (2) the counsel, or reference of the particular to the universal; and (3) the final decision, or the self-determination, into which all else returns and from which it receives the beginning of its actuality." It does not follow, however, from the imposing nature of the princely functions that the prince himself must be in any sense a superman. Allegiance, in fact, is not a matter of utility derived either from the nature of the office and its organization, nor from peculiar capabilities of the person who holds the office. "A monarch is not remarkable for bodily strength or intellect, and yet millions permit themselves to be ruled by him. To say that men permit themselves to be governed contrary to their interests, ends, and intentions, is preposterous, since men are not so stupid. It is their need and the inner power of the idea which urge them to this position in opposition to their seeming consciousness, and retain them in this relation." 8 s

The discussion of the internal constitution is followed by an account of external sovereignty, under which topic belongs the subject of wars between nations. "Individuality, as exclusive and independent existence, appears as a relation to other self-dependent states. The independent existence of the actual spirit finds an embodiment in this general self-dependence, which is, therefore, the first freedom and highest dignity of a people." Herein is to be found the ethical element in war. War is not to be regarded as an absolute evil. It is

85 Ibid. Section 273.

${ }^{86} \mathrm{Ibid}$. Sections $272,275,281$, addition. 
not merely external accident, having its accidental ground in the passions of powerful individuals or nations, in acts of injustice, or in anything which ought not to be. Accident befalls that which is by nature accidental, and this fate is a necessity." 87

Finally, in conclusion to the above analysis of the state may be quoted this glowing tribute: "In the state, we must have nothing which is not an expression of rationality.

"Just so high as the Spirit stands above nature, the state stands above physical life. We must hence honor the state as the divine on earth, and later learn that if it is difficult to conceive of nature, it is infinitely harder to apprehend the state."

87 Ibid. Sections 322,324 , note. 
II.

\section{HEGEL'S PHILOSOPHY OF RIGHT AND CORRESPONDING MARXIAN PRINCIPLES}

Marxians regard the state as the special weapon of the propertied class against any opposition to their supremacy from the propertyless class under their domination. Since this is its sole function, the state can have come into existence only with the growth and conflict of classes. In addition to the state, as such, that is, the actual government offices, and closely connected with it, are certain other potent master-class weapons, namely, the laws of the state, along with the sentiment of the people in favor of anything tending to support the status quo, and opposed to anything which endangers it. Thus, the Marxians, too, in a way, considered the state a synthesis. It is a sinthesis, or resolution of the opposition between the two antagonistic classes in society.

On the question of property, Marx is in agreement with Hegel as to its fundamental importance. However, Marx fails to invest it with the same metaphysical significance-it is not necessary to the realization of individuality, nor does it possess necessary ethical attributes. Private property, according to the Marxians, is fundamental to the state, because without it the state would have no reason for existence. It is important to all persons in society because the form of ownership of property is at the basis of all other social, political, religious, and intellectual institutions. Thus in the Marxian system, privaie property receives neither a metaphysical nor an ethical interpretation. The explanation of its origin is taken essentially from Louis Morgan's Ancient Society, and is briefly as follows: Primitive communism broke down through the development of field agriculture, which made possible the recognition of each individual's products, the marking off of land into private plots, to be cultivated by private persons, and likewise made possible ownership of human beings, which was then for the first time useful.

On the matter of the possibility of equal ownership of property, there is complete disagreement between Marx and Hegel. Not only does Marx deny that real equality (that is, equality of needs as opposed to equal division) is either wrong or impossible, but, he holds it is the essence of communism, the system which follows naturally after the collapse of capitalism.

Chattel slavery is not opposed by Marx on any such philosophical grounds as those of Hegel. It is recognized by the Marxians to be the natural form of class division of ancient society, and to be outgrown naturally with the passing of that society. It is outgrown, not because of the "realization of Spirit," but because of the disappearance of the economic forms on which it rests. The sort of selling of one's ability to labor for a stipulated period, which Hegel does not regard as slavery, and therefore condones, is considered by the Marxians the special form of slavery peculiar to capitalism. It is called by thern, 
"wage-slavery," and is thought to have most of the vicious features of the older forms, and some others as well.

Marx's attitude towards contracts, at least between employe and employer, can be seen from the following rather sarcastic passage: "This sphere that we are deserting, within whose boundaries the sale and purchase of labor-power goes on, is in fact a very Eden of the innate rights of man. There alone rule Freedom, Equality, Property, and Bentham. ${ }^{88}$ Freedom, because both the buyer and seller of a commodity, say of labor-power, are constrained only by their own free will. They contract as free agents, and the agreement they come to, is but the form in which they give legal expression to their common will. Equality, because each enters into relations with the other, as with a simple owner of commodities, and they exchange equivalent for equivalent. Property, because each disposes only of what is his own. And Bentham, because each looks only to himself . . . . ."ss Thus, while Hegel assumed the validity of the so-called free-contract, Marx expressly denies, and even ridicules it. The key to the Marxian view of the nature and significance of contracts is found, of course, in the theory of historical materialism, according to which the laws of contracts, like all laws and moral codes, are made in the interest of the dominant economic class. Contracts first became important with the advent of capitalism, because, whereas under former social systems, custom reigned, under this system, there is a formal recognition of the equality of people, whose dealings, therefore, become binding through a "free-contract." This form is beneficial to the capitalist, and not to the laborer-it is the device by which the actual inequality between men is disguised.

It follows, therefore, that the Marxian attitude toward crime, fraud, wrong, and so forth, cannot be the same as Hegel's, since Hegel's analysis is based on an interpretation of contracts to which the Marxians do not subscribe. As will appear later, the Marxians hold a sort of relativity view of morality according to which each moral code (none is permanent) corresponds to a particular social system, and is one of the means by which the lower class is kept submissive, and the system is maintained. Consequently, in so far as wrong, fraud, and crime pertain to the breaking of contracts, as they do now very largely, they are offenses peculiar to capitalism, and will pass out of existence with the passing of that system. Revolutionists against this system can hardly join in the condemnation of acts against it, and in this regard, Marx was for the most part quite consistent. When in his histories, Marx speaks very harshly indeed of certain "forgers," "thieves," "embezzlers," and "perjurers," referring to Louis Bonaparte, and his associates of the "Society of December the 10th," and to the politicians of the "Versailles Government," he seems to me to have been speaking sarcastically, calling attention rather to their

${ }^{88} \mathrm{It}$ is interesting to consider this statement in the light of Veblen's strange contention that one of two lines of antecedents of the Marxian system is the theory of Natural Rights. Cf. Veblen, Socialist Economics of Karl Marx and His Followers, Quarterly Journol of Economics (August, 1906, and February, 1907) 584.

so Marx, Capital 1.195. 
inconsistency in breaking their professed moral codes than to the intrinsic wrong of their acts. However, Marx's perfect consistency on this point is perhaps questionable. It need only be mentioned, that even in the ideal society of the Marxians, crimes against the person, such as murder, will be, if not punished in the ordinary sense of the term, at least restrained in every way necessary.

Though nothing very definite is said by either Marx or Engels about the nature and function of punishment, it is fairly obvious from the trend of their ethical philosophy that they would not hold, as Hegel does, that punishment is the necessary complement, the other half of crime, that there is any metaphysical connection between them, or that the criminal is necessarily benefited by the punishment meted out to him. Only a purely utilitarian view of punishment can possibly fit in with the Marxian scheme of things. And in its truest sense, this can apply only in a society free from classes of exploited and exploiters. Under capitalism, punishment is but another tool of the capitalist class against the workers.

Regarding the interpretation of morals Engels gives a fair statement of the Marxian position: "But if we now see that the three classes of modern society, the feudal aristocracy, the bourgeoisie, and the proletariat have their distinctive ethical systems, we can only conclude therefrom that mankind consciously or unconsciously shapes its moral views in accordance with the material facts upon which in the last instance the class existence is based-upen the economic conditions under which production and exchange are carried on. . . . U U to the present time all ethical theory is in the last instance a testimony to the existence of certain economic conditions prevailing in any community at any particular time. And in proportion as society developed class-antagonisms, morality became a class morality and either justified the interests and domination of the ruling class, or as soon as a subject class became strong enough, justified revolt against the domination of the ruling class in the interest of the subject class."

In the same book, Engels points out that there is a certain truth in Hegel's reconciliation of freedom and necessity. "Hegel was the first man to make a proper explanation of the relation of freedom and necessity. In his eyes freedom is the recognition of necessity. Necessity is blind only in so far as it is not understood, Freedom does not consist in an imaginary independence of natural laws but in the knowledge of these laws, and in the possibility thence derived of applying them intelligently to given ends.

". . . . Freedom, therefore, consists in mastery over ourselves and external nature; it is, therefore, necessarily a product of historical development."

The Marxians disagree with Hegel's idea that the family is a divine insti127-9.

${ }^{90}$ Engels, Landmarks of Scientific Socialism (Chas. H. Kerr \& Co., Chicago, 1907)

i1 Ibid. 147. 
tution with definite characteristics which must not and cannot change. Family forms, they hold, are subject to the most complete changes, each of which is directly reflective of the prevailing economic situation. Engels describes the origin of the monogamous family as follows: "The transition to full private property was accomplished gradually and simultaneously with the transition from the pairing family to monogamy. The monogamous family began to be the economic unit of society." From this it follows that the permanent existence of the family in its present quasi-monogamous state is very improbable.

The Marxians agree with Hegel that it is on the basis of the division of labor that classes in society were formed originally, but they do not agree that this is the foundation for the present class division. They grant that there are the two classes, the landowners, and those who do not own any land to speak of, but for them the class of landowners is under capitalism all but insignificant. The non-landowners are not divided by the Marxians in the way they are by Hegel, according to occupation and product, but according to the ownership or non-ownership of the means of production. Thus, to the Hegelian division of industrial classes into: the artisan, who satisfies the wants of individuals, the manufacturer (by which he seems to mean both the owner and the worker), who produces for the general public, and the merchant, who brings about the exchange of goods, is opposed that of the Marxians according to which society is divided in the main, or tends to be divided as capitalism develops, into the class of capitalists who own the means of production, and hire workers to operate them, and the workers who own only their capacity to labor. There are also sub-divisions of these two main classes, recognized by the Marxians, which are often of considerable importance, for their interests may diverge and bring them into sharp conflict with each other. These important sub-divisions of the çapitalist class are: the industrial capitalists (factory, railroad, and mine owners, and to a lesser extent capitalist farmers), merchants, and financiers (bankers).

The proletariat may also be divided on the basis of skill. The skilled workers may be said to include the class of professionals, such as doctors, lawyers, teachers, and even state officials, police and soldiers.

In addition to these classes, characteristic of capitalism, there are others, remnants of previous systems. For example, there is the previously mentioned class of landowners, who do not manage their land as capitalistic enterprises, but rent it out to tenants. Then, too, there is the group of handicraftsmen, workers who own their own tools, buy and sell their own products. The corner grocer who does not hire workers, nor work himself for wages, belongs also to this group of disappearing classes, as does also the land-owning peasant. In addition may be mentioned certain miscellaneous types: the professional beggars and criminals, the comparatively few remaining titled nobility, Hegel's "princes" and, perhaps, the priests.

The judges and police, who are endowed by Hegel with such exalted (2) Engels, Origin of the Family (Chas. H. Kerr \& Co., Chicago, 1902) 198-9. 
roles, are, of course, in the Marxian scheme, but parts of the machinery of the capitalist state, which is one of the most important of the capitalistic weapons against the workers. Regarding the doctrine of laissez faire brought up in this connection by Hegel, Marx can hardly be said to take a partisan view, inasmuch as it applies only under capitalism, to which system he is unqualifiedly opposed. The same thing may be said of his attitude toward Hegel's solution of the problem of poverty, namely, colonization. To the Marxians, anything short of some sort of socialized scheme is but an ineffective palliative.

With Hegel's rather inconsistent statement that the origin of the state depends on the appearance of class divisions in society based on the division of labor, and that it therefore came into existence coincidently with the growth of agriculture, the Marxians are more than willing to agree. However, they reject Hegel's metaphysical interpretation of these, for them, purely empirical facts of the world of experience. These facts are not true because logically necessary, as Hegel thinks; the Marxians hold them to be "logically" necessary because they have been found to be true.

The state according to Hegel is both "rational and necessary." For the Marxians, it is not only not in any sense "rational" and binding because selfimposed upon all those within its boundaries, as Hegel thinks, but on the contrary, it is for the non-ruling class, which constitutes the great majority, a thing very much opposed to their interests, and the chief instrument by which they are kept in bondage. It is manifestly "necessary" in the sense (also used by Hegel), that its appearance was inevitable in the course of social development. In this sense, its disappearance is also "necessary." Engels very neatly contrasts his own view of the state with the metaphysical view of Hegel: "The state, then, is by no means a power forced on society from outside; neither is it the 'realization of the ethical idea', the 'image and the realization of reason', as Hegel maintained. It is simply a product of society at a certain stage of evolution. It is the confession that this society has become hopelessly divided against itself, has entangled itself in irreconcilable contradictions which it is powerless to banish. In order that these contradictions, these classes with conflicting economic interests, may not annihilate themselves and society in a useless struggle, a power becomes necessary that stands apparently above society and has the function of keeping down the conflicts and maintaining 'order.' And this power, the outgrowth of society, assuming supremacy over it and becoming more and more divorced from it, is the state." And, again, even more clearly, "The state is the result of the desire to keep down class conflicts, but having arisen amid these conflicts, it is as a rule the state of the most powerful economic class that by force of its economic supremacy becomes also the ruling political class and thus acquires new means of subduing and exploiting the oppressed masses. The antique state was, therefore, the state of the slave owners for the purpose of holding the slaves in check. The feudal state was the organ of the nobility for the oppression of the serfs and dependent 
farmers. The modern representative state is the tool of the capitalist exploiters of wage-labor." ${ }^{\prime s}$

That the Marxians do not consider the state in any form an ideal or permanent institution (and are therefore wrongly referred to as State Socialists) is proved by the following quotation from Engels: "The state, then, did not exist from all eternity. There have been societies without it, that had no idea of any state or public power. At a certain stage of economic development, which was of necessity accompanied by a division of society into classes, the state became the inevitable result of this division. We are now rapidly approaching a stage of evolution in production, in which the existence of classes has not only ceased to be a necessity, but becomes a positive fetter on production. Hence these classes must fall as inevitably as they once arose. The state must irrevocably fall with them. The society that is to reorganize production on the basis of a free and equal association of the producers, will transfer the machinery of state where it will then belong: into the Museum of Antiques, by the side of the spinning wheel and the bronze ax." ${ }^{94}$ Then, in another work, Engels says, "The proletariat seizes political power and turns the means of production into State property.

"But in doing this, it abolishes also the State as State. Society thus far, based upon class antagonism, had need of the State. That is, of an organization of the particular class which was pro tempore the exploiting class, an organization for the purpose of preventing any interference from without with the existing conditions of production, and, therefore, especially, for the purpose of forcibly keeping the exploited classes in the condition of oppression corresponding with the given mode of production (slavery, serfdom, wagelabor). The State was the official representative of society as a whole: the gathering of it together into a visible embodiment. But it was this only in so far as it was the State of that class which itself represented, for the time being, society as a whole; in ancient times, the State of slave-owning citizens; in the Middle Ages, the feudal lords; in our own times, the bourgeoisie. When at last it becomes the real representative of the whole of society, it renders itself unnecessary. As soon as there is no longer any class to be held in subjection; as soon as class rule, and the individual struggle for existence based upon our present anarchy in production, with the collisions and excesses arising from these are removed, nothing more remains to be repressed, and a special repressive force, a State, is no longer necessary. The first act by virtue of which the State really constitutes itself the representative of the whole of society-taking possession of the means of production in the name of society-this is, at the same time, its last independent act as a State. State interference in social relations becomes, in one domain after another, superfluous, and then dies out of itself; the government of persons is replaced by the administration of things, and by the conduct of processes of production. The state is not 'abolished.' 
It dies out. ${ }^{95}$ This gives the measure of the value of the phrase 'a free State,' both as to its justifiable use at times by agitators, and as to its ultimate scientific insufficiency; and also the demands of the so-called anarchists for the abolition of the State out of hand."

Then, Marx and Engels in collaboration: "When, in the course of development, class distinctions have disappeared, and all production has been concentrated in the hands of a vast association of the whole nation, the public power will lose its political character. Political power properly so called, is merely the organized power of one class for oppressing another. If the proletariat during its contest with the bourgeoisie is compelled, by the force of circumstances, to organize itself as a class, if, by means of a revolution, it makcs itself the ruling class, and, as such, sweeps away by force the old conditions of production, then it will, along with these conditions, have swept away the conditions for the existence of class antagonisms, and of classes generally, and will thereby have abolished its own supremacy as a class." ${ }^{07}$

With the Hegelian interpretation of the "internal constitution" and the "separation of functions" according to which there may be functions, but they cannot be really separate from each other, but, as with the notions, each must contain the others, and be one with the others, the Marxians can, in a sense, agree. Since for them the state is the tool of the master class, it is fundamentally a unity, and any internal separation, or "checks and balances" must be for the most part, if not a sheer farce, at least of but slight significance; though, sometimes, especially during the transition from one system of society to another, such as that in England during the birth of capitalism, it is true that the struggle between branches of the government may be very violent indeed, since each branch, at such a time, may represent a faction of the governing class as a whole.

Hegel's peculiar division of powers into the legislature, the government, and the prince, which function to fix the universal, and to bring the particular under it, and so forth, finds no parallel whatever in Marx. Except, perhaps, that for Marx, too, the prince or king in a constitutional monarchy may be considered a sort of synthesis of, because he helps to preserve, or rather, is a symbol of, the balance between the opposing groups of landowners and capitalists. When Hegel speaks of the "legislation of the multitude," the Marxians can but disagree flatly, saying that such a thing never happens in any sort of a monarchy. 'They agree heartily that the prince is usually not in any sense a "superman," or "remarkable for bodily strength or intellect."

It is, of course, a truism in the Marxian philosophy that wars between nations have, not as Hegel maintained, the function of realizing "the first freedom and highest dignity of a people," but rather a sound material object,

${ }^{25}$ This expression is more often translated "wither away" as in Lenin's book, The State and the Revolution. This translation is more popular among Marxians because it it more graphic and more expressive of the gradual nature of the state's disappearance.

${ }^{20}$ Engels, Socialism, Utopian and Scientific 127.

${ }^{97}$ Marx and Engels, Communist Manifesto (Chas. H. Kerr \& Co., Chicago, 1918) 42. 
usually markets or colonies, for which the master-class in each of the contending countries is striving. Wars, then, of this type are, at least for the working class, almost entirely evil. Class wars, on the other hand, are absolutely necessary to attain the goal of the workers, the social commonwealth. Consequently, it is not force as such to which the Marxians object. They are not in any degree pacifists, as the following sentence from Engels, quoted by Lenin, will prove: "That force also plays another part in history (other than that of the perpetuation of evil), namely, a revolutionary part; that, as Marx says, it is the midwife of every old Society when it is pregnant with a new one; that force is the instrument and the means by which social movements hack their way through and break up the dead and fossilized political forms; -of all this not a word by Herr Duehring." ${ }_{98}$ Following the quotation, Lenin refers to it as "this eulogy of a revolution by force."

Regarding Hegel's allusion to the state as the "Divine on Earth," it is probably sufficiently apparent from the above that the Marxians would simply say "nonsense."

${ }^{98}$ Lenin, State and the Revolution (printed by under-ground party, about 1920) 17, quoting Engels, Anti-Duehring (Third German Edition) 193.

${ }^{90}$ There is probably an elaborate statement by Marx to this effect, for, according to D. B. Ryasanov, in an article entitled The Posthumous Writings of Marx and Engels, he found, in the course of his search for Marxian manuscripts, a criticism of Hegel's Philosophy of Law which is as yet both unpublished and untranslated. Cf. International Press Correspondence (Vienna, January 4, 1924) 4.1.8. 
PART III.

ECONOMIC THEORY 


\section{A GENERAL SURVEY OF MARX'S CAPITAL}

The Marxian system of economics is presented in a work called Capital. It consists of three volumes. Volume $\mathrm{I}$ is a treatment of the essentials of capitalist production; Volume II deals with the process of capitalist circulation; Volume III is a treatise on the system of capitalist economics as a whole. It is obvious that little significance, in point of view of its relationship with Hegel, can be attached to the bare fact that the work is composed of three volumes, the number of parts in a triad, for three volume works are too common, and Marx originally planned for the three volumes of Capital to consist of four books. (The fourth was published after his death, as a separate essay, but has not been translated). However, when the contents of the three volumes are considered, it is found that, as a group, they do seem to make up a sort of Hegelian triad, probably of the first, or purest form. The first two volumes consider two different processes, that of production, and that of circulation. These processes are first treated abstractly, in an artificial, isolated fashion, separated from each other, and from all other qualifying influences. Then, in the third volume, the concrete social system is analyzed as composed of these two processes very much qualified and altered by the complex interrelationship between them. It is very easy in this way to view the third volume as something like an Hegelian synthesis of the other two, since it is of the nature of such syntheses to unite in a modified, elevated and above all, more concrete form, two terms which have been abstracted for purposes of analysis. According to Hegel, this tendency to a partial, isolated view of things is due to the involuntary form of cognition characteristic of the Understanding, ${ }^{100}$ which must be corrected, or made concrete by the operation of the Reason. Even Hegel, however, does not consider this partial view entirely erroneous, for it is part of his metaphysical doctrine that Reality, or the Absolute, consists not merely of the last all-complete reconciliation, but is composed of every antagonistic phase, and every synthesis, however incomplete, which appears in the process of its logical evolution. It thus becomes easy to appreciate the intention of Marx when for purposes of more accurate and complete analysis he isolated and considered separately the important features of the capitalist system. Marx relies on the principle that although the operation of a definite tendency in a complex situation is altered by its contact with other tendencies, it still has truth considered apart from the modifying influences, and an inspection of it by itself may be beneficial to our understanding of the whole to which it belongs. Therefore, it is possible for him to maintain

${ }^{100}$ Engels speaks of it as the "metaphysical" attitude, for which the true or dialectical method must be substituted. See above, 103, 109. 
the truth of the theory of value contained in the first volume as a definite tendency which is not proved false by the fact that other forces interfere to alter its operation. The same applies to the truth of the principles of capitalist circulation as contained in the second volume. Both volumes I and II contain true analyses of the two important features of our system of produtcion as they are in their pure, or abstract form. It is in this form that they operate as tendencies in the complex actual system. The third volume, which deals with the system as it actually operates is but an account of the combined, or synthesized, workings of these two groups of economic laws.

At any rate, it has been made sufficiently clear that the three volumes may well be considered an example of a Marxian-Hegelian triad. Nor should the fact that the abstract process of circulation does not seem to be the negative of the corresponding process of production mitigate against this conclusion. It is not at all unusual in either the Hegelian or the Marxian systems for two parallel and equally important processes which in ordinary speech would not be considered antagonistic, to be designated as "opposites." The only thing to do, apparently, is to view this as just one more inexplicable, though manifestly unimportant, Hegelian twist. Neither does the contemplated fourth book offer any insurmountable difficulty to this interpretation, for according to Marx's own expressed intention, it was to be in the nature of a supplement rather than an integral part of the theoretical system. A history of the theories of value, which was to be the subject of this book, can hardly be regarded as interfering seriously with the symmetry of the economic triad.

Of the detailed doctrine contained within the three volumes, only the theories of value and money as stated in the first volume are of very great importance to this comparison. For it is these portions of the doctrine that are basic to the entire system, contain the original contribution to the science, and above all, are characteristic of the author in his most theoretical, speculative mood, when his Hegelian training and influences are most clearly exhibited. Therefore, it will be sufficient, as an introduction to this more important investigation, to pass over rapidly the contents of the remainder of the work.

In the first part of the first volume wealth, value (three kinds), price, and capital (five kinds) are defined; theories of money, surplus value, and wages are developed, and the process of circulation, in so far as it is necessary to production itself is traced; the remainder of the book contains formulae for the rates of profit, of surplus value, and of exploitation, gives a history of the introduction of the machine process, gives statistics on industrial conditions for $1860-70$, and lastly presents a theory and history of primitive accumulation.

The first part of Volume I as described above contains all the essential theories of the entire doctrine, and they are stated in highly abstract Hegelian 
form. On the other hand, the analysis of the magnitude and rate of surplus value, which follows, is presented in strictly mathematical rather than Hegelian formulae. The next part after that, devoted largely to history and statistics concerning the development of capitalism, is, with the exception of certain scattered expressions, entirely free from Hegelian influences. Lastly, a clearcut, statistical and historical proof, as contrasted with the earlier more speculative argument, is given of the theory that primitive accumulation is primarily not saving, but robbery.

The second volume seems to be of little value to the complete doctrine, chiefly because of its labored, involved, artificial and almost unreadable form. It is concerned with a discussion of the circulation of capital and of consumable products so far as necessary to an understanding of capital. Its method is that of an abstract, somewhat arbitrary, and bewilderingly complicated division of the process of circulation into spheres, based on purely hypothetical cases, and involving elaborate arithmetical calculations. ${ }^{101}$

The formulae and the argument turn largely on the distinction between fixed and circulating capital, and the production of goods for consumption. However, in the first chapter or two Marx considers the formulae for the metamorphosis of money into capital, elaborating the intermediate term. This discussion, which but supplements the similar subject in the first volume, involves, as does the latter, certain Hegelian concepts.

As explained before, the third volume is an application of the abstract theories contained in the first two volumes; it concerns itself with the counteracting influences and the actual situation in the light of these modifications. Detailed practical attempts to increase surplus value are explained, along with the effects of fluctuation of the market on manufacturers' income. Rates of profit are taken up, and a solution secured for the phenomenon of the "falling rate of profit" (it consists of a change in the composition of capital). The reasons for an average rate of profit are seen in the effects of the competition of capitals. This is the "great contradiction" because it involves the consequence that individual commodities do not exchange at prices fluctuating around their exchange values, but at prices which fluctuate around their prices of production. ${ }^{102}$ Since these prices of production are themselves based on the Marxian value we have here really no contradiction but rather a fine example of the operation of a tendency being influenced by other tendencies in a complex situation.

The last part of the volume is devoted principally to the division of surplus value into rent, interest, profit, and taxes. The formation of great trusts and monopolies is also prophesied.

101 Engels points out that many of the formulae are of no practical value, and the book is largely filled with them. He has taken the trouble to summarize and simplify in a few pages the formulae which Marx gives in full, and which cover hundreds of pages. He explains, however, that they were really only Marx's notes, and by no means prepared by him for publication. The second and third volumes of Capital were published by Engels some years after Marx died.

${ }_{102}$ Labriola says that this "great contradiction" is not an inconsistency in thought but a true representation of an actual contradiction in reality. 
Hegelian expressions in Volume III are comparatively few, and quite scattered; the reasoning for the most part, is couched in economic rather than philosophical terms. This may be due to the fact that Engels compiled the book, and probably wrote a great deal of it, from very incomplete manuscripts. 
II.

\section{MARX'S THEORY OF VALUE}

This resume of the theory of value may seem more metaphysical than Marx really is because wherever possible I have selected those statements of his which are most Hegelian, following his Critique of Political Economy rather than his Capital since this earlier work is the more Hegelian. Nevertheless, this is probably the best way to bring out the sort of influence exerted by Hegel.

Marx says that the economics of the capitalist system must concern itself with the wealth of that system. "The wealth of those societies in which the capitalist mode of production prevails, presents itself as an immense accumulation of commodities,' its unit being a single commodity."10s In the first place, the exact nature of the unit-commodity must be determined-its difference from other objects noted. The commodity, it is found, has four distinguishing features; it must be a reproducible object, it must satisfy some want, it must be the product of human labor, and it must be made for the consumption of some one other than the producer, in other words, it is essential that it be produced for exchange.

This last characteristic, that all commodities must be produced for exchange, and exchange for each other is the key-note to the detailed analysis of the commodity, and determines its relation to other commodities, and to the entire capitalist system, which is but the complex of the inter-relatedness of these, its unit objects; for, from this fact, that commodities exchange for each other, it follows that they must have some common basis which can be measured. Since the measurement of the exchange ratio between commodities is based on their value, according to the definition of value, the discovery of the nature of this fundamental basis will solve the problem of the nature of value.

Two of the essential characteristics of the commodity are of prime importance, and may be viewed as its two sides. Thus a commodity has use-value, that is, it has certain physical properties which give it utility; but it has also another side, for it is likewise an exchange-value, that is, it exchanges for other commodities at a certain numerical rate, which figure represents its value in exchange. It then becomes necessary to distinguish not only the exchange-value and the use-value, but also the exchange-value and the value. The exchange-value is but the expression of that something which all commodities have in common, namely, their value. The question arises, what is this something, or what is value?

The proof which Marx gives of his theory of value is really a proof by elimination. Value must be something which is independent of the physical peculiarities of any particular commodities, because all commodities, regardless

${ }^{103}$ Marx, Capital (Chas. H. Kerr \& Co., Chicago, 1919) 1.41. 
of what they are physically will exchange for each other. So use-value, which is a matter of the physical properties of the object, cannot be the basis of value. But then, too, there are some things which possess use-value without having any exchange-value; among these, the necessities, air, water, and sunshine may be mentioned. It is evident that value must be something which all commodities have in common, and also, it must be something without which they will not exchange. Use-value does not satisfy these requirements, nor does any particular physical quality. However, abstract human labor does satisfy every requirement fully, and must, therefore, be recognized as the value element in all commodities.

Exchange-value is not identical with value; it is the "form" of value, the "mode of expression," the "phenomenal form."104 The commodity as a physical object, on the other hand, is the crystallization of this same abstract, tenuous thing, it is the materialization of the human, simple, uniform, abstract labor embodied in it. Value itself, then, is quite the opposite of the coarse materiality of substance; as such, it contains no matter at all; consequently, it is not discernable in the body of an individual commodity, but reveals itself only in the social relationship between commodities in exchange-which is another way of saying, in the exchange-value. ${ }^{105}$

Value is by its very nature susceptible of measurement; its basis is universal labor, abstract and unquantified, its measurement, therefore, must be sought for in its duration-labor-time is the measure of abstract labor, and consequently, of value. ${ }^{106}$ Since exchange-value is but the form of value, it follows, in Marx's words, that "as exchange-values, all commodities are but definite measures of congealed labor-time. ${ }^{107}$

Obviously, the use-value and the value of a commodity are, respectively, its qualitative and quantitative aspects. It is not so obvious, but just as true, that corresponding to these two aspects there is a two-fold character to the labor involved in its production. The qualitative side of the commodity, that is, its use-value, is dependent upon a certain kind of labor, which the Marxians, for purposes of distinction, have called work; while the value is independent of the physical nature of the labor (that is, of the work), requiring only that some useful labor, of a certain quantity, be employed. In other words, the qualitative aspect of the labor is responsible for the qualitative aspect of the commodity, and the same relation holds for the quantitative side of each. Thus, it may sometimes happen that an increase in the material wealth, that is, an increase in the actual body of goods may correspond with a decrease in the value of the entire amount-the possibility of such an antagonistic movement rests, of course, on the fact of this two-fold polar character of the factors involved. ${ }^{108}$

${ }^{104}$ Ibid. 42-43, 55.

105 Ibid. 55.

${ }_{108}$ Marx, Critique of Political Economy (Chas. H. Kerr \& Co., 1911) 23-24.

${ }^{107}$ Ibid. 24.

${ }^{108}$ Marx, Capital. 1.53. 
These two polar aspects of the commodity, the use-value and the exchangevalue, are not so easily explained away as by merely pointing out that they constitute its quantitative and qualitative sides. When considered more closely, the different types of value present many complicated and subtle difficulties, even contradictions.

Though the use-value of a commodity is its qualitative aspect, its nature is such that it does not become a reality except in actual use, or consumption. Even though the use-value is identified with the material being of the object, and has no existence apart from it, it does not follow from the mere existence of certain physical properties that the object is a use-value in the economic sense. The use-value, or the utility, depends on the wants of the consumer, and its existence is actually established only in the act of consumption.

The exchange-value, though the other, or quantitative side of the commodity, does not have quite the same intimate relationship with it. Its connection is more external and relative, since it serves to indicate the proportion in which use-values exchange for each other. ${ }^{109}$ Above all, it is important to remember the much more intimate connection between value and exchangevalue, for, exchange-value is the form of value, justifying Marx's statement, as quoted before, that "as exchange-values all commodities are but definite measures of congealed labor-time." From this connection another paradoxical situation becomes apparent. To quote again from Marx, ". . . labor which is expressed in exchange-value at once appears as the labor of a separate individual. It becomes social labor only by taking on the form of its direct opposite, the form of abstract universal labor." ${ }^{110}$

Considering the commodity carefully as exchange-value and use-value, it becomes evident that these two sides presuppose each other, and in general involve the analysis in at least several difficult and contradictory relationships, which must in some way be resolved. The commodity is a use-value and an exchange-value only because it is the embodiment of universal labor-time. In other words, the exchange-value as the form of value, and in fact, the entire exchange relationship exhibits the peculiar, reversed order, that the social relationships of men appear in the opposite form of a social relationship between things. ${ }^{111}$ This means, merely, that things exchange because they are the embodiments of universal abstract labor, which in itself depends, after all, on the social relationships of the laborers-it is abstract and universal only because it is social. However, actually, it is not units of abstract labor which exchange, such a thing is impossible, but material objects which assume the social intercourse of mutual exchange. Therefore, though attention is directed to the physical commodity itself as use-value and exchange-value, its basis in abstract labor, or value, must never be lost sight of if the contradictions and their solution are to be understood.

109 Ibid. 42-43.

${ }_{110}$ Marx, Critique of Political Economy 29.

111 Ibid. 27-29. 
There is, first, the contradiction that a commodity both is and is not a use-value. For the owner it is certainly not a use-value, or at any rate, it is a use-value only because it is an exchange-value-its utility consists in the fact that it will exchange. For the consumer, of course, it is truly a usevalue, for it is only when the act of consumption is performed that the use-value of the article is finally and indubitably established. But the contradiction is even more grave than it would at first appear. If the commodity becomes a use-value only in use or consumption, then it does so only after it has gone through the process of exchange (since it is the nature of a commodity to be consumed, not by its original owner, or producer, but by the consumer who has purchased, that is, exchanged, for it). But, an object must have use-value, that is, it must be a commodity, before it can participate in economic exchange. ${ }^{112}$ Thus, in order to be realized as exchange-values, commodities must be realized as use-values, and in order to be realized as use-values they must be realized as exchange-values. The contradiction is obvious, and Marx attempts to solve it. However, before giving his solution, the other important contradiction evolved in the process of exchange should be analyzed, for the solutions of both really go together.

This time the contradiction arises between the pair: value, and its form, exchange-value. Individual labor (for, after all, all labor is the labor of individuals) becomes social labor, that is, universal labor, in the process of exchange, for, if it were not for exchange, social, universal labor would be a meaningless expression. Exchange is essential to the existence of abstract, homogeneous, universal labor, and it is in the process of exchange that exchange-value necessarily functions. But, then, a contradiction emerges, since, exchange-value is but the form of value, or universal labor, its existence (that is, the existence of exchange-value) must presuppose the existence of that of which it is but the form, or phenomenon. Thus, again, in order to become social, labor must become active in exchange, and in order to be active in exchange, or to be exchange-value, labor must be social-another glaring contradiction which Marx also undertakes to solve.

The solution of the contradictions is accomplished through an analysis of the process of exchange itself, for in reality, it is in the actual process that the actual solution takes place. Now, in exchange every commodity appears as both a use-value and exchange-value. Its actual bodily form is, of course, its use-value. However, it is obvious that the exchange-value of any commodity cannot express itself in its own bodily form (the exchangevalue of hats cannot be measured in hats-it is meaningless in economics to say that the exchange-value of this hat is equal to or measured by this hat), it must therefore express itself in the bodily form, or use-value, of some other commodity, called its equivalent, for only commodities can confront each other in exchange. When all commodities express their values in the bodily form of a single kind of commodity, that kind of commodity is excluded 
from the ordinary run of merchandise and becomes the universal equivalent, or money. ${ }^{113}$ It is this feature of the exchange process which solves all the contradictions evolved in its movement, the difficulty of the two-fold, contradictory nature of the commodity, the two sides of which are not only opposite, but presuppose each other, is cleared up, made rational, through expression in the universal equivalent of the values of all commodities. And when, in this connection, the expression "exchange-process" is used, it is intended quite literally, for it cannot be said that the contradictions are solved by the exchange relation, since it is a process, not a static condition which is required.

Thus, following Marx's order, and assuming for the time being that the first contradiction, between use-value and exchange-value does not exist, or has been solved, ${ }^{114}$ the second main difficulty, of the manner in which individual labor becomes social labor, thus forming the basis of exchangevalue, is cleared up in the following manner: in exchange, commodities must appear to each other as equivalents, that is, as exchange-values; they must, therefore, drop away from themselves all particular physical properties, in other words, their use-values. Now, the question is, how does the individual labor in the article become social, which it must before exchange can take place. It is at this point that the universal equivalent comes in and removes all difficulties, for it is directly through the universal equivalent that the individual labor in commodities becomes social in character. The universal equivalent is that commodity, or type of commodities, in the bodily form of which all other commodities have come to express their exchange-values. Thus, through a social act, the individual labor in the universal equivalent becomes socialized. The socialized labor serves as a measure of the labor contained within all other commodities, and, of course, is indicative of the proportions between them; in other words, commodities have now acquired a social, and universal basis for their exchange-values.

But, there is still the first contradiction, between use-value and exchangevalue which presuppose each other, demanding solution. The answer is simply, that until the actual exchange takes place, the exchange-value, and certainly the use-value, exist ideally, or latently, this ideal expression being made possible by the universal equivalent, or money, the value or exchangevalue being verbally, or ideally expressed in the price. ${ }^{115}$

Thus, in the last analysis, it is because of the peculiar characteristics of a single commodity that this most contradictory relationship, that of the exchange between commodities, is made possible. For, this commodity, the universal equivalent, has, as Marx puts it, a sort of double use-value, or it is a use-value in two ways, "Besides its special use-value as a particular commodity, it assumes a universal use-value. This latter kind of use-value constitutes its special feature, emanating as it does from the specific part

118 Ibid. 47.

114 Ibid. 45 .

115 Ibid. 50 . 
which the commodity plays as a result of the universal relation which all other commodities bear toward it in the process of exchange. The usevalue of every commodity as an object of a particular want, has a different value in different hands, for instance, it has a different value in the hands of the one who disposes of it, than in those of the one who acquires it. But the commodity singled out as the universal equivalent, is now an object of a universal want arising from the very process of exchange, and it has the same use-value to everybody, namely, that of serving as the depository of exchange-value, of being a universal means of exchange. Thus we find in one commodity the solution of the contradiction which is inherent in commodity, as such, namely, of being at one and the same time a particular usevalue and a universal equivalent, and, therefore, a use-value for everybody or universal use-value..16 In money, then, the opposition between exchangevalue and use-value is overcome, because here the two are combined in one and the same thing, namely, the bodily form of money, which is at the same time the exchange-value of all other commodities, crystallized, and a universal use-value, because of the function of expressing all exchange-values.

In three successive logical steps, Marx then analyses the role of money in the exchange process-in the Critique as part of the solution of the above contradictions, in Capital, more fully in a separate discussion. From the point of view of its relation to Hegel, the more detailed account is significant enough to be reviewed here.

The first step, or form, of the relation of commodities in exchange is called the elementary, or accidental form of value. ${ }^{117}$ It is the simplest form of exchange since it envolves only two commodities which are exchangeable for each other. However, it contains the germ of the higher forms; the elements of all three relations remain the same. Therefore, analysis of this simplest form is an aid to understanding the higher and more complicated forms. The two commodities which encounter each other in the value relation may be viewed as the two poles of that relation, one expressing the value of the other. The two poles are called, respectively, the relative and the equivalent forms of the expression of value. The exchange-value of the relative term expresses itself in the bodily form of the other commodity, its equivalent. Thus the relative term fluctuates with changes in the amount of labor-time contained in either term. In the value relation, these two terms are mutually connected and inseparable, yet antagonistic, and, though they are exactly equal to each other, (if they were not they could not exchange) they cannot be reversed without reversing also the form, and, consequently, the function of each. ${ }^{118}$

Comparing further the two forms (the nature and import of the relative form has already been given in its essential features), it is found that this first form is something with a certain value due to the amount of labor-time

116 Ibid. 49.

117 Marx, Capital 1.56.

$118 \mathrm{Ibid} .56$. 
embodied within it. The value, however, is not the object itself, nor can it be measured by the bodily form of the object in which it is realized. It must, as explained above, express itself in the bodily form of another object, its equivalent. ${ }^{119}$ The value of the equivalent, on the other hand, receives no direct quantitative expression. It differs from the relative in that the relative expresses something of itself other than its bodily substance and properties, something which exists only in a certain relation, namely, its value, in the bodily form of another object; while the peculiar value of the equivalent is expressed in its own bodily form. (Thus, the value of gold is expressed in gold, because gold happens to be the universal equivalent, while the value of a hat cannot be expressed in itself because the commodity hat did not happen to become the universal equivalent. $)^{120}$ It is in this relation, too, that the labor of individuals, for example, concrete labor, expresses itself, or in a sense, becomes its opposite, universal, abstract labor. ${ }^{121}$ As a whole, the importance of this first form of value consists in the fact that the contrast between the opposites, use-value and value is made explicit through the equivalent. "The opposition or contrast existing internally in each commodity between usevalue and value, is, therefore, made evident externally by two commodities being placed in such a relation to each other, that the commodity whose value it is sought to express, figures directly as a mere use-value, while the commodity in which that value is to be expressed, figures directly as mere exchange-value. Hence the elementary form of value of a commodity is the elementary form in which the contrast contained in that commodity, between use-value and value, becomes apparent.,"

In spite of the fundamental nature of this form, it is hopelessly deficient because it is in terms of but one commodity; it fails to satisfy fully the requirements of the value relation because it does not express the "qualitative equality and quantitative proportionality of a commodity with all other commodities." ${ }^{123}$

This fatal defect is remedied by the second step in the value relation, or, as Marx called it, the total, or expanded form. The relative form is in this case equated, not only to one, but to every other commodity in a certain proportion, thus abolishing the former accidental relationship. The equivalent no longer stands alone, but becomes a particular form, one out of innumerable others. However, in spite of the expansion, and the comprehensiveness of this form, it also suffers from certain very grave defects. In the first place, the relative form is "incomplete" and unsatisfactory because expressed in a never ending series ${ }^{124}$ - to express the value of a commodity in every single other commodity when there is an indefinite number of commodities in existence, does not help very much. In the second place, such a "mosaic" of in-

110 Ibid. 64 .

120 Marx, in a note (Capital 1.66) refers to this relationship as an example of the "reflex-category of Hegel."

121 Ibid. $67,68,71$.

122 Ibid. 71

123 Ibid.

124 Ibid. 74. 
dependent expressions of value is eminently confusing and unworkable; when the value of a commodity is given as a certain proportion of every other commodity, the expression, to say the least, becomes inconveniently cumbersome. Therefore, this form, too, is relinquished, and is superseded by the third form of value called the general form.

This last form is derived from the second by simply reversing the equation in which the second is expressed. Thus, if the value of $A$ is represented in the equation of the second form; commodity $A$ equals commodity $B$ equals commodity $C$ equals commodity $D$, etc., and this equation is reversed in such a way that the single relative term is no longer equated successively to the entire series of commodities as equivalents, but instead, commodities $B, C, D$, etc., in linear order, are all equated to the single commodity $A$, the equation of the new form will look like this:

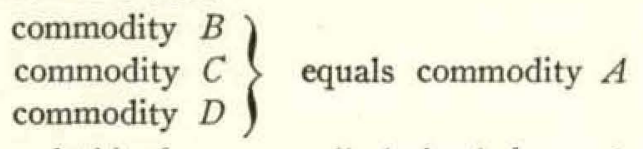

The characteristics of this form are all derived from the two preceding forms. Thus, it may be said that all commodities express their value in an elementary form because the expression appears in but one commodity; they express their value in an expanded form because all commodities are involved in the relation. This last form is called general because characterized by complete unity, in that all commodities express their value in one single commodity. In this way the basic condition of a true exchange relationship is realized, namely, that all commodities be "qualitatively equal and quantitatively proportional." 
III.

\section{THE THEORY OF VALUE AND THE PHILOSOPHY OF HEGEL}

Of the manner in which the Hegelian philosophy influenced his economic theories, Marx gives very little information, except to declare that he "coquetted" with Hegelian logical concepts. In the atsence, then of any positive knowledge of the parts of Hegel's philosophy which affected, directly or indirectly, the Marxian economic theory, discovering the logical relationship can consist merely in pointing out similarities in the two systems.

Though in Hegel's Philosophy of Right there is a discussion of the nature of value, ${ }^{125}$ Hegel does not begin, as do the economists Ricardo and Marx, by pointing out that the wealth of society consists in the collection of economic objects called commodities. However, in this same discussion the existence of certain economic goods which are exchanged for each other, is recognized. The one essential characteristic, apparently, of these objects is that they satisfy want, or be useful, a quality of economic goods to be found also in Adam Smith, Ricardo, and Marx. In fact, the treatment comes under the category of use, which in turn belongs to the first section, property, under the first main member of the triad which makes up this work, namely, abstract right. Use, then is the only one of the characteristics enumerated by Marx as essential to a commodity which is explicitly mentioned also by Hegel, who, by the way, gives its meaning a metaphysical twist entirely foreign to the Marxian discussion. Hegel explains that in desire for an object the will becomes properly particularized-"use is the realization of my want through change, destruction, and consumption of the object, which in this way reveals that it has no self and fulfills its nature." ${ }^{126}$ From the nature of this discussion of use as compared with that of Ricardo and Adam Smith, it is safe to conclude that the important Marxian concept of use-value was derived directly from the economists, and not from the philosopher.

The next point, on the other hand, that commodities exchanging for each other must have a common basis for that exchange, finds a much more significant parallel in Hegel's theory of value. According to Hegel, ${ }^{127}$ it is very significant that objects of any want may be compared with each other, thus indicating that all have in common some basis on which the possibility of this comparison rests. "In use the object is a single one, definite in quality and quantity, and answers to a special usefulness, when fixed quantitatively it can be compared with other objects capable of being put to the same use, and a special want, served by the object, and indeed any want may be compared with other wants; and their corresponding objects may be compared. This universal characteristic which proceeds from the particular object and

125 Section 63.

${ }^{126}$ Hegel, Philosophy of Right (G. Bell \& Sons, London, 1896) Section 59.

127 Ibid. Section 63. 
yet abstracts from its special qualities is the value. Value is the true essence or substance of the object, and the object by possessing value becomes an object of consciousness." ${ }^{128}$ Thus, both Hegel and Marx emphasize the fact that when objects having different properties meet as equivalents there must be something about them, underlying their differences which is identical and measureable, and for both, this common basis constitutes their value. Perhaps, then, the inference is proper that for this important feature, at least, of his theory, Marx was indebted to Hegel. But, in his own discussion of the subject Marx quotes from Aristotle whom he credits with this discovery, though recognizing wherein the ancient philosopher failed to perfect his solution. "'Exchange,' he," that is, Aristotle, "says, 'cannot take place without equality, and equality not without commensurability.' Here, however, he comes to a stop, and gives up the further analysis of the forms of value. 'It is, however, in reality impossible, that such unlike things can be commensurable-that is, qualitatively equal. Such equalization can only be something foreign to their real nature, consequently only a makeshift for practical purposes.' "120 Thus, Aristotle discovered long ago that there must be some common basis if true exchange is to take place, but he failed to arrive at the nature of that basis, or value. "The brilliancy of Aristotle's genius is shown by this alone, that he discovered, in the expression of the value of commodities, a relation of equality. The peculiar conditions of the society in which he lived, alone prevented him from discovering what, 'in truth,' was at the bottom of this equality."180

That Hegel as well as Marx and the other classical economists recognized that commodities have sides, a qualitative and a quantitative, is attested by the statement quoted above, that "in use the object is a single one definite in quality and quantity." However, used in this connection, the term quantity seems to have the same meaning intended by Marx when he says, on page 42 of Capital, Vol. I, that "every useful thing, as iron, paper, and the like, may be looked at from the two points of view of quality and quantity. It is an assemblage of many properties, and may therefore be of use in various ways. To discover the various uses of things is the work of history. So also is the establishment of socially-recognized standards of measure for the quantities of these useful objects." "Quantity" here and in the quotation from Hegel means, probably, quantity in the sense of the amount of any object considered as a use-value, that is, an object having certain physical properties. Ordinarily, when Marx speaks of an object having two sides, a qualitative and a quantitative, he is referring to the use-value and the exchangevalue, using quantity in quite a different and more characteristic sense. When, in the course of his discussion of value, Hegel says, "Quality here becomes quantity. 'Want' is a term common to the greatest variety of things, and enables me to compare them." And, again, "In property the quantitative

128 Ibid.

${ }^{129}$ Marx, Capital 1.68.

130 Ibid. 69. 
aspect which issues from the qualitative is value,"111 is seems that he, too, is using the term "quantitative" in a value sense, corresponding with that of Marx when he speaks of a commodity as being both a use-value and an exchange-value, or a value.

Little difference of meaning can be attached to the terms use and usevalue. All agree that use-value is the qualitative side of the object, and is a matter of its physical properties in relation to certain human wants. The other side of the commodity, for Marx, is the exchange-value, the proportion in which commodities exchange; its basis is the value, or the abstract human labor embodied in the article. Value, according to Hegel, is something very different. The physical properties of certain goods make them the objects of human want. It is this common characteristic which makes it possible for them to exchange for each other, and which constitutes their value. Therefore, when Hegel makes such statements as: "Quality here becomes quantity," and, "the qualitative determines the quantum," capacity of the physical properties to determine worth, he is attributing to these objects a quantitative or value side, in some sense analogous to that of Marx. However, judging from his statement of the nature of value, the quantitative side corresponds, not to exchange-value in Marx's scheme, but rather to value itself, though no distinction is given between value and exchange-value. Quantum here refers to a definite amount, but a definite amount of want, or value, and not the proportion for which objects will exchange for each other. Marx, too, speaks of a definite value, or a definite amount of labor-time embodied in a commodity, which however, does not necessarily coincide with the exchange value. It is very difficult to decide this point exactly, because, in the absence of any explicit distinction on Hegel's part between the two types of value, it is impossible to tell which of the two forms he has in mind. It is necessary to depend entirely on his wording, and though by no means very precise, it is most consistent with the interpretation I have made.

The difference between the Marxian and the Hegelian conceptions of the nature of value has already been indicated. For Hegel, the basis of value is want or utility-in other words, Hegel represents the so-called Hedonist school of economists to which the Marxian and classical theories of value are opposed. The Hegelian statement that "value is the true essence or substance of the object" is suggestive of many similar expressions by Marx. But for Marx, these statements usually include some reference to the social labor involved, for example: "As the embodiment of social labor, all commodities are the crystallization of the same substance, ${ }^{\prime 133}$ for, unless the object is the product of human labor, it is not, according to Marx, the crystallization of value, even though it has utility, or "want." On the other hand, it would seem from

${ }^{181}$ Hegel, Philosophy of Right, Section 63, addition.

132 Ibid. Section 63 .

${ }^{133}$ Marx, Capital 22. 
Hegel's analysis that every object which is of use has value, since for him, use, or want, is the basis of value.

So far it has been possible to compare the Marxian theory of value with a similar Hegelian theory. However, all the features of the Marxian theory to which there correspond principles in Hegel's value doctrine have been exhausted, and the remainder of the comparison, (not only of the theory of value, but of the other economic doctrines as well) can consist only in the indication of those Hegelian logical categories which resemble most closely the concepts and terminology of Marx. It is altogether impossible to say whether or not Marx had any particular categories in mind while making his analysis. The closeness of the resemblance in some cases seems, nevertheless, very significant. It is probable that Marx had so thoroughly imbibed the logic of Hegel that his reasoning, more or less unconsciously, followed the Hegelian mode.

So certain features of the Marxian theory of value must now be reconsidered, this time in connection with categories of the Hegelian logic. Abstract, universal, human labor constitutes the basis of value in Marx's scheme. The abstract, universal feature might well have been derived from Hegel's theory of value, since his account contains very similar expressions-- "The thiversal characteristic which proceeds from the particular object and yet abstracts from its special qualities is the value." 184 There must, however, be some means of measuring abstract human universal labor, which in itself-as abstract and universal-affords no basis for measurement. According to Marx, labor time is the measure required. Obviously, these matters of value and measurement fall within the category of quantity. Value, manifestly, conforms to the first member of the triad of quantity, namely, pure quantity, because, while quantitative in character, it is not in itself a definite quantity. Hegel's own statement seems to fit it very well: "Quantity is mere being, in the case of which the character or determinateness ceases to be identified with Being itself, and is explicitly set aside or rendered indifferent."13s Labortime, on the other hand, may be placed under the second member of this triarl, the category of quantum (how much) - "Quantity, when the exclusionist character which it involves is explicitly attached to its essence, is a Quantum (or How Much): that is, limited quantity." ${ }^{13 e}$ This seems to hold in spite of Marx's statement that, "as exchange-values all commodities are but definite measures of congealed labor-time," which with other similar passages seems to suggest that exchange-value is the proper measure of value, and should occupy the position of Quantum. However, it seems to me, the other interpretation is the more reasonable, since, after all, exchange-value is not a definite measure of value, but a relative quantity, which fluctuates though the value itself remains constant.

Many of Marx's expressions suggest placing exchange-value with value

\footnotetext{
134 Hegel, Philosophy of Right, Section 63.

${ }^{135}$ Hegel, Logic, Section 99.

196 Ibid. Section 101.
} 
under the category of appearance. Thus, Marx speaks of exchange-value as the "form" of value, the "mode of expression," the "phenomenal form," and though any judgment based on the mere mode of expression when translations are used is necessarily questionable, the consistency with which these very clear expressions appear, and the fact that all explanations of their meaning fall in with this interpretation, makes it well worth considering. The Hegelian category of appearance is the second member of the triad of essence, which constitutes the second main division of the logic. Since, with very few exceptions, the remainder of the principles which make up the Marxian theory of value seem to fall, as related to Hegel, somewhere within the realm of essence, a brief discussion of this doctrine may help to elucidate the connection.

Hegel begins his dissertation on essence with the following more or less clear general statement of the nature of this main category as contrasted with the one preceding: "The terms in Essence are always mere pairs of correlatives, and not yet absolutely reflected in themselves: hence in essence the actual unity of the notion is not realized, but only postulated by reflection. Essence-which is Being coming into mediation with itself through the negativity of itself-is self-relatedness, only in so far as it is relation to an Other-this Other, however, coming to view at first not as something which is, but as postulated and hypothetised.-Being has not vanished: but, firstly Essence, as simple self-relation, is Being, and secondly as regards its one-sided characteristic of immediacy, Being is deposed to a mere negative, to a seeming or reflected light-Essence accordingly is Being thus reflecting light into itself." ${ }^{137}$ He goes on to point out that the central conception of essence resembles a reflected ray of light, which involves two things, the ray of light itself, and its reflected, or thrown back, counterpart. Everything, then, according to essence, may be regarded as twofold in this manner, for everything is both "underlying essence and the reflected appearance, Reflexion-in-sich and Reflexion-inanderes." ${ }^{138}$ And when Hegel speaks of this stage as "Being coming into mediation with itself through the negation of itself," he is referring to the fact that the "other" to which being is now opposed, is, in the last analysis, but its own reflected self; the complete union, or identity, of the two constituting the ground of essence. Further details of this conception are suggested by one of Hegel's paragraphs at the conclusion of the introduction to this topic: "As the one notion is the common principle underlying all logic, there appear in the development of Essence the same attributes or terms as in the develcpment of Being, but in a reflex form. Instead of Being and Nought we have now the forms Positive and Negative; the former at first as Identity corresponding to pure and uncontrasted Being, the latter developed (showing in itself) as Difference." ${ }^{139}$ Though the general conception as stated above is sufficient, probably, to establish a connection between the various principles of the theory of

${ }^{137}$ Ibid. Section 112.

${ }^{138}$ Hibben, Hegel's Logic (Chas. Scribner's Sons, New York, 1902) 141.

${ }^{130}$ Hegel, Logic Section 114. 
value and the doctrine of Essence, it is possible, I think, to find significantly close parallels between the Marxian concepts and some few of the subordinate categories' and notions contained within this important division.

Thus, the two sets of correlative terms, use-value and exchange-value, and work and labor, fall quite neatly, in the manner of their relationship, under the Hegelian maxim of opposition. According to this principle, true opposites, related to each other as positive and negative, are at the same time, inseparably bound up with each other, mutually dependent, even identical, as shown by the inevitable resolution of the contradiction between them. Hegel's own explanation of opposition may well be quoted rather fully at this point, because of its important bearing on the central conceptions in the theory of value and exchange: "Difference implicit is essential difference, the Positive and the Negative: and that is this way, the Positive is the identical self-relation in such a way as not to be the Negative, and the Negative is the different by itself so as not to be the Positive. Thus either has an existence of its own in proportion as it is not the other. The one is made visible in the other, and is only in so far as that other is. Essential difference is therefore Opposition; according to which the different is not confronted by any other but by its other. That is, either of these two (Positive and Negative) is stamped with a characteristic of its own only in its relation to its other: the one is only reflected into itself as it is reflected into the other. And so with the other. Either in this way is the other's own other. . . . . (1) . . . Positive and negative are supposed to express an absolute difference. The two, however, are at bottom the same: the name of either might be transferred to the other . . . "140 "Contrariety then has two forms. The Positive is the aforesaid various (different) which is understood to be independent, and yet at the same time not to be unaffected by its relation to its other. The Negative is to be, no less independently, negative self-relating, self-subsistent, and yet at the same time as Negative must on every point have this its self-relation, that is, its Positive, only in the other. Both Positive and Negative are therefore explicit contradiction; both are potentially the same. Both are so actually also; since either is the abrogation of the other and of itself. Thus they fall to the Ground. Or as is plain, the essential difference, as a difference, is only the difference of it from itself, and thus contains the identical: so that to essential and actual difference there belongs itself as well as identity. As self-relating difference it is likcwise virtually enunciated as the self-identical. And the opposite is in general that which includes the one and its other, itself and its opposite. The immanence of essence thus defined is Ground."

Now the pairs use-value and exchange-value, and work and labor have many of the characteristics of opposition as contained in the above quotations. When use-value and exchange-value are considered dynamically also, in the exchange process, it will be seen that they have many more. As such, however,

140 Ibid. Section 119.

$141 \mathrm{Ibid}$. Section 120. 
these pairs were referred to by Marx as "polar opposites" because they are, in the first place, diametrically opposed to each other, one as the qualitative, and the other as the direct opposite, or quantitative, in nature, which makes it appropriate to regard them as, respectively, positive and negative; but, in the second place, they are as intimately connected as they are opposed-they are not only necessary to each other, but, in the last analysis, they are identical. This is proved by the fact that Marx used such expressions as: "the commodity is a use-value," "the commodity is an exchange-value"-and, if the same commodity is both (or either) of these two things in this way, they must be identical (in the Hegelian sense, of course, which does not preclude their difference, but rather depends upon it). Exactly the same sort of analysis may be applied to the labor (in its wider meaning) embodied in commodities-it is both labor, that is, abstract, and work, that is, concrete.

Before taking up use-value and exchange-value more fully as they appear in the exchange relation, the pair already referred to, of value and exchangevalue must be analyzed under a somewhat different type of relationship, still within the general category of essence, namely, that of appearance. Though the category of appearance occupies the position of second member in the triad of essence, it seems in many ways to peculiarly exemplify the essential characteristics of this category, especially in its character of reflexiveness. The relation between value and exchange-value resembles this category in more than the mere manner of expression, although the terms, "form," "phenomenon," "appearance," and the like, used in this connection, are very suggestive. "The Essence," says Hegel, ${ }^{142}$ explaining the nature of the category of appearance, "must appear or shine forth. Its shining or reflection in it is the suspension and translation of it to immediacy, which, whilst as reflection-on-self it is matter or subsistence, is also form, reflection-on-something-else, a subsistence which sets itself aside. To show or shine is the characteristic by which essence is distinguished from being-by which it is essence; and it is this show which, when it is developed, shows itself, and is Appearance. Essence accordingly is not something beyond or behind appearance, but just because it is the essence which exists-the existence is Appearance (Forth-shining) . . . The appearance which is thus created does not stand on its own feet, and has its being not in itself but in something else."143

Now, exchange-value is not only expressly called the appearance of value, but it is explained also that it is the sort of an appearance which is identical with that of which it is the appearance-for is not the commodity a two-sided object, a use-value and a value, or an exchange-value, value and exchangevalue used interchangeably because essentially the same thing? Exchangevalue's chief distinction from value is its relative nature, its dependence cn "others," both of which distinctions are given by Hegel in the above quotations to differentiate essence (as ground of existence) and appearance. It

${ }^{142}$ Logic, Section 131.

${ }^{143}$ Ibid. Section 131. 
seems quite safe, too, in view of this rather close parallel, to regard value as "reflection-on-self," and exchange-value as its inseparable, but quite distinguishable counterpart, its relative expression as "reflection-on-something-else." To place this relation more closely under one of the subordinate categories of appearance: (a) the world of appearance, (b) content and form, (c) relation, whole and parts, and the like, is a very difficult thing to do. It bears more resemblance to the first two than to the third, but cannot be placed definitely under either of these, since their peculiar characteristics do not seem to apply, especially.

Now, we must consider the various contradictions of the exchange relation-the contradictions which have a real existence, and are not merely mental difficulties. In the first place, the commodity both is and is not a usevalue. This paradoxical situation for Hegel is not at all impossible, for even common-sense admits, he holds, that a thing may exhibit contradictory attributes, from different points of view. "A notion, which possesses either or both of two mutually contradictory marks, for instance, a quadrangular circle, is held to be logically false. Now though a multangular circle and a rectilineal arc no less contradict this maxim, geometers never hesitate to treat the circle as a polygon with rectilineal sides." ${ }^{144}$

The contradictory situation in exchange between use-value and exchangevalue, and value and exchange-value, brought about by the fact that the members of each of these pairs mutually pre-suppose each other, receives ample Hegelian justification by the bare fact of being a contradiction-since for Hegel contradictory situations are not only possible, but the normal state of reality. 'Instead of speaking by the maxim of Excluded Middle (which is the maxim of abstract understanding) we should rather say: Everything is opposite . . . Contradiction is the very moving principle of the World: and it is ridiculous to say that contradiction is unthinkable. The only thing correct in that statement is that contradiction is not the end of the matter, but cancels itself." And with this last statement, that contradictions must cancel themselves, or be resolved, Marx agrees perfectly, for according to him, the exchange-process constitutes just such a solution of all the above contradictions. The solution, which all hinges about, or may be said to be accomplished by, the universal equivalent, conforms beautifully to the requirements laid down by Hegel in continuation of the last quotation: "But contradiction, when cancelled, does not leave abstract identity; for that is itself only one side of the contrariety. The proximate result of opposition (when realized as contradiction) is the Ground, which contains identity as well as difference superseded and deposed to elements in the complete notion."145

However, before the universal equivalent is reached as the all-decisive solver of the contradictions involved in the exchange of commodities, the resemblance between Marx's solution of the contradiction between use-value and

${ }^{144}$ Ibid. Section 119.

${ }^{145}$ Ibid. Section 119. 
exchange-value, and value and exchange-value, arising from the fact that though they (that is, the two members of each pair considered as such) must both exist, the existence of each presupposes the existence of the other, and Hegel's discussion of actuality, possibility, and the like, should be considered without too much stress being put upon it. According to Hegel, the actual, or the real world, the concrete result of the dialectic movement, is, as the actual, that which was formerly the potential, or the merely possible-which must, however, be "real possibility." Consideration of the possible and the actual introduces another element, namely, condition, or the contingent, which is the other without which the possible could never have become actual. Though there are many other principles included within this category of actuality, they do not seem to have much bearing on the Marxian doctrine at present under consideration. It does, however, seem possible to make a significant comparison between the above important concepts of this category and the potential existence of use-value, exchange-value, and social labor, which become actual during the course of the essential exchange process if certain conditions do not fail to materialize - if, for example, there is a consumer ready, for whom the physical properties of the object constitute a real use-value, and who is in possession of the necessary commodities (usually money) to make the exchange, and finally, who is able to overcome whatever other difficulties stand in the way of his coming into contact and making a bargain with the owner of the commodity in question.

Now, returning to the universal equivalent, which in another sense is a necessary condition to the potential existence of the various properties of the commodity, it may seem queer and distorted to place it under the category of ground, which in the logic precedes the discussion of the actual, appearing in the first member of the category of essence, while the actual is the third member of this same category. However, if it is correct that (to again quote Croce, with whom I agree on this point) “... the Hegelian dialectic of concepts, . . . seems . . . to bear a purely external and approximate resemblance . . . to the notion . . . . of antithetical conditions of society," and further, " . . . the Hegelian phraseology beloved by Marx, of which the tradition is now lost, and which, even within that tradition he adapted with a freedom that at times seems not to lack an element of mockery," then the simple reversal of the Hegelian order should not mitigate at all against the validity of this comparison. Neither do I claim that the meaning of categories and concepts as fully explained by Hegel coincides exactly, or is very nearly parallel to the analogous relations in Marx. Some of the Hegelian concepts as such were certainly used, though not necessarily in al! their Hegelian relationships. Indeed it may very well be true that Marx, by isolating certain of Hegel's ideas, falsified them badly, yet even in their false position the ideas are distinctly Hegelian in character, and were certainly derived from him.

"The Ground," Hegel defines, "is the unity of identity and difference, the truth of what difference and identity have turned out to be-the reflection- 
into-self, which is equally a reflection-into-another, and vice versa! It is essence put explicitly as a totality." Then in fine type certain cautions are given: "We must be careful, when we say that the ground is the unity of identity and difference, not to understand by this unity an abstract identity. Otherwise we only change the name while we still think the identity (of understanding) already seen to be false. To avoid this misconception we may say that the ground, besides being the unity, is also the difference of identity and difference . . . The ground and what is grounded are one and the same content: the difference between the two is the mere difference of form which separates simple self-relation, on the one hand, from mediation or derivativeness on the other." ${ }^{146}$ It will be remembered that the universal equivalent is that factor in the exchange process which solves the contradictions of the process arising from the two-fold nature of the commodity. It is able to do so by virtue of the fact that in its bodily form the exchange-values of all other commodities are expressed. Thus it is itself an exchange-value, though a universal one. And, the ability of the bodily form to function in this manner, makes it also a use-value, a universal use-value. In its single bodily form the universal equivalent, without becoming involved in the contradictions of the ordinary commodity, unites within itself the two opposing characteristics. Because, in this manner, it unites the opposites previously referred to as the positive and the negative, which as also explained, are both "identical" and "different," and because, in so doing it becomes itself, not an "abstract identity," but retains differentiated as much as united, these polar opposites, I think it is justifiable to place the universal equivalent under the category of ground as above defined.

Though the account of the three forms of the exchange process overlaps to some extent the more general account of the same process given above, certain new comparisons are also made possible by this more detailed analysis. In the first, or elementary form, two commodities face each other as, respectively, relative and equivalent. They are, then, Marx holds, opposite, yet identical, the one but the reflection of the other. The quotation from Hegel's category of difference fits this much of the relationship almost perfectly. That these two, the relative and the equivalent, are related to each other in this manner, and may appropriately be viewed as positive and negative in this sense, is further attested by the fact that though the terms are equal, they can be reversed only by changing the form, or function, of each. It makes no difference at all which term is placed on the left hand side of the equation, and is therefore regarded as expressing itself in the other, in any case its function is that of the relative. This situation is analogous to Hegel's statement of the equivalence of positive and negative. ${ }^{147}$

The further characteristic of this form, that the value of the equivalent is expressed in its own bodily form, places this with the universal equivalent

$147 \mathrm{Ibid}$. Section 119. 
(of which it is but the elementary form) under the category of ground, which, after all, is but a development of difference. The exposition of ground given by Hibben seems to fit this point particularly well: "The ground and whatever is grounded combines reference to self with a reference to its other as well. Such a reference involves the idea of mediation, or relativity, that is, the process of explaining a given thing by a reference to something else with which it is essentially related." 148 Thus, the equivalent as ground, "combines a reference to self with a reference to its other as well," by expressing its own value as well as the value of its other (that is, any other commodity, as relative) in its own self.

The chief defect of this form, which constitutes its transition to the next, is its extremely limited character. The form which expresses the value of only one commodity certainly lacks the universality necessary to capitalistic exchange. This is not at all an un-Hegelian basis for transiticn to a new and more adequate stage in the dialectical process. Therefore, the total, or expanded form is introduced to obviate the specific difficulty of the preceding form by equating the relative term, not only to one, but to all other commodities.

Of the two difficulties developed by this form, one at least, the most important, is very suggestive of a certain Hegel's transition from one category to the next. This form is unsatisfactory chiefly because one side of the equation is a never-ending series, which, of course, lacks the requisite definiteness for an expression of value. Says Marx, " . . . . the relative expression of value is incomplete because the series representing it is interminable,"140 and Hegel, discussing limit, and infinity under the category of being-determinate: "Something becomes another: this other is itself somewhat: therefore it likewise becomes another, and so on ad infinitum." Then, "In the attempt to contemplate such an infinite, our thought, we are commonly informed, must sink exhausted. It is true indeed that we must abandon the unending contemplation, not however because the occupation is too sublime, but because it is too tedious." 150 Or to quote Hibben in exposition of this Hegelian principle of transition: "But when we pass from any definite being to its other, this other, itself, possessing definite being, must also have its other to complete its meaning, and so on without limit. We thus find ourselves launched upon an infinite series that can never be satisfactory, because never complete. It is an endless progression, and can only bring weariness unutterable to the mind which attempts to follow it." 151

The third and last form of value in exchange is derived from the second by reversing its equation. This most developed form is, of course, that of the universal equivalent, and its relation to Hegel has consequently been taken up under that head. In this connection, however, another point is brought out,

${ }_{148}^{148}$ Hibben, Hegel's Logic 158.

149 Marx, Capital 1.74.

${ }^{150}$ Hegel, Logic, Sections 93, 94.

151 Hibben, Hegel's Logic 97. 
namely, that the general form of value constitutes a synthesis of the other two, and that therefore the three forms of value make an Hegelian triad. The elementary form gives expression to the value of the commodity in only a single commodity - to this extent it is unified. The expanded form, including all commodities, is universal, (that is, all inclusive) but not unified. The general form, however, is both universal and unified. 
IV.

\section{THE MARXIAN PROCESS OF CIRCULATION}

AND

\section{ITS RELATION TO HEGEL'S LOGIC}

SECTION 1.

\section{MARX'S THEORY OF THE METAMORPHOSIS OF COMMODITIES}

The process of circulation as a whole involves two different types of cycles, the first, represented by the letters C-M-C (Commodity-Money-Commodity) is the "selling in order to buy" phase, while the second, M-C-M (MoneyCommodity-Money) is just the reverse, or the "buying in order to sell" aspect. C-M-C is the direct expression of the circulation, or as Marx calls it, the "metamorphosis" of commodities. The cycle is made up of two transactions, first, there is the act of selling, C-M, then the act of buying, M-C. Together, since the same $\mathrm{M}$ is common to them both, they form the whole, C-M-C, the net result of which is the material exchange of two commodities, or C-C.

Following the steps in the transformation more closely, we have: $\mathrm{C}$ is sold for $M$, or, as shown by the analysis of the exchange process, the use-value of this commodity becomes, in the body of its equivalent, the opposite, or exchange-value. $\mathrm{M}$, however, is used to purchase another commodity, which means that the exchange-value is transformed back again into its old form of use-value, or again becomes $\mathrm{C}$. This last $\mathrm{C}$ differs from the first in that it is actualized in consumption, thus completing this process, the function of which is to realize the use-values of commodities, which thereupon drop out of circulation.

Each of the two phases, C-M and M-C is, of course, reversible, and in other cycles of which each forms a part, the function is reversed. However, even within any particular cycle, for the purchaser the process is one thing and for the seller it is exactly the opposite. Consequently, C-M becomes definitely a sale only when considered in relation to the C-M-C cycle, in this fixed order. In the sale $\mathrm{C}-\mathrm{M}$, the terms have the real relation to each other already described when the exchange process as such was considered. The same analysis applies also to the $\mathrm{M}-\mathrm{C}$ relation with this single difference: while, as previously indicated, the realization in $\mathrm{M}$ of the ideal price assumed by $\mathrm{C}$ depends upon accidental circumstances, or conditions, in the second phase of the cycle, $M$ takes the initiative, acting whenever ready, because always effective in purchase, thus affording a point of rest, a pause, between the two acts during which anything might happen to prevent the consummation of the cycle. It is this possibility of a period of inactivity which makes the separation of the process into two phases so very important, because it is during such a pause that commercial crises, and other economic disturbances occur. 
When it is considered that the C-M of any particular cycle is the M-C of other adjoining cycles, and that the same is true of $\mathrm{M}-\mathrm{C}$, it becomes apparent that $\mathrm{C}-\mathrm{M}-\mathrm{C}$ is but one member in a chain process which is without beginning or ending, and further, that it is inseparably mixed up with many other chains, crossing and re-crossing each other. This complex arrangement is especially important since it affords an opportunity for the view that the process is not that of the metamorphosis, in regular fashion of one $\mathrm{C}$, but a medley of accidental criss-crossings. ${ }^{152}$

A very significant characteristic of the single cycle is the fact that the two extremes do not bear exactly the same relation to the middle term, M. The first $\mathrm{C}$ is related as the member of a special class of things to its universal (commodity) form, M. M is related to the second $\mathrm{C}$ as the universal form to the individual form of the commodity. This relationship, reduced to its abstract logical form, Marx points out, gives the formula: S-U-I, or Species-Universal-Individual. ${ }^{153}$ While Marx gives no further explanation of his reason for calling the first $\mathrm{C}$ species, and the second individual, the explanation seems to be quite evident. Commodities are sold only when they constitute a surplus, when to the owner, they are objects of a certain class, with certain physical properties which to him mean merely the possibility of exchange. A commodity is consumed, on the other hand, when to the consumer its specific properties satisfy a definite want; the individual commodity as such has a specific importance, which as an exchange-value in the hands of the merchant or manufacturer, it does not have. Therefore, the commodity as exchangevalue may be regarded as belonging to a class, or as a member of a species, while as a use-value it has become an individual.

Another significant thing is brought out by the process of the circulation of commodities, namely, that in the actual circulation, the owners of the commodities appear only as the guardians of these commodities-in other words, as personified bread versus personified gold. Accordingly, the process is not one primarily of the intercourse between men, but rather between men only in so far as they satisfy the conditions of the production and exchange of commodities, which become related to each other in a manner determined by the characteristics inherent within them.

152 "The actual process of circulation thus appears not as a complete metamorphosis of a commodity, not as its movement through opposite phases, but as a mere agglomeration of many accidentally coinciding or successive purchases and sales."-Marx, Critique of Political Economy (Chas. H. Kerr \& Co, Chicago, 1911) 118.

${ }_{153}$ Marx, Critique of Political Economy 119. 


\section{HEGELIAN CONCEPTS IN THE THEORY OF THE METAMORPHOSIS OF COMMODITIES}

The main features of the Marxian theory of the metamorphosis of commodities, so far as they do not overlap the general discussion of exchange, may be compared with Hegel's principles of the syllogism, under the third main division of the logic, the doctrine of the notion. It will be observed that the same relationship of exchange considered in chapters 9 and 10 as belonging properly under the division of essence, now appears under the division of the notion. The entire movement of exchange, involving three terms, is considered as an example of an Hegelian syllogism, while two terms taken together (either end, and the middle), I now maintain has the form of an Hegelian judgment. The relationship now held to be an example of the judgment is exactly the same previously held to exhibit the characteristics of the categories of identity and difference. M, the middle term of this syllogism, is the same $M$, or $U$, which as the universal equivalent was designated as the ground. This apparent discrepancy in our treatment, however, far from detracting from the soundness of the comparison, lends it valuable Hegelian support. In Hegelian language it is necessary only to point out that in the earlier stage of the argument the discussion was at a lower level in the dialectical movement (at the level of the Understanding) and that it has now progressed logically to a more concrete view of the same things (at the level of the Reason). For, it must be remembered that every category, and every categorical relationship in the Hegelian logic applies to, or is expressive of the nature of everything in the universe. They characterize not different things but different phases (at higher or lower levels) of all things.

The cycles are undoubtedly Hegelian triads, viewed either as composed of the three terms, $C, M$, and a return on a higher plane to $C$, or as $C-M, M-C$, and the synthesis, C-M-C. Now, Marx says, as stated above, "C-M-C can, therefore, be reduced by abstract logic to the final form S-U-I." He therefore suggests very strongly that C-M-C is really a syllogism of the Hegelian type, which does not exist merely in an abstract logical sense, but constitutes the nature of the real world. "Accordingly the Syllogism is the essential ground of whatever is true; and at the present stage the definition of the Absolute is that it is the Syllogism, or stating the principle in a proposition: Everything is a Syllogism." 154

Considered as a syllogism, the major premise is $\mathrm{C}-\mathrm{M}$, represented by $\mathrm{C}$ or $\mathrm{S}$; and, since by "species" Marx means what Hegel does by particular"-

${ }^{154}$ Hegel, Logic (Clarendon Press, Oxford, 1892) Section 181. 
"Again, the particular is the different or the specific character . . . "155 in the course of the discussion nothing will be lost, and much will be gained by using $\mathrm{P}$ instead of $\mathrm{S}$ for the first premise; the minor premise is $\mathrm{M}-\mathrm{C}$ represented by $\mathrm{M}$, or $\mathrm{U}$ (that is, universal), and the conclusion is C-C, which in its turn can be represented by $\mathrm{C}$, this time the last $\mathrm{C}$, or I (that is, individual). $\mathrm{C}-\mathrm{M}-\mathrm{C}$, then, or P-U-I, turns out to be a qualitative syllogism of the third figure, ${ }^{156}$ the conclusion of which is P-I, or C-C, the middle term, M, or U, having dropped out in the course of the dialectical movement of exchange. Just as Hegel explains, when referring to an entire syllogism as I-P-U, that "of course the subject (terminus minor) has other characteristics besides individuality, just as the other extreme (the predicate of the conclusion, or terminus major) has other characteristics than mere universality. But here the interest turns only on the characteristics through which these terms make a syllogism," ${ }^{157}$ so the same justification can be made for calling the movement C-M by the single letter $P$ (standing for particularity). C-M means a commodity of a certain type, changing its form for the universal characteristics of M (or money). P (or particularity) in this connection is its essential characteristic, and makes possible the syllogism. The same explanation applies to the designation by the single letter U, of M-C-the essential characteristic of money is its universality, and in this phase of the circulation of commodities, money is of prime importance. The reason for calling the conclusion, C-C, by the single letter I is even more easily explained. The conclusion of the cycle is the exchange between two commoditis through the mediation of money, which, after all, is but a means to this end. The real object and end of the transaction, however, is the purchase, and the consumption of a certain commodity. Therefore, in the conclusion, the individuality of the last commodity is of greatest "interest" in producing the syllogism (or exchange).

Since $\mathrm{C}-\mathrm{M}$ and $\mathrm{M}-\mathrm{C}$ are the premises of a syllogism they are themselves judgments; from this point of view, then, the exchange relation must now be considered a form of judgment, which, by the way, its characteristics make very possible. In describing the nature of the judgment, Hegel says: "The abstract terms of the judgment, 'The individual is the universal,' present the subject (as negatively self-relating) as what is immediately concrete, while the predicate is what is abstract, indeterminate, in short, the universal. But the two elements are connected together by an 'is': and thus the predicate (in its universality) must also contain the specialty of the subject, must, in short, have particularity: and so is realized the identity between the subject and predicate; which, being thus unaffected by this difference in form, is the content." ${ }^{158}$ C-M, according to Marx, means: the commodity, as particular is (that is, becomes in exchange), money, or universal. But this is possible (as explained previously) only because the commodity is really also universal, that is,

\footnotetext{
155 Ibid. Section 164.

$156 \mathrm{Ibid}$. Section 187.

157 Ibid. Section 183.

158 Ibid. Section 169.
} 
has value.- "and so is realized the identity between subject and predicate." The same is true of M-C, for, money is not only universal, but it is also in a sense individual, that is, it has a definite use-value, thus the identity between the two notions necessary to their connection in the judgment plainly exists.

Referring to the subject and predicate of these judgments as "notions" brings out the fact that they really are notions in a somewhat Hegelian sense. The important characteristic of the Hegelian doctrine of the notion is its concreteness, in other words, the inseparability of its three moments: particularity, universality, and individuality. Though it is rather difficult to make the concepts which Hegel attaches to these words at this point fit into the scheme of their application in connection with the Marxian doctrine of value and exchange, it is sufficient, probably, merely to indicate the similarity of their relationship toward each other. Hegel explains their inherent connection and identity as follows: "Universality, particularity, and individuality are, taken in the abstract, the same as identity, difference, and ground. But the universal is the self-identical, with the express qualification, that it simultaneously contains the particular and the individual. Again, the particular is the different or the specific character, but with the qualification that it is in itself universal and is an individual. Similarly the individual must be understood to be a subject or substratum, which involves the genus and species in itself and pcssesses a substantial existence. Such is the explicit or realized inseparability of the functions of the notion in their difference-what may be called the clearness of the notion, in which each distinction causes not dimness or interruption, but is quite as much transparent." 150 In very much the same manner, the first C, in addition to, and inseparable from its own most important quality in this connection, its particularity, is also the other two qualities: as value, it is universal, and as a use-value for consumption it is individual. Similarly, $M$ and the second $\mathrm{C}$ can be shown to be the concrete notion, having the three moments, universality, particularity, and individuality.

Coming back again to the syllogism, it is interesting to compare Marx's observation that the C-M and M-C of any cycle are also M-C's and C-M's of other adjoining cycles, with Hegel's analysis of the difficulties of the qualitative syllogism, which he explained as follows: "This contradiction in the syllogism exhibits a new case of the infinite progression. Each of the premises evidentiy calls for a fresh syllogism to demonstrate it: and as the new syllogism has two immediate premises, like its predecessor, the demand for proof is doubled at every step, and repeated without end." ${ }^{160}$ The difference between Hegel's unending and interconnected series of syllogisms and those of Marx, is, of course, that in the case of Marx, all of the syllogisms would be of the same type, while for Hegel, all the different figures must appear.

Then, the point Marx makes about the relations between men being but

159 Ibid. Section 164.

$160 \mathrm{Ibid}$. Section 185.

101 Alluded to by Marx in a footnote, Capital 1.51. 
the reflection of the relation between their commodities is suggestive of a statement in the Philosophy of Right, quoted by Bonar"191, "The legal relation of persons who only realize their personality by having property, is characteristic of the bourgeois society."162

The one very important point in this doctrine for which there seems to be no significant Hegelian parallel is that of the rest period between the two movements of the circulation process; though, in a way, the division of the syllogism into premises suggests it, the resemblance is probably not a very close one.

\section{SECTION III}

\section{THE TRANSFORMATION OF MONEY INTO CAPITAL- THE MARXIAN GENERAL FORMULA FOR CAPITAL}

The formula C-M-C represents the circulation of commodities for the purpose of reaching their proper consumers, and they then drop out of circulation. M-C-M on the other hand, describes the circulation of money for the sole purpose of accretion, which is the same thing as the accumulation of capital. The problem to be solved, of course, is the source of the new capital, in view of the essential tenet of the value theory, that cvery exchange must take place between equivalents (that is, in value). It is to solve this problem, then, that the formula $\mathrm{M}-\mathrm{C}-\mathrm{M}$ is subjected to analysis.

M-C-M, or buying in order to sell, like C-M-C, consists of the two antithetical phases, M-C and C-M, a purchase and a sale, involving, therefore, persons related to each other as buyers and sellers. "Each circuit is the unity of the same two antithetical phases, is brought about by the intervention of three contracting parties, of whom one only sells, another only buys, while the third both buys and sells." ${ }^{16 s}$ The differences between the two formulae are too numerous to be repeated here; it is enough to say that with the exchange of commodities, the simpler formula, or relationship, comes to an end, while, with the reflux of $\mathrm{M}$, the second continues indefinitely; and more significantly: the first formula is terminated qualitatively different, but quantitatively equal to its initial state, while the reverse is true of the second formula which ends qualitatively equal, but quantitatively unequal, that is, with an increment.

This increment is the surplus-value for which the entire capitalistic process is set in motion. Yet its existence is in contradiction to the general form of commodity-circulation which rests on the incontrovertitle principle that all exchange must take place between commodities which have equal value. It is because of this difficulty that Marx speaks in this connection of the "Contradictions in the General Formula of Capital." ${ }^{164}$ What is there about this pro-

${ }^{162}$ Hegel, Logic Section 190.

${ }^{163}$ Marx, Capital (Chas. H. Kerr \& Co., Chicago, 1919) 1.64.

164 Ibid. Chapter 5. 
cess, which involves the same two antithetical phases as C-M-C, and yet introduces this new and quite foreign element, the increment? What is the source of this increment? Since its origin cannot possibly be the exchange process itself, or the exchange-value of any one of the commodities in the process of its transformation, it must then be derived from the peculiar value of one of them. "It is therefore impossible for capital to be produced by circulation, and it is equally impossible for it to originate apart from circulation. It must have its origin both in circulation and yet not in circulation." ${ }^{105}$ And, since there is nothing about M which can increase itself, this "one of them" must be the $\mathrm{C}$ which is purchased, evidently for this purpose, and its nature, consequently, must be particularly examined-only in this way can the problem be solved of the origin of surplus-value which can be created only in exchange, yet cannot be produced by exchange. The solution is found in the specific nature of the commodity in question, which is the labor-power ${ }^{166}$ purchased by the first $\mathrm{M}$ to be used in the production or exchange of goods. "By labor-power, or capacity to labor," Marx explains, "is to be understood the aggregate of those mental and physical capabilities existing in a human being, which he exercises whenever he produces a use-value of any description." ${ }^{107}$

The peculiar characteristic of this commodity which makes it fruitful in the creation of surplus-value, and consequently, useful to the capitalist, is the double nature of its use-value: it is "a source not only of value, but of more value than it has itself." 16 s In other words, the capitalist purchases from the laborer his labor-power for which the laborer receives the value of this, as of every other commodity. The value of the commodity labor-power is determined by the amount of food, clothing, and shelter required to produce, (or rather, reproduce) it. However, having bought the labor-power, the capitalist proceeds to use it, that is, to apply it in the production of new value. It is at this point that its ability to create more than its own value comes into play. And it is by this means that the origin of the increment $M$ has been explained without in any way going contrary to the equivalence law operating in exchange. For, the first phase, M-C, or money-purchasing-commodity-labor-power is an exchange of equivalents, as is also the next phase, C-M, or the sale of the commodity taken over again, this time in the form of the product of labor, sold on the market for its equivalent in money.

185 Ibid. 184.

${ }^{166}$ Many arguments are given by Marx to prove that this commodity, in order to produce the increment must be labor-power, but they cannot be taken up here.

$167 \mathrm{Ibid} .186$.

168 Ibid. 216. 
SECTION IV.

\section{HEGELIAN CONCEPTS IN THE GENERAL FORMULA FOR CAPITAL}

The formula M-C-M, is also an Hegelian triad, composed of the members, M-C, C-M, and the synthesis, M-C-M. It is likewise and more importantly, a syllogism of the form U-P-U, because the middle term is sold; but also since the middle term, C is consumed, it is a syllogism of the form U-I-U. The conclusion of this syllogism has the peculiar, because purely tautological, form U-U. In other words, considered qualitatively, no result at all has been attained by the movement. The only result is the quantitative one, $M-(M$ plus increment M). For the logical form of the syllogism, U-I-U, there is no parallel in Hegel, since all true Hegelian syllogisms must contain all three forms of the notion. Though no brief, concise statement to this effect is available, the entire discussion of the syllogism bears it out, and all the different types of the syllogism listed contain all three notions. Marx himself explicitly recognizes that, since the result of the process is but a repetition, qualitatively, of the same thing, namely, money, its source cannot be the process of exchange as such, and this is all that is represented by the bare logical formula. Therefore, the explanation of this point at least, is outside of the Hegelian principles of the syllogism.

Of the other differences between the two formulae of circulation, apart from the purely formal ones, such as the different positions occupied by the various terms, it is noteworthy that the middle term of the formula M-C-M, unlike that of C-M-C, does not serve merely to transfer the extremes from one person to another, but is reflexive in its function, serving to bring back to the same person the initial term. This type of repetition is certainly contrary to the ordinary form of the syllogism, though it may possibly be comparable to the type of mathematical syllogism, described by Hegel as follows: "In the round by which each constituent function assumes successively the place of mean and of the extremes, their specific difference from each other has been superseded. In this form, where there is no distinction between its constituent elements, the syllogism at first has for its connective link equality, or the external identity of understanding. This is the Quantitative or Mathematical Syllogism." ${ }^{100}$ The comparison here, if real at all, is admittedly very tenuous, but is nevertheless suggestive of the type of almost purely verbal relationship existing between the Marxian and Hegelian theories.

The distinction of which Marx makes so much, that M-C-M, unlike the other formula, does not come to an aboslute end, but, on the contrary, because of the reflux of $\mathrm{M}$, the process immediately repeats itself, and so on, without end-this distinction, too, is without parallel in the Hegelian doctrine of the syllogism. While the difference, already referred to, that, whereas C-M-C ends qualitatively unequal, $\mathrm{M}-\mathrm{C}-\mathrm{M}$ comes to an end qualitatively equal, but

${ }^{160}$ Hegel, Logic (Clarendon Press, Oxford, 1892) 188. 
quantitatively unequal, though corresponding to no syllogistic distinction, is certainly couched in pronouncedly Hegelian language. In the same manner, it is interesting that the difficulty of the origin of surplus-value should be entitled by Marx the "contradictions," in the formula to which it belongs. The solution, which is the peculiar capacity of labor to produce more than its own market value, and which can be made intelligible only by distinguishing between labor-power, and the actual labor itself, is one of the most important principles of the Marxian theory of value, and is claimed by all Marxians to be the improvement of the Ricardian labor theory which made the labor theory tenable. Since this important distinction did not come from Ricardo, it is interesting to speculate, on the basis of the extent of its resemblance, as to its possible indebtedness to Hegel. The only Hegelian feature that I can discover is the manner of statement (and this can easily be remedied) ; labor-power is the capacity or potentiality of something else, namely, labor. Consequently, Marx speaks in Hegelian fashion, of "labor-power realizing itself as labor," "Labor-power, however, becomes a reality only by its exercise; it sets itself in action only by working." 


\section{CONCLUSION}

In support of the conclusion that the connection between the Marxian and Hegelian systems is for the most part a purely external and verbal rather than an integral one, it may well be demonstrated that the Marxian system in every essential feature stands, though all the basic Hegelian tenets are refuted. In spite of the fact that the theory of historical materialisnı was probably derived very largely from certain Hegelian doctrines, it may hold true though the doctrines from which it was derived are proven false.

Now the question is, will it be possible to accept the Marxian theory while at the same time denying the validity of the three central Hegelian principles which may be stated as follows: (1) the internality of relations, (2) the inseparability of identity and difference, (3) the partial and relative nature of ail finite truths. From the language of both Marx and Engels, it cannot be doubted that they accepted these principles, and even argued for some of them vigorously. Nevertheless, it seems to me that the essential features of the Marxian theory may be stated in such a way that they are independent of the Hegelian philosophy. Principles, which when first considered, especially in the terminology of Marx and Engels, seem to fit in with the Hegelian logic, and therefore to be contrary to the accepted non-Hegelian tenets of logic, turn out, on closer examination to be but a peculiar way of stating ideas which in no manner conflict with the common-sense view of things.

When Engels speaks of the "internal connection and concatenation of things," "their oneness," "inseparability," and the like, he probably has in mind an Hegelian connection which involves the internality of relations between all things. But that he was not aware of the logical issue, and that his view really is not essentially different from any modern evolutionary conception is indicated by the fact that he credits Darwin with having "dealt the metaphysical conception of nature the heaviest blow."17i Thus we may believe in the evolutionary continuity of events in the historical as well as in the biological realm; we may believe that all things are related, either through direct contact, or through the intermediation of connected things; and we may believe that the merging of one historical event into the next is governed by "necessary" laws of nature, without holding also that the character of the relationship between these events and things is such that they are really but parts of the "One Whole." In a sense, we may even agree that they are parts of one whole, but in the Marxian theory it may be the collective whole of commonsense, the universe as a whole, or the world considered in its entirety-certainly not necessarily the Absolute Unit of Hegel.

Part of the evolutionary, or dialectical view of things is the doctrine of 82-83.

${ }^{171}$ Engels, Socialism, Utopian and Scientific (Chas. H. Kerr \& Co., Chicago, 1918) 
opposites. The works of both Engels and Marx abound in examples of "polar opposites," which are antagonistic, but necessary to each other. To say that these opposites exclude each other, is believed by Marx and Engels, as well as by Hegel, to be a cardinal error. Engels emphasizes the fact that it is not necessary, or even correct, to say that a thing must be either form or content, cause or effect, positive or negative; it is obvious that things may be and are, both these opposites. On the face of it, this point seems hopelessly Hegelian, but from Engels' further explanation it becomes evident that again the real logical issue was not recognized by the Marxians. The polemic in their day was of such a different character-the evolutionary versus the static view of nature-that it is not surprising if a mere logical quibble was overlooked in the face of the larger issue in which Hegelian principles might be put to use. We may all again agree with the Marxians that the same thing can be at the same time, both cause and effect, or both form and content. But we may hold also, without in any way falsifying the Marxian view, that a thing is both cause and effect, and the like, at the same time, but from different points of view. The thing is both alive and dead, as Engels maintains, but only if the meaning of death be not too carefully defined. The difficulty in all of these cases can be avoided by making a careful distinction-but it is plain from the exposition of it already given that the Hegelian principle is not necessary to the Marxian doctrine.

Marx and Engels speak of the economic crisis and other disturbing features of the present social system as its "inherent contradictions." They speak, too, of the "resolution" of these contradictions, of the "negation of the negation," which is the new society, and so forth. Engels' answer to the accusation that the Marxian hypothesis of the collapse of capitalism and the appearance of communism is based only on a purely abstract Hegelian dialectic has already been given. ${ }^{172}$ We may call attention here to the common tendency of modern historians to refer to any epoch (and especially to any transitional period) as being from different points of view, a period of "decline and decay" of the old, and of the "reconstruction and growth" of the new. Hegel undoubtedly did much to establish this evolutionary, dynamical view of history, but this does not make it Hegelian in the sense of the peculiar and generally conceded untenable features of that philosopher's doctrine.

The theory of truth, which seems in Engels' works to be strongly Hegelian in character, is really, on closer inspection, the ordinary (correspondence) view, with a peculiar emphasis and manner of statement. When Engels argues so vehemently against so-called Absolute truth, or rather, as it turns out, against certain absolute truths, he was actually but upholding a relativity view of morality and thought, which is very different from the doctrine of partial truths and the One Absolute Truth propounded by Hegel. Though Engels speaks of actual truths changing, it is possible with a little variation and modification of terminology, but without any real alteration of principles, to sum172 Chapter V. 
marize Engels' statements on this point so that they say merely that since the opinions of people reflect their surroundings, these opinions must undergo changes corresponding to changes in the social environment. It is, then, not the true propositions which change, but the facts, to which other and later propositions are made to correspond. Engels' argument amounts to a tirade against those who fail to recognize the changing circumstances, and who reiterates as true, propositions which are true only if intended to correspond with facts of the past.

The Marxian system is by no means incompatible with an absolute theory of the nature of the good. The critical side of Marxism is not really concerned with the nature of the good as such, or in itself, but rather with actual moral codes disclosed by history, regarding specific types of action. The practical side of the theory as a revolutionary philosophy, on the other hand, finds its surest theoretical support in a realistic view of the good as something objective, absolute. Then, armed revolution and the proletarian dictatorship a:e ethically justified as necessary means toward the end of the greatest amount of human happiness. This end, it holds, is not only consistent with a purely working class point of view, but depends upon it. The class struggle allows no compromise-either the workers or the capitalists must win completely. And a modern Utilitarian ethics requires that it must be the masses of the workers who are victorious.

The independence of the definitely economic side of Marxism from any necessary connection with Hegel's philosophy is proved by the fact that Marx himself, when occasion demanded, gave a presentation of the economic theories in which appeared not a trace of Hegelian terminology or principles. Marx's two pamphlets, Value, Price and Profit, and Wage, Labor, and Capital, written for working class consumption, and containing (though in brief form) all the essentials of the economic theory, are a standing proof of the reality of this logical independence.

It is not the purpose of this study to prove in detail the merely verbal, external character of the numerous points of contact between Marxism and Hegelianism here disclosed. A bare suggestion of the possibility of divorcing the economic theories will not, however, be out of place.

To select only the more outstanding points, it may in the first place, with very little difficulty, be shown that the much emphasized pair of "polaropposites"; use-value and exchange-value (or value), are quite needlessly so designated. They appear, having the same fundamental meaning, in the works of Adam Smith, Ricardo, and others, and their unnecessarily Hegelian form in Marx's works can be explained only by the author's whim to "coquette" with Hegel's modes of expression. It is obvious that any two important aspects, or phases of an object may be spoken of as in a sensc identical-they are qualities of one thing; and at the same time, different-they are not the same quality.

In much the same manner, it is wholly unnecessary to the meaning of 
value in its relation to exchange-value to refer to the latter as the "phenomenal form," the "mode of expression," the "form," and the like, of the former. Many scientific theories, (including the Einsteinian) involve this distinction between an entity considered absolutely, and in its relation to other things (which may be either frames of reference or other commodities, or anything else under the sun).

It is more difficult, in a few words, to dispose of the Hegelian features of Marx's treatment of the universal equivalent, and the various "contradictions," and relations of exchange. But, when Marx speaks of the universal equivalent as solving the contradictions of the commodity and the exchange relation he is merely saying (what any economist will tell you) that only through money is exchange (as contrasted with barter) made possible at all.

Regarding the Marxian exchange cycles and their presentation in the form of Hegelian syllogisms, it is perhaps sufficient to point out how perfectly natural it was for a close and sympathetic student of Hegel to treat in this highly artificial way a relationship involving two different terms, or types of commodities which appear in two main types of economic exchange, one type of commodity assuming the dominant role in one form of exchange relation and the other being dominant in the remaining form. In the exchange act for the purpose of acquiring ordinary consumption goods, the commodity (C) is the more important and Marx expresses this by having it appear twice in his formula; while in exchange for productive purposes, it is obvious that money is of prime importance, and appears two times in the formula. It is of the utmost significance that the central, the most characteristic, and original feature of the Marxian theory of value, namely, surplus value, involving the accumulation of capital, should have been admittedly anomalous to the Hegelian formulae employed.

The comparison in the preceding pages between the main points of the Marxian theories and the philosophy of Hegel has not always laid bare any very close relation. It has been necessary to trace down many apparent relations to find a few real ones, and of the real relations, some, most of them in fact, are what might be called accidental, rather than necessary.

Marx, thoroughly trained in Hegelian dialectic, a member of the group of Young Hegelians, deliberately and consciously employed the method of his teachers when it came to presenting his newly acquired views. The Hegelian method then, is undoubtedly there, though in varying degrees in different works; and in general both the method and the phraseology of the school of Hegel were used most in Marx's early works, and employed less and less as time went on. More specifically, in the earliest works, on economics, especially, there is much Hegelian method and terminology, and very little, though possibly some, Hegelian content. Historical materialism, however, is much more dependent upon Hegel's actual philosophy; it embodies much of the Hegelian content, and comparatively little of the Hegelian phraseology, though in this there is resemblance to Hegel's own more popular works. The Marxian his- 
tories themselves do not even suggest Hegel. All the most fundamental features of the two sides of the theory, for instance, the economics and the philosophy of historical materialism, may be stated and have at times been stated, in language entirely free from the encumbering Hegelianism. 
The Publications in Language and Literature are designed to include studies in the various languages and literatures, ancient and modern, represented at the University. The series replaces and absorbs The Publications in English, of which the following volumes have appeared:

Vol: 1. Uno Linderlof's Elements of the History of the English Language, transiated by Robert Max Garrett. Cloth.................\$\$1.00

Vol. 2. The Political and Eeclesiastical Allegory of the First Book of the Faerie Queen, by Frederick Morgan Padelford. Boston, Ginn. For sale only by Ginn and Company. Cloth................ .75

Vol. 3. Johannes Steenstrup's The Medieval Popular Ballad, translated by Edward Godfrey Cox. Boston, Ginn. For sale only by Ginn and

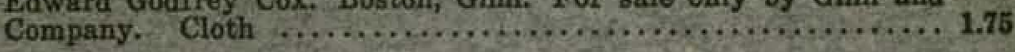

Vol. 4. 1. The Pearl: An Interpretation, by Robert Max Garrett. Paper.. . 50

\section{MATHEMATICS}

Vol. 1. 1. An Arithmetical Theory of Certain Numerical Functions, by Eric Temple Bell. Pp. 1-44. August, 1915,.................. .50

2. Cyclic-Harmonic Curves: A Study in Polar Coordinates, by Robert E. Moritz. Pp. 1-58. June, 1923................. 1.00

\section{THE SOCIAL SCIENCES}

Vol. 1. 1. Studies in Matriculation Statistics, Intelligence Ratings and Scholarship Records at the University of Washington, by Alexander Crippen Roberts. Pp, 68. January, 1924,.................

2. Causation and the Types of Necessity, by Curt John Ducasse. Pp. $69-200$. February, $1924 \ldots \ldots \ldots \ldots \ldots \ldots \ldots \ldots \ldots \ldots \ldots \ldots .1 .50$

Vol. 2. 1. Tiberius Caesar and the Roman Constitution, by Olive Kuntz. Pp, 1-78. August, 1924 .............................. 75

2. The Logical Influence of Hegel ou Marx, by Rebecea Cooper.

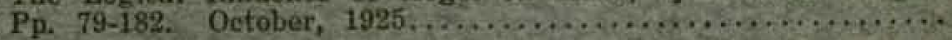




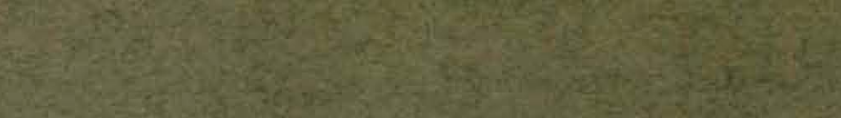

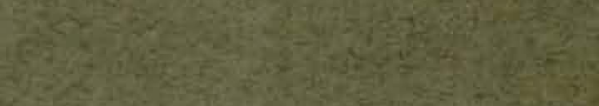 \\ - \\ 5.}

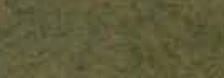

(

का

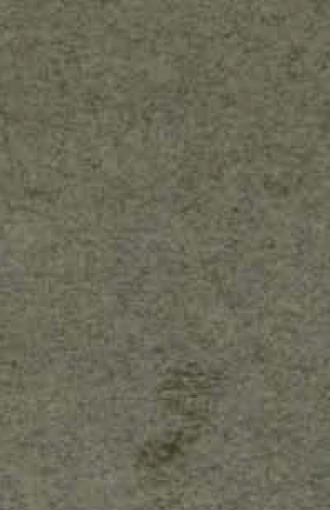

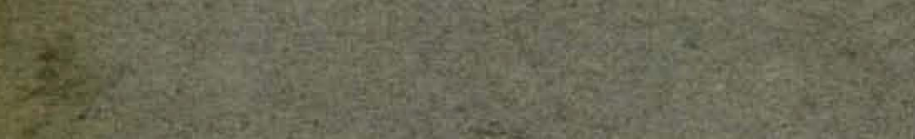

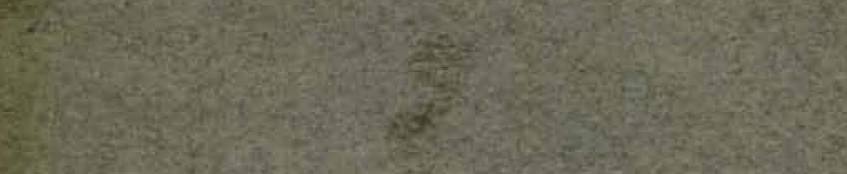

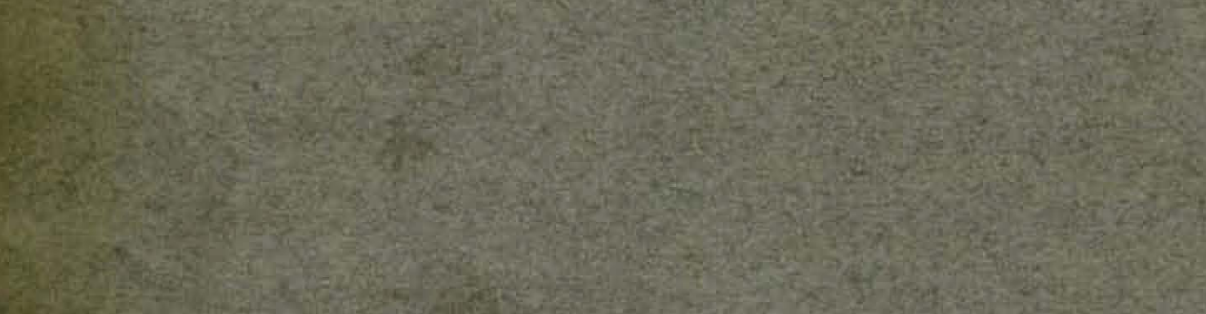

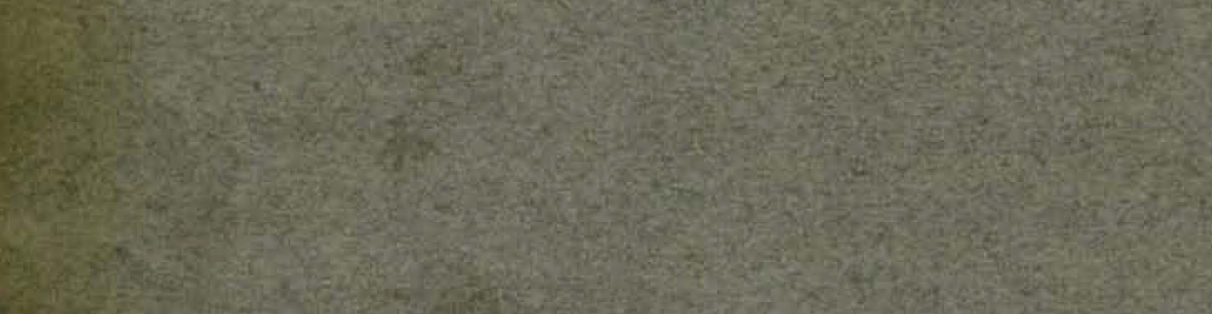

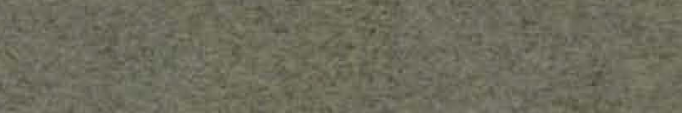

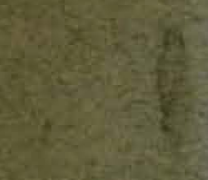

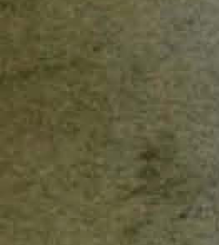

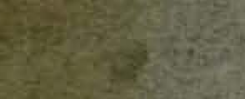

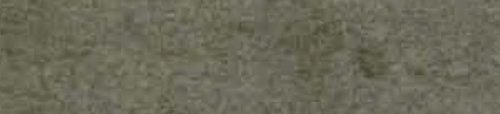

2.

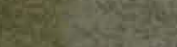

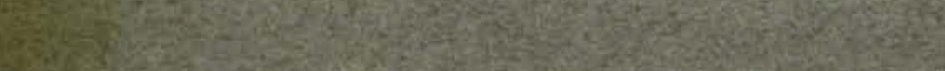

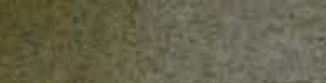

3
4

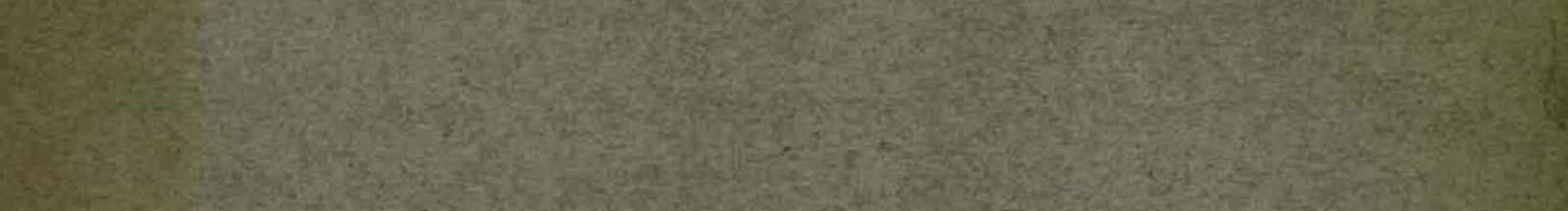

